\title{
WestVirginiaUniversity
}

THE RESEARCH REPOSITORY @ WVU

Graduate Theses, Dissertations, and Problem Reports

2002

\section{Energy analysis and diagnostics in wood manufacturing industry}

Amol Anant Mate

West Virginia University

Follow this and additional works at: https://researchrepository.wvu.edu/etd

\section{Recommended Citation}

Mate, Amol Anant, "Energy analysis and diagnostics in wood manufacturing industry" (2002). Graduate Theses, Dissertations, and Problem Reports. 1270.

https://researchrepository.wvu.edu/etd/1270

This Thesis is protected by copyright and/or related rights. It has been brought to you by the The Research Repository @ WVU with permission from the rights-holder(s). You are free to use this Thesis in any way that is permitted by the copyright and related rights legislation that applies to your use. For other uses you must obtain permission from the rights-holder(s) directly, unless additional rights are indicated by a Creative Commons license in the record and/ or on the work itself. This Thesis has been accepted for inclusion in WVU Graduate Theses, Dissertations, and Problem Reports collection by an authorized administrator of The Research Repository @ WVU. For more information, please contact researchrepository@mail.wvu.edu. 


\title{
Energy Analysis and Diagnostics in Wood Manufacturing Industry
}

\author{
Amol Mate \\ Thesis submitted to the \\ College of Engineering and Mineral Resources \\ at West Virginia University \\ in partial fulfillment of the requirements \\ for the degree of \\ Master of Science
in
Industrial Engineering
}

B.Gopalakrishnan, Ph.D., Chair

Ralph Plummer, Ph.D.

Bruce Anderson, Ph.D.

Department of Industrial and Management Systems Engineering

\author{
Morgantown, West Virginia \\ 2002
}

Keywords: Energy Assessment, Wood Manufacturing Industry, Sensitivity Analysis, Motor Downsizing, Demand Reduction, Motor Master + 


\section{Abstract \\ Energy Analysis and Diagnostics in Wood Manufacturing Industry Amol Mate}

Energy conservation is the need of the hour. It is a continuous process that requires consistent efforts for identifying potential areas for conservation, formulation of proposals and implementing the same. Energy is the most critical resource today. Gap between demand and supply of energy will be continuously widening in the years to come. Scarcity of fuels, insufficiency in energy systems and ever rising cost of energy, lead to energy crisis, alarming for energy conservation.

In the above context, there is certainly a need for more research and diagnostics in the different industrial sectors, especially in those where much of the efforts have not been concentrated in the past. Wood manufacturing (SIC 24 manufacturing facilities) is definitely one of those industries where more research efforts are required. It would be extremely beneficial if more energy analysis and research is done in SIC 24. This thesis and research work is concerned with the energy analysis and diagnostics in wood manufacturing industry in West Virginia. This work involves actually conducting site assessments at several lumber and wood manufacturing plants in West Virginia. Using the collected data, we determined energy conservation opportunities and made recommendations. It is important that manufacturers understand the potential for these assessment recommendations with respect to the parameters governing them. Research emphasis is on the demand side management. We found that demand charge plays a crucial role in the total energy charges for this industry. An exhaustive utility bill analysis was performed followed by a sensitivity analysis for demand reduction. Instantaneous motor load test are carried out to determine the load factor of the motors using a digital stroboscope. After motors are identified as suitable candidates for downsizing, an extensive analysis of the motor replacement decision is performed using the Motor Master + software. It is found from the research work that the SIC 24 is indeed heavily oversized for the application. There is tremendous potential for downsizing the motors to their appropriate size in this sector. It is certain that this downsizing will result in the tremendous demand savings as well impact the total energy bill. This work will definitely help the wood industry reduce its production and energy cost and obtain good profits in this ailing economy. 


\section{ACKNOWLEDGEMENTS}

I would like to wholeheartedly thank my advisor Dr. B. Gopalakrishnan for his continued support, guidance and encouragement during the course of this research work. I also wish to thank Dr. Ralph Plummer and Dr. B. Anderson, my committee members, for their advice and support.

Above all, I wish to thank god and my parents for their constant support and blessings and enabling my success and happiness in all my pursuits and endeavors in life. 


\title{
Table of Contents
}

\begin{abstract}
\end{abstract}
ACKNOWLEDGEMENTS .............................................................................................................III

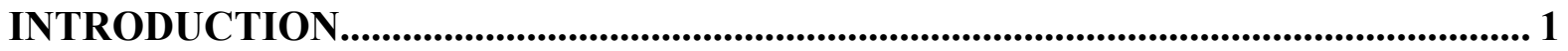

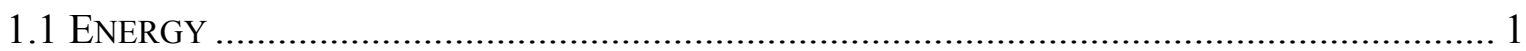

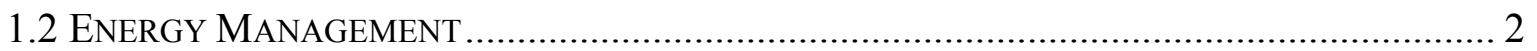

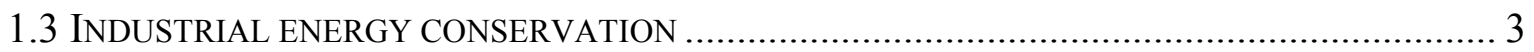

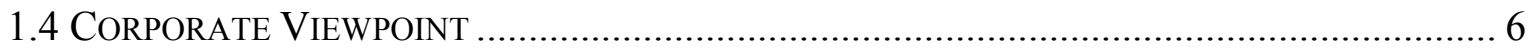

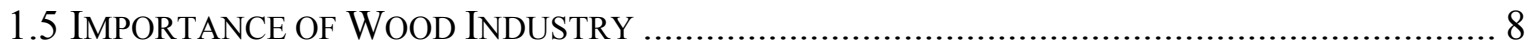

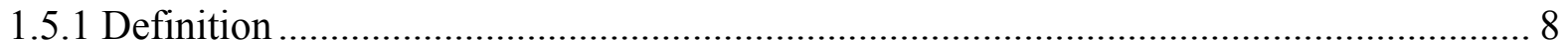

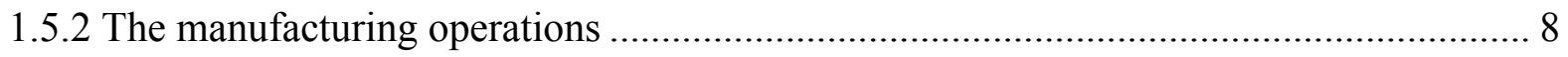

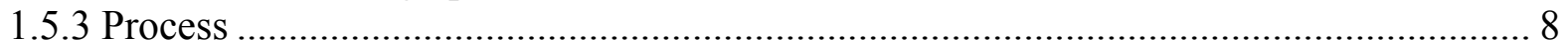

1.5.4 Introduction to the lumber and wood products industry.............................................. 10

1.6 ECONOMIC PROFILE AND TRENDS OF THE LUMBER AND WOOD PRODUCTS INDUSTRY .. 10

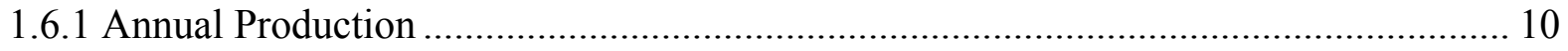

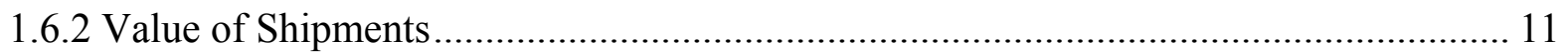

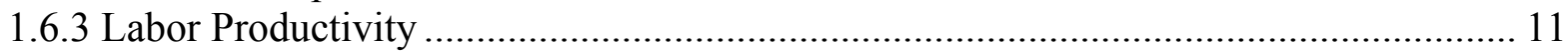

1.7 ENERGY USE IN FOREST AND WOOD PRODUCTS INDUSTRY ………............................ 12

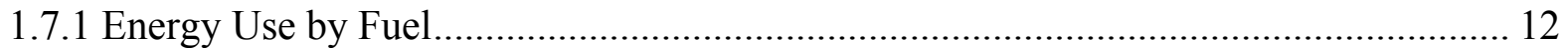

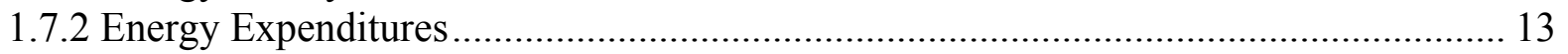

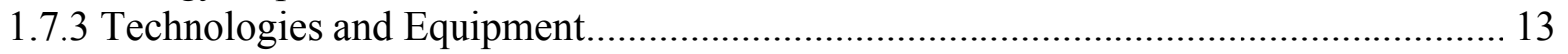

1.7.4 Energy management activities ................................................................................. 14

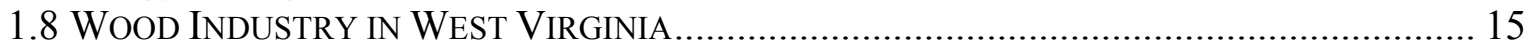

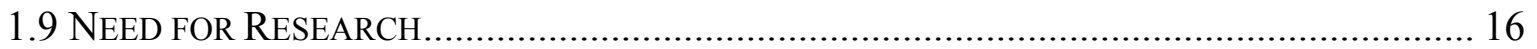

1.10 ENERGY RESEARCH IN WEST VIRGINIA........................................................... 16

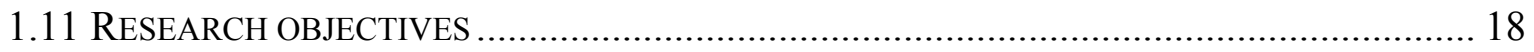

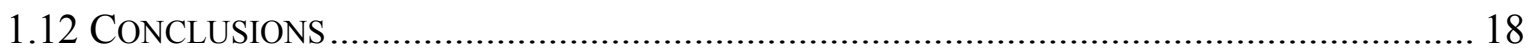

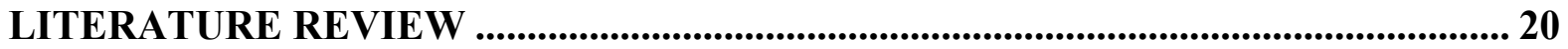

2.1 ENERGY ANALYSIS IN FOREST PRODUCTS INDUSTRY ............................................... 20

2.2 ENERGY TECHNOLOGY RESEARCH AND DEVELOPMENT ……...................................... 22

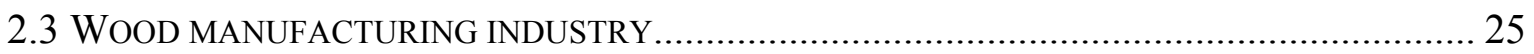

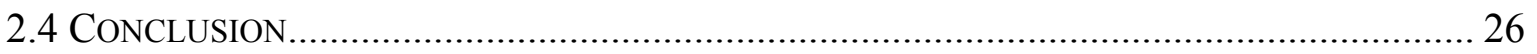

UTILITY BILL ANALYSIS ............................................................................................... 27

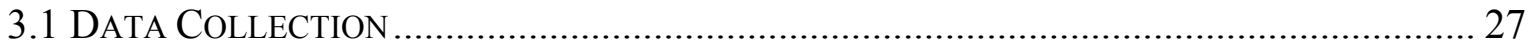

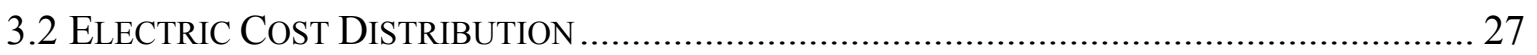

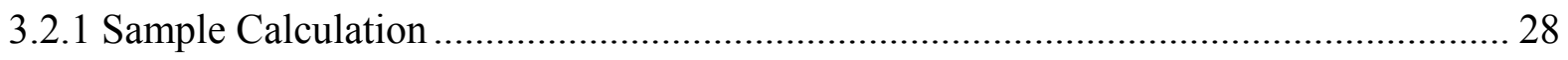

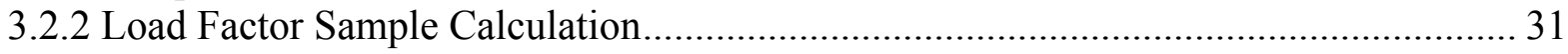

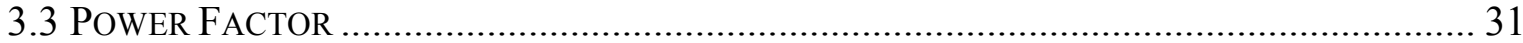

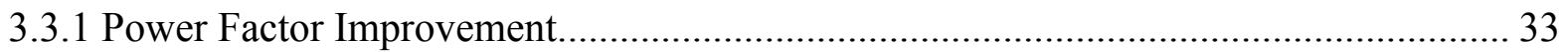

3.3.2 General Considerations for Power Factor Improvements............................................. 34 


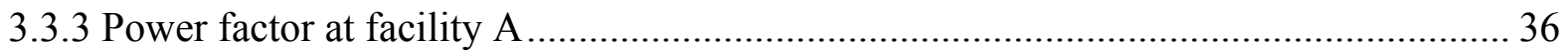

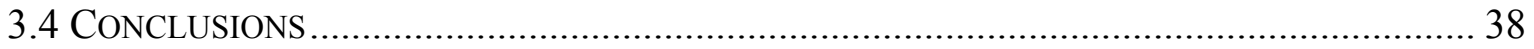

ELECTRICAL DEMAND REDUCTION........................................................................39

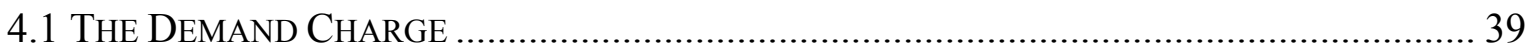

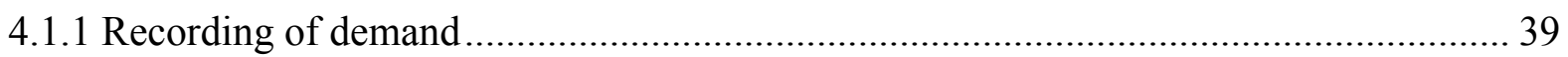

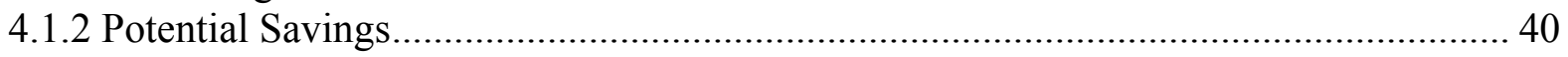

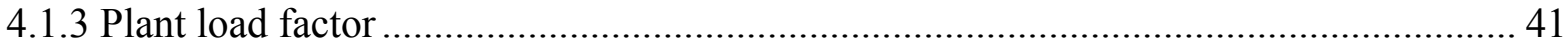

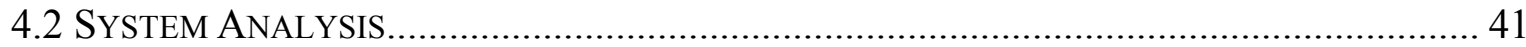

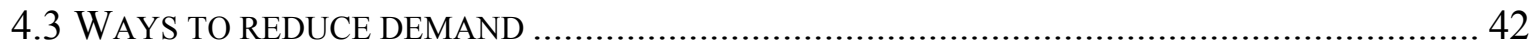

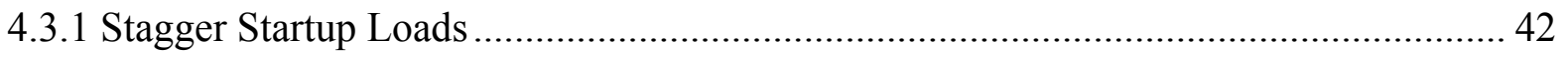

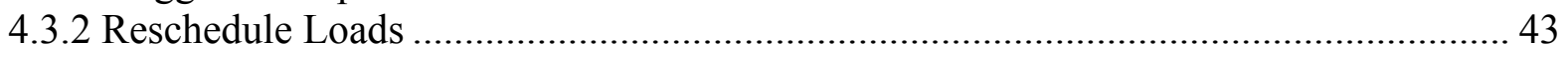

4.3.3 Increase Local plant Generation ............................................................................ 44

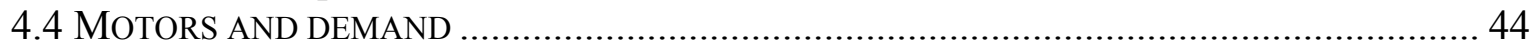

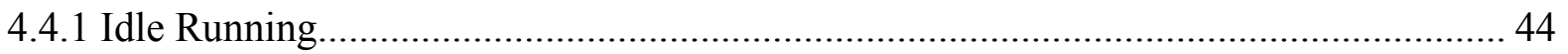

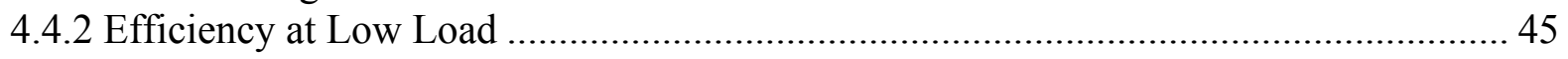

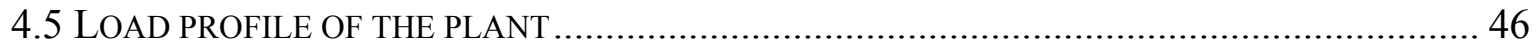

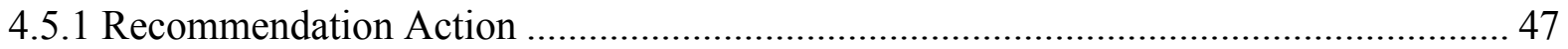

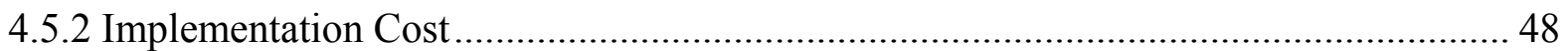

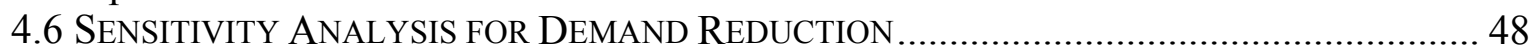

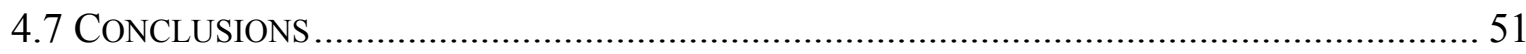

MOTOR LOAD TEST ....................................................................................................... 52

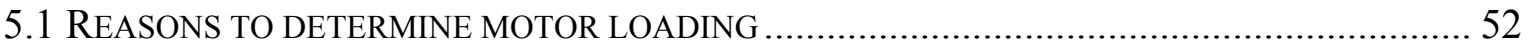

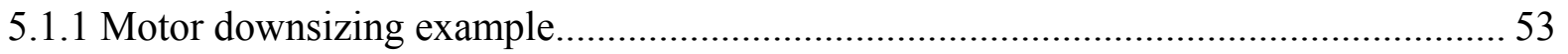

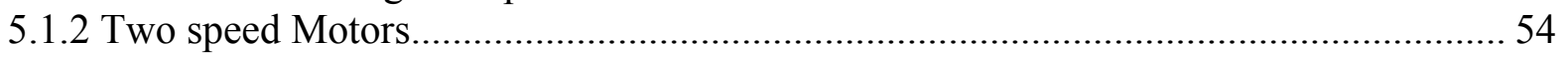

5.1.3 Comparison between downsizing and two-speed motor option ...................................... 56

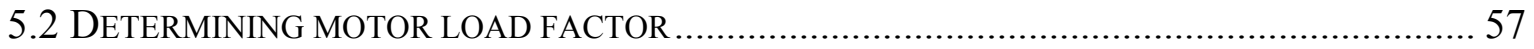

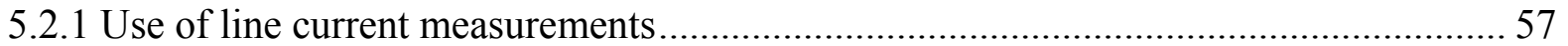

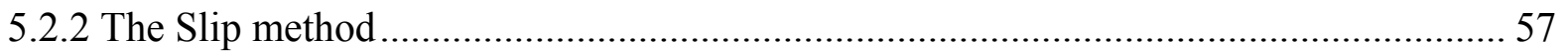

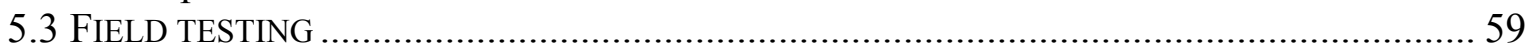

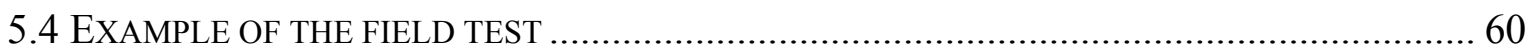

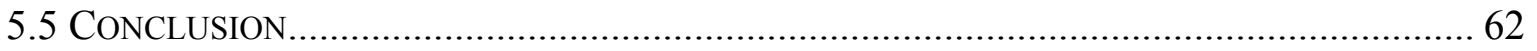

MOTOR MASTER ANALYSIS...................................................................................... 63

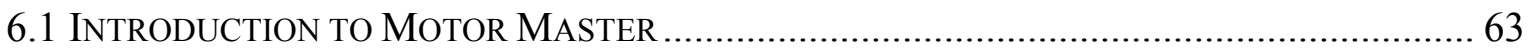

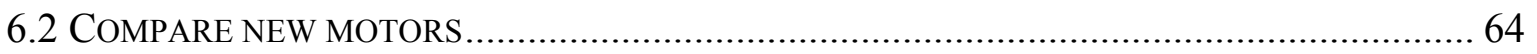

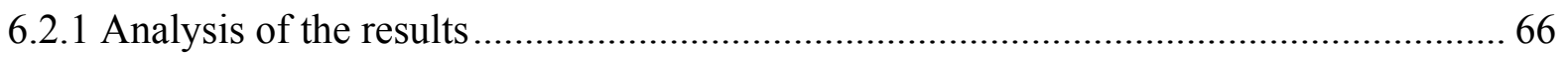

6.3 REWIND VS NEW EFFICIENCY MOTOR PURCHASE DECISION.................................................. 67

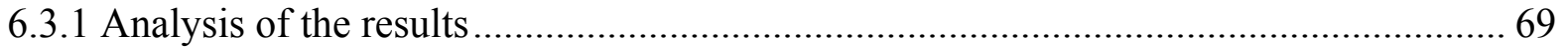

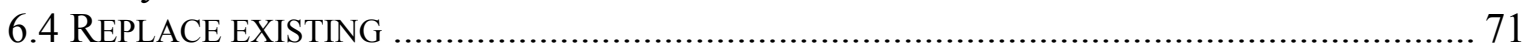

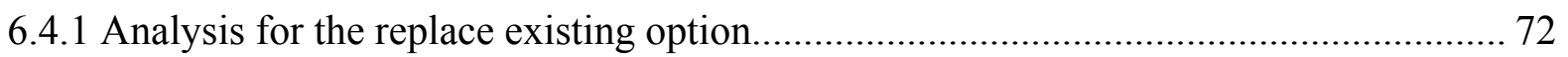

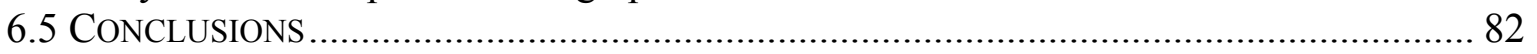

REPLACE DRIVE BELTS ON LARGE MOTORS WITH ENERGY EFFICIENT

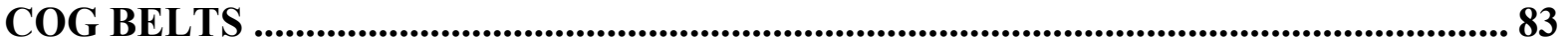

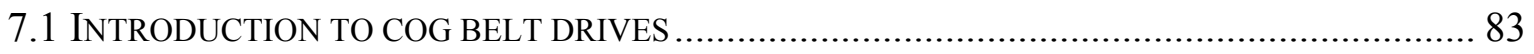




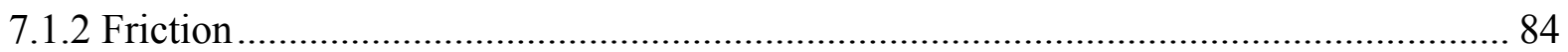

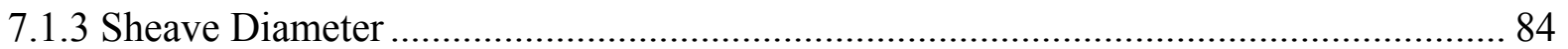

7.2 ADVANTAGES OF COGGED V BELTS OVER CONVENTIONAL V BELTS.............................. 84

7.3 CURRENT PRACTICE AND OBSERVATIONS IN WOOD INDUSTRY …………………............ 85

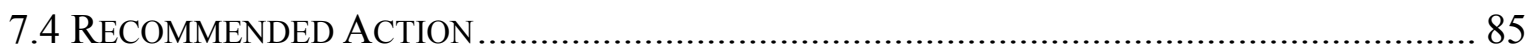

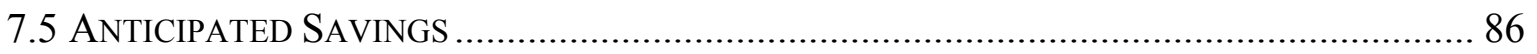

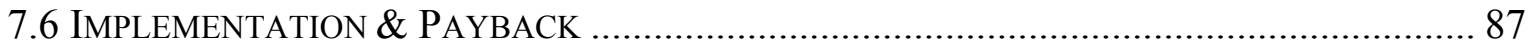

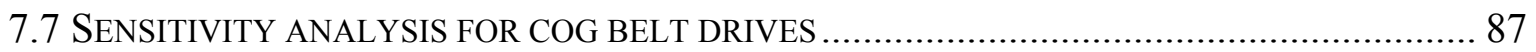

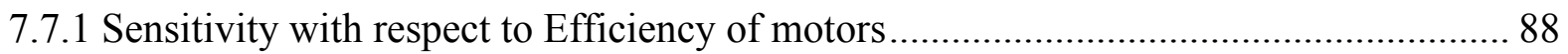

7.7.2 Sensitivity with respect to the load factor of the motors ................................................. 89

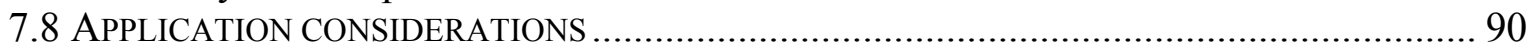

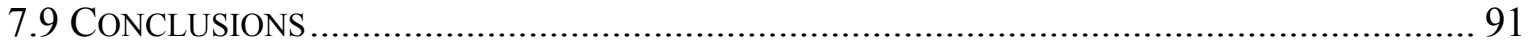

SUMMARY AND COMPARISONS FOR THE ASSESSMENT FINDINGS.................92

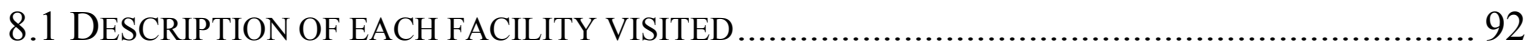

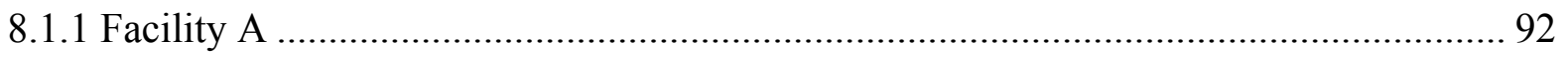

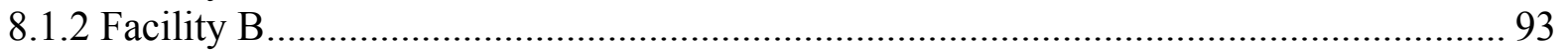

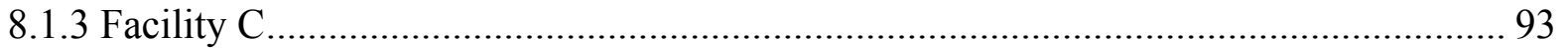

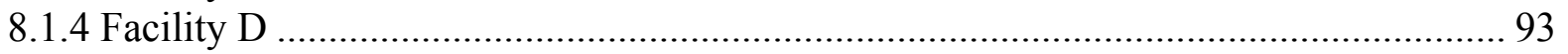

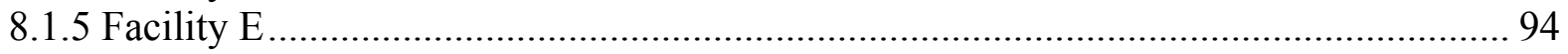

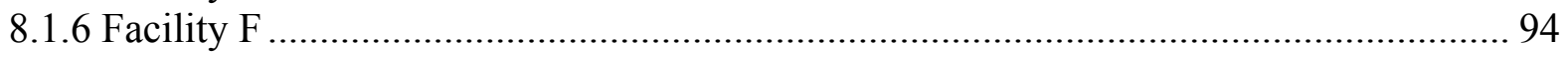

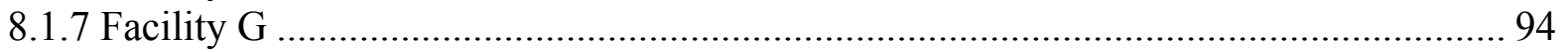

8.2 COMPARISON MATRIX FOR THE FACILITIES VISITED ………….................................. 95

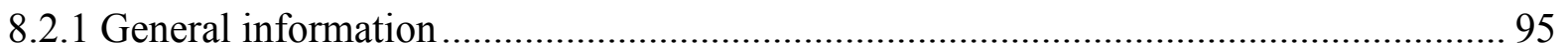

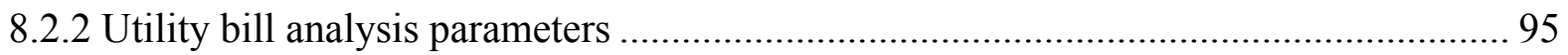

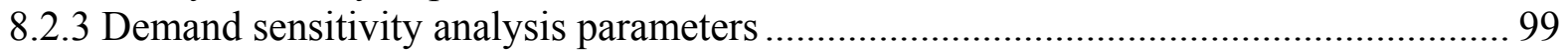

8.2.4 Specific energy consumption parameters ………..................................................... 99

8.3 PLOTS FOR SPECIFIC ENERGY CONSUMPTION …………............................................. 99

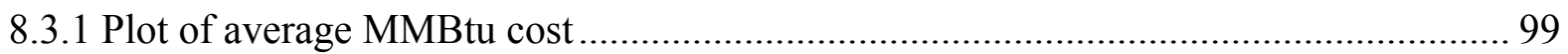

8.3.2 Plot of energy usage per mbf of production.......................................................... 100

8.3.3 Plot of total electricity cost per mbf of production ................................................... 101

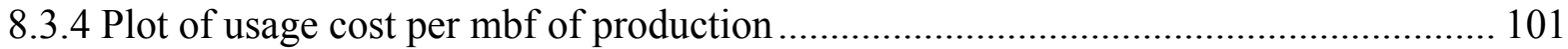

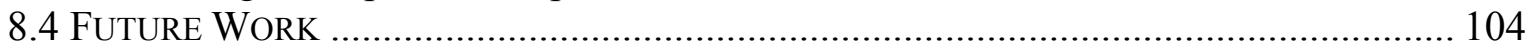

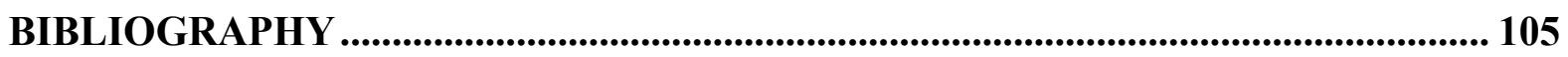

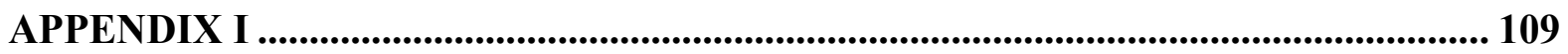

APPENDIX II................................................................................................................................. 115

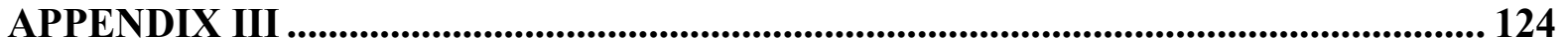

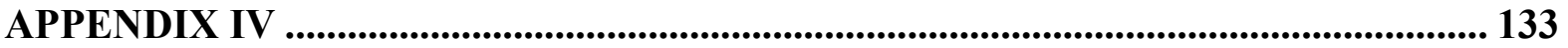




\section{List of Figures}

Figure1.1: Flow Chart of a typical sawmill process ..................................................... 9

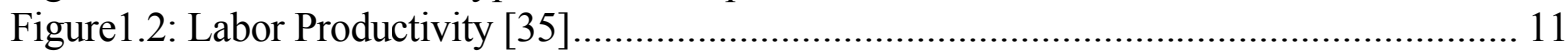

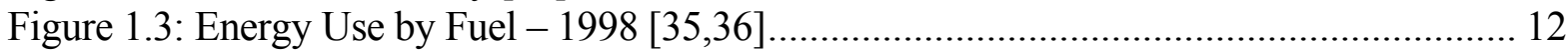

Figure 1.4: Energy Expenditures (SIC 24) - 1994 [35,36] ............................................. 13

Figure 3.1 Electricity cost distribution for facility A................................................... 30

Figure 3.2: Components of Electrical Power [29] ...................................................... 32

Figure 4.1: Load profile of facility A...................................................................... 47

Figure 4.2: Plot for demand sensitivity analysis for facility A ........................................ 51

Figure 6.1: Compare module - Compare new motors.......................................................... 65

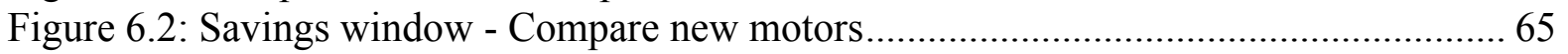

Figure 6.3: Comparison for different sizes of the motors with respect to the payback ......... 67

Figure 6.4: Compare module - Rewind Vs New efficiency motor purchase decision ........... 68

Figure 6.5: Savings window - Rewind Vs New efficiency motor purchase decision............. 69

Figure 6.6: Analysis of the Rewind Vs new efficiency motor purchase decision ................. 70

Figure 6.7: Compare module - Replace existing option.................................................. 71

Figure 6.8: Savings window - Replace existing option ............................................ 72

Figure 6.9: Comparison for the TEFC and ODP enclosure type .................................... 75

Figure 6.10: Analysis for comparing different annual operating hours ............................ 76

Figure 6.11: Comparison of different existing standard efficiencies................................. 79

Figure 6.12: Comparison for different values of efficiency for downsizing ....................... 81

Figure 7.1: Sensitivity with respect to Efficiency of motor ............................................ 89

Figure 7.2: Sensitivity with respect to Load factor of motor ............................................. 90

Figure 8.1: Plot of average MMBtu cost for the plants A to $\mathrm{H}$...................................... 102

Figure 8.2: Plot of energy usage per mbf of production for the plants $\mathrm{A}$ to $\mathrm{H}$..................... 102

Figure 8.3: Plot of total electricity cost per mbf of production for the plants $\mathrm{A}$ to $\mathrm{H}$.......... 103

Figure 8.4: Plot of usage cost per mbf of production for the plants $\mathrm{A}$ to $\mathrm{H}$....................... 103 


\section{List of Tables}

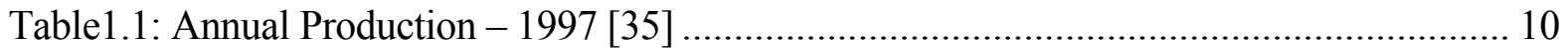

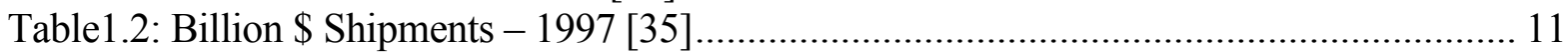

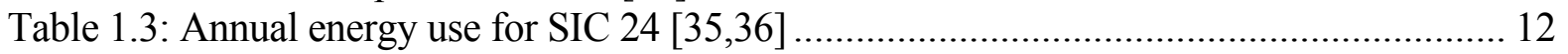

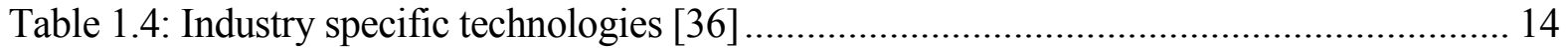

Table 1.5: Energy Management Activities - 1994 [36] ...................................................... 15

Table 1.6: Volume by species of Saw timber - 2001 [37] ................................................ 16

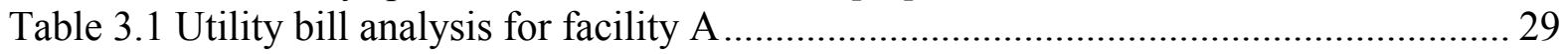

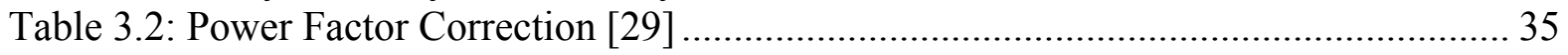

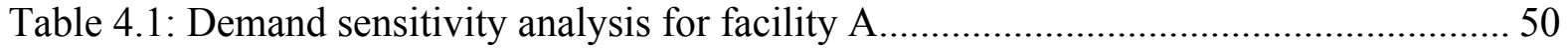

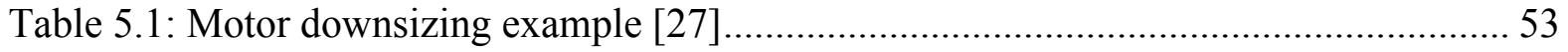

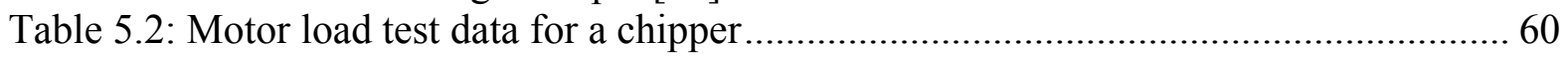

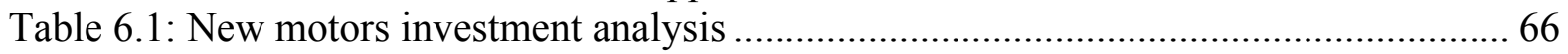

Table 6.2: Rewind Vs new efficiency motor purchase decision...................................... 70

Table 6.3: Analysis for TEFC enclosure type for motors ............................................... 74

Table 6.4: Analysis for ODP enclosure type for motors................................................ 74

Table 6.5: Replacement analysis for a two-shift operation........................................... 76

Table 6.6: Analysis with $3 \%$ reduction in standard efficiency of the existing motors .......... 78

Table 6.7: Analysis with $5 \%$ reduction in standard efficiency of the existing motors ......... 78

Table 6.8: Downsizing analysis for default efficiency values for existing motors............... 80

Table 6.9: Downsizing analysis for 3\% reduced efficiency values for existing motors.......81

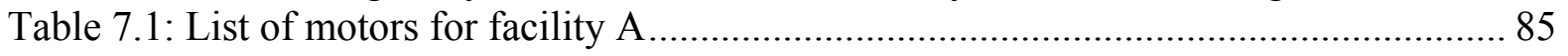

Table 7.2: Sensitivity analysis for cog belt drives ................................................... 88

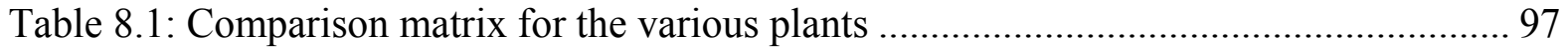




\section{Chapter 1}

\section{Introduction}

\subsection{Energy}

Energy is essential to life and survival. Energy may well be the item for which historians remember the last century. We are at the beginning of a new era of change, an era of possibly greater fundamental significance than the industrial revolution. For several centuries mankind has grown lazy, lulled into complacency by the ease with which multitudes can be fed, housed, and transported using the abundant supplies of low cost energy which were readily available. Then around 1970-80, the bubble, which had taken so long to swell finally, burst. Long unheeded warnings took on a prophetic aspect as fuel shortages and rising costs nearly paralyzed the industrial economies and literally shocked the world into an inflationary period that is not yet ended [38].

Of course in reality the problem is much more complex, involving not only oil prices but also the uneven geographical distribution of energy resources, the exponential growth of populations and fuel consumption, political and national security considerations and long term environmental effects. When energy problems caused by rapidly increasing demand in the face of dwindling fuel supply first became apparent, the immediate response was to seek new supplies and alternative fuels [38].

Later, consideration was given to the user as a means of conserving fuels and capital by improving end-use efficiency, supply problems were automatically eased. Approaching energy problems from the user's end, rather than the supply end, introduces new challenges. First, the number of users is much greater than the number of suppliers, thus complicating the problem. Second, communication with users is difficult due to their number and diversity. Third, due to its diversity, end use is not readily approached by legislative or regulatory controls. Fourth, the technological sophistication of end users varies widely, as do their capital resources, limiting the technical improvements that are feasible. Finally, the nearly infinite variety of uses invokes a need for a great many different technologies, materials and equipment.

On the positive side, changes made by end-users can have an immediate (days) or short term (months) impact on energy use, compared to five to ten years needed to add energy supply capacity. The previous availability of energy with its low cost resulted in situations in which 
there was little incentive for more efficient energy use. Both of these conditions are changing. So users now perceive economic signals (rising prices), which provide positive encouragement to reduce or eliminate all unnecessary uses of energy. Finally even though the diversity of enduse technology is considerable, it appears that there are certain basic approaches or "general principles" which apply in a wide variety of applications [38].

\subsection{Energy Management}

Energy management is the application of Industrial engineering principles to the control of energy costs at a facility. The primary goal here is to save money on energy expenses, resulting in increased profits through improved energy productivity. Often there is also an interest in conserving energy and reducing harmful environmental emissions associated with commercial and industrial operations. With this definition, energy management is just good Industrial engineering, where one of the cost factors to be controlled is the cost of energy to operate a facility and to produce a product or a service in an environmentally responsible manner [39].

Business and industry have also realized that their large uses of energy contribute to global environmental problems such as climate change, acid rain, and ozone depletion. Commercial and industrial energy use accounts for $45 \%$ of the carbon dioxide released from the burning of fossil fuels, and $70 \%$ of the sulfur dioxide emissions from stationary resources. Energy efficiency and energy conservation efforts on the part of business and industry can have substantial positive impacts on these national and global problems, as well as the bottom line of the company's balance sheet [39].

Energy conservation is the need of the hour. It is a continuous process that requires consistent efforts for identifying potential areas for conservation, formulation of proposals and implementing the same. Energy is the most critical resource today. Gap between demand and supply of energy will be continuously widening in the years to come. Scarcity of fuels, insufficiency in energy systems and ever rising cost of energy, lead to energy crisis and ultimately to energy conservation. Energy conservation is based on a worldwide BAT (best available technology) principle. Certain aspects considered while going through the energy conservation program include: 
* Up gradation of technology

* Systems development

* Fine-tuning methods

\subsection{Industrial energy conservation}

Energy is an integral component of modern industrialized society. It is an essential ingredient in nearly all goods and services, but its use exacts heavy financial, environmental and security costs. A key method of reducing energy's costs while retaining its benefits is to utilize it more efficiently than before [38]. Important questions that arise in the context of industrial energy use are as follows:

1. How does industry use energy? What is the outlook for future energy use?

2. What technologies are available to improve energy efficiency? How much energy can be saved?

3. How do corporations view energy? What are the incentives for using more efficient technologies?

Industry is a large consumer of energy. U.S. manufacturing plants, mines, farms and constructions firms currently consume about 25 quads (quadrillion British thermal units or Btu) of energy each year [38], about $30 \%$ of the nations total consumption of energy and manufacturing industries account for the lion's share. Industry thus has a major role in making the U.S. more energy efficient. Industrial energy use and the opportunities for improving its energy efficiency depend on many technical, economic, institutional and political factors. The largest energy users are industries, such as petroleum refining, chemicals, primary metals, pulp and paper, food and ceramics and glass, which chemically or physically convert matter. These industries account for $74 \%$ of total industrial energy use [38]. The fabricating and assembly industries are the largest electricity users, because of relative prominence of motor driven devices, lighting and ventilation. There are many energy efficient technologies and practices, both currently available and under development, that could save energy if adopted by industry. Energy efficiency can be improved through the cost effective use of the following: 


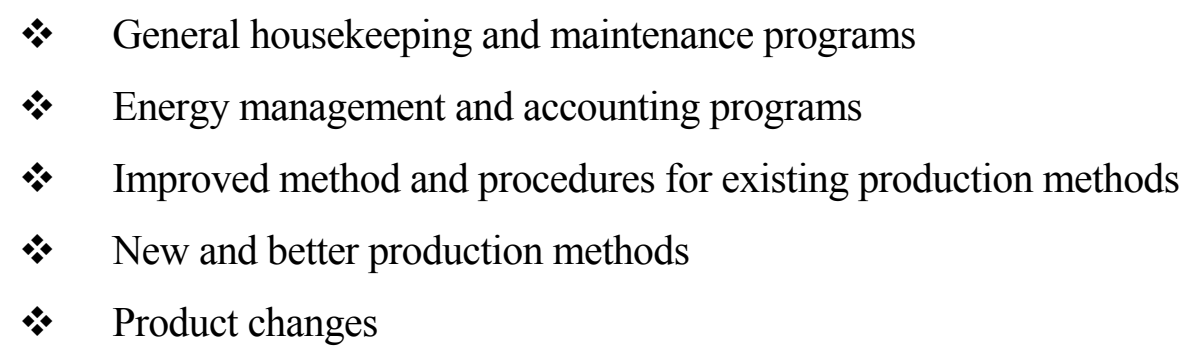

Most of the equipment and process enhancements are specific to particular industries, but several (e.g., heat recovery technologies, high efficiency motors and variable speed drives, boiler efficiency, sensors and controls and cogeneration) have applications in many industries. These generic technologies are particularly attractive targets for government policies.

The costs and benefits of energy efficient improvements vary widely. Minor operational changes, such as house keeping and maintenance, are typically the cheapest, easiest to implement, least risky and usually, though not always, yield the smallest energy and cost savings. Production equipment changes and energy conservation add-on technologies involve larger investments, typically $\$ 100,000$ to tens of millions of dollars, and may or may not be justified by reduced energy costs alone. Major process changes often require building a new facility, at costs typically exceeding \$ 100 million, and usually are justified only by strategic, market development concerns. Energy savings are seldom sufficient to justify the investments of this magnitude.

Potentially, the greatest increase in efficiency will come not from direct efforts to reduce energy consumption but by pursuing other economic goals like improved product quality, lower capital and operating costs, or specialized product markets. Many projects yield energy efficiency gains as a secondary consequence. For example, steel makers have installed continuous casters more for the improved product yield than the energy savings. Metal stamping plants have implemented new techniques for cushioning presses not for the $10 \%$ energy savings, but for the consistent products and lower maintenance cost [38]. Sometimes, however, pursuing improved quality or specialized markets can diminish energy efficiency. Such is the case in petroleum refining where several factors have combined to increase the energy requirements per unit of product in recent years as shown herein: 
* The reduction in capacity utilization

* The decline in crude oil quality

* The increased demand for lighter products relative to heavier products (residual oil)

The requirements for enhanced products such as reformulated gasoline

At any given time, the mix of technologies used by industry ranges from outdated to state-of-the-art. Energy efficiency improves as the older facilities are replaced with the state-ofthe-art ones. In the petroleum refining, chemical, pulp and paper, steel, aluminum, cement and glass industries, most state-of-the-art technologies use 12 to $38 \%$ less energy than the mix of processes currently used. This comparison does not imply that these industries would find it economical to bring all their existing plants to state-of-the-art tomorrow. Advanced technologies, no yet commercialized, could possibly reduce energy use in the various processes by an additional 9 to $35 \%$.

There are various potential areas that can be identified as prospective candidates for considering energy conservation measures. Some of them are the lighting, motors, destratification, insulation of process equipment, boilers and compressors. If we consider lighting in facilities, modifications to the operation of the lighting system would provide great opportunities to reduce energy consumption. Simply turning off unnecessary lights, day and night, and making greater use of available daylight for illumination saves energy for both lighting and air-conditioning with no added costs. If we consider the boiler, which is used to generate process steam in facilities usually, the efficiency of the boiler unit drops when the combustion process is improper or when combustion process increases the stack temperature. Any percentage increase in seasonal boiler efficiency directly reduces fuel consumption in the same proportion. If we consider the three phase-induction electrical motors in the facilities, usually the industrial personnel lack prior knowledge about the high efficient motors available in the market and the cost savings that can result from a replacement schedule. Another example would be the employment of de-stratification fans in the workplaces where heating units have been set up in place but comfort level has not been attained at work level. Several cases involving various ideas about utilizing the energy consumers more efficiently can be presented but for the purpose of the work in consideration, the above in itself would be sufficient to create awareness about this universal problem [38]. 


\subsection{Corporate Viewpoint}

Corporation's internal cultures and external relationships are very important factors on industrial energy use and efficiency. Here, it is attempted to focus on the question of "why and when the industrial user would care about energy?" The investment and implementation steps encompass major hurdles. Technical and economic feasibility are the most commonly studied factors influencing energy efficiency investments while the company's general willingness to invest in process improvements, their energy awareness, their access to information also have important impacts.

Perhaps the most important factor affecting industrial energy efficiency is the willingness of firms to invest in new technologies, whether energy conscious or not. Capital investment in modern equipment usually enhances energy efficiency, even when efficiency is not the primary purpose of the investment. The propensity to invest depends on the business climate, corporate culture, manager's personality and regulations. These determine the incentives for the corporations in general and managers in particular to improve their production processes [38].

If there is willingness to invest, the next hurdle for the managers is to know how the energy is used in their plants and to be aware of technologies available to improve the situation. Industrial companies consider energy primarily in terms of cost. They have direct financial incentives for reducing their energy costs by improving their energy efficiency. The importance that companies attach to reducing costs in general, and energy costs in particular, varies greatly however. In industries such as steel, aluminum, cement and industrial gases, where energy is a major portion of the total costs, concerns about energy efficiency are high. The existence of energy efficiency "Champions", enlightened management or efficiency promotion programs can also give energy a high profile in corporate decision making. For example, Dow Chemical's Louisiana Division [38] has a very successful contest for identifying and funding energy efficiency projects. Sudden energy price shocks or availability problems can also prompt companies to improve their energy efficiency.

Cutting energy costs via technical means is not a high profile concern in most industrial companies. Energy costs do not command the attention of the senior management and do not garner the resources needed to implement the improvements. Even in the operations divisions of the firms, where costs issues are most focused, energy is but one of the many concerns. An 
operations manager's top priorities are keeping the production line up and running smoothly, making products that meet the consumer's specifications and expectations, and meeting regulatory guidelines. Energy costs tend to be secondary concerns. This could also be because the energy costs are low. The general lack of concern afforded energy in many corporations is a major barrier to implementation of energy efficiency improvements.

Low energy awareness is less of a setback to efficiency in situations where there are new technologies with the production benefits in addition to energy saving characteristics. Fortunately, many technologies fall in this category. They are implemented primarily to boost product quality, further automate production or enhance some other characteristics. They improve energy efficiency as a side benefit. For example, continuous casting is put into steel mills primarily to improve material yields and product quality and to shorten processing times. Secondarily, the improved design of the process uses less energy per ton of steel produced.

Convenient information regarding new technologies and their energy characteristics is vital to energy efficiency implementation. Managers, especially those in small firms, do not have the time and the resources for gathering and analyzing large amounts of information to support their decisions. This is particularly true when equipment fails and needs immediate replacement. There is little time to research the available best replacement technologies, and then test and tune them up once they arrive. Consequently, in these situations the managers usually stick to the technologies that they know well - the ones that have used before. Providing information is the role that the State and the Federal governments are involved in. Utilities are also involved in dissemination information as well as conducting audits to inform companies about energy saving opportunities.

Lastly, technological feasibility and economic feasibility are driving factors as well. Technologies must not only work successfully, but also be reliable, serviceable and proven. In addition they must be economical with respect to capital outlays, energy and other input prices and costs of capital.

Energy and energy management have been in the limelight in various manufacturing and service operations across the industry in US. The lumber and wood manufacturing industry has not been a major part of this discussion. So, in this study, wood and lumber manufacturing industry will be the considered for a thorough analysis of the energy use and energy management activities. A general background of the wood industry and the wood manufacturing 
process will be discussed in the following paragraphs followed by economic profile and trends in that industry.

\subsection{Importance of Wood Industry}

Wood has played a leading role in the advancement of the human race. It has been used by mankind to provide shelter, fuel, weapons, transportation, and in many other ways, since the beginning of civilization. It is at once the best known and the least known among the important basic structural materials. Wood is used in many different forms in its service to man. Although large quantities are utilized as fuel wood, pulpwood, railroad ties, etc, lumber is the important form in which wood is used. In the United States the volume of wood converted into lumber exceeds the volume used for all other purposes [32]. In spite of the tremendous advances that have been made in the development of new ways of using wood, it is probable that lumber will continue for a long time to be the most important wood product from a value standpoint. The business of converting trees into lumber will always occupy an important place in the industrial economy [32].

\subsubsection{Definition}

Lumber has been defined as " the product of the saw and planning mill, not further manufactured than by sawing, re-sawing, and passing length wise through a standard planning machine, crosscutting to length and working." [32].

\subsubsection{The manufacturing operations}

The essential operations in the manufacture of lumber are (1) breakdown of the log into boards or timbers; (2) cutting the boards or timbers lengthwise in a ripping or edging operation, with the objective of removing wane, improving the grade, or dimensioning to width; and (3) cutting the boards across the grain in a cross cutting or trimming operation, for the purpose of removing defects, improving the grade, or dimensioning to length.

\subsubsection{Process}

Saw logs are trucked in to the plant by the logger contracted to haul them from the harvest site. Logs are stored in the area outside the plant and initial inspection and sorting is 
done. They are then fed to the Debarker where the bark is abraded off. With the help of a material handling system they are sent to the Head saw where sideboards are cut off from the cant. The cant is then cut into desired dimensions. The boards proceed on a conveyor to the Edger where smooth parallel edges are rendered on to the boards. The Trimmer then cuts the boards to square and precise lengths. The boards are then sent to grading and then final sorting and storage. The lumber is then packaged by grade and length and shipped via trucks. A detailed flow chart of a typical sawmill is shown in the Figure 1.1.

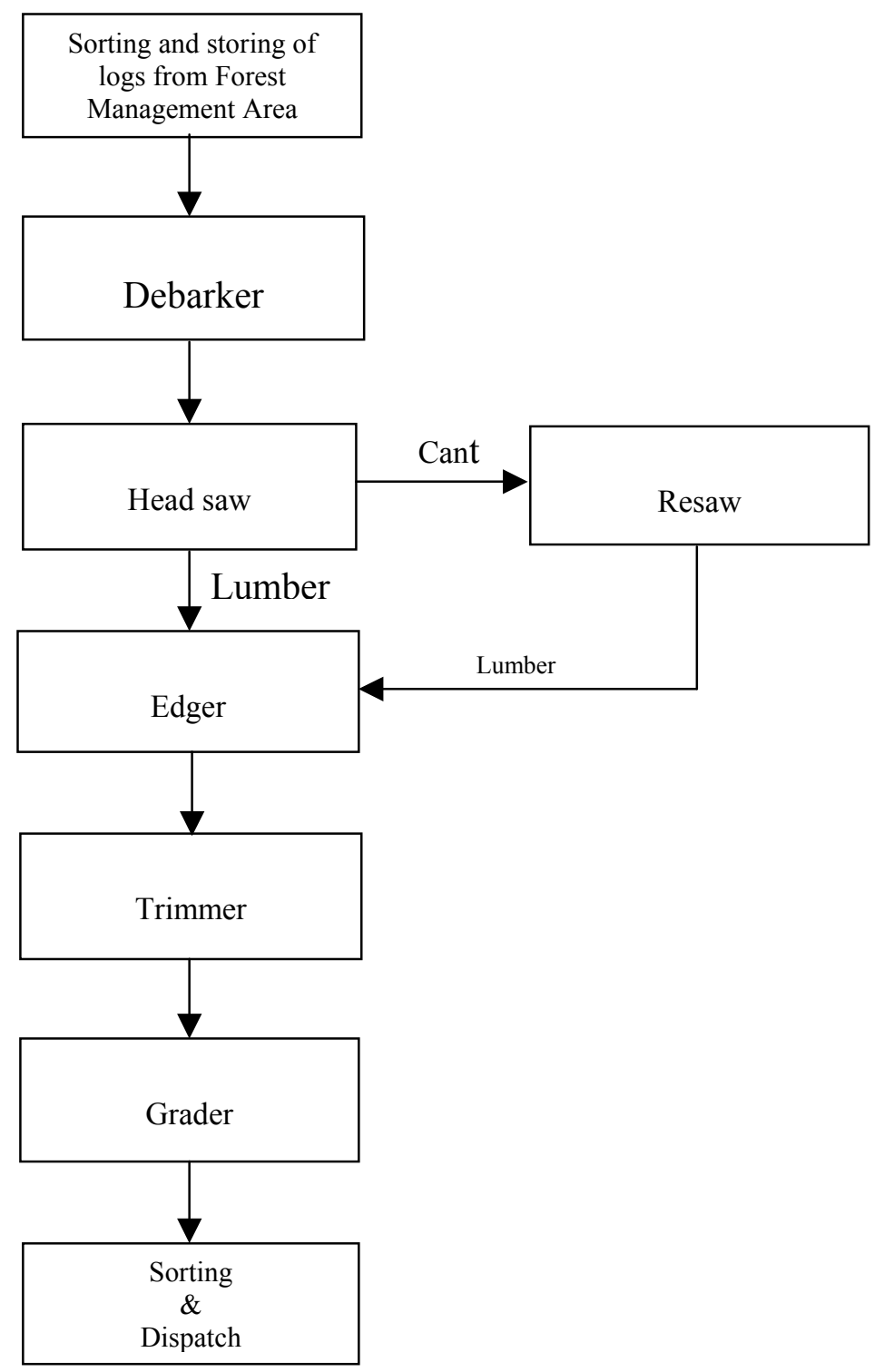

Figure 1.1: Flow Chart of a typical sawmill process 


\subsubsection{Introduction to the Lumber and wood products industry}

The lumber and wood products industry includes establishments engaged in cutting timber and pulpwood; sawmills, lath mills, shingle mills, cooperage stock mills (wooden casks or tubs), planing mills, plywood mills; establishments engaged in manufacturing finished articles made entirely or mainly of wood or related materials such as reconstituted wood panel products manufacturers. The categorization corresponds to the Standard Industrial Classification (SIC) code 24 established by the Department of Commerce's Bureau of the Census to track the flow of goods and services within the economy. In this profile, the industry's processes are divided into four general groups: logging timber; producing lumber; panel products and wood preserving.

\subsection{Economic Profile and Trends of the Lumber and Wood products Industry}

The economic profile and trends in the lumber and wood manufacturing industry in the year 1994 \& 1998 are obtained from the manufacturing Consumption of Energy Survey in the years 1994 and 1998, which is published by the US Department of Energy's, Energy Information Administration. The annual production in the SIC 24 category, the value of shipments for SIC 24 category and the labor productivity in the wood manufacturing industry are discussed in detail in the following paragraphs.

\subsubsection{Annual Production}

Lumber and wood products include a wide range of products, including cut timber, rough wood products, such as hewn posts, lumber and flooring, millwork, such as moldings and cornices, cabinets, plywood, containers, and wood buildings. The annual production of the lumber and wood products is shown in Table 1.1.

\begin{tabular}{|c|c|}
\hline Type & Annual Production Quantity \\
\hline Software Lumber & 34.5 billion board feet \\
\hline Hardwood Lumber & 12.9 billion board feet \\
\hline
\end{tabular}

Table1.1: Annual Production - 1997 [35] 


\subsubsection{Value of Shipments}

The strong U.S. economy of the late 1990's has revived the pulp and paper industry and also the lumber industry. Softwood and hardwood lumber production is again climbing, both up 2\% from 1996. Table 1.2 shows the value of shipments in 1997.

\begin{tabular}{|l|c|}
\hline \multicolumn{1}{|c|}{ SIC Type } & $\begin{array}{c}\text { Value of shipments } \\
\text { (Billion \$) }\end{array}$ \\
\hline Logging (SIC 241) & 13.6 \\
\hline Sawmills and Planning mills (SIC 242) & 35.2 \\
\hline $\begin{array}{l}\text { Millwork, Plywood, and Structural members } \\
\text { (SIC 243) }\end{array}$ & 22.4 \\
\hline Wood containers (SIC 244) & 4.5 \\
\hline Wood buildings and Mobile homes (SIC 245) & 13.2 \\
\hline Miscellaneous wood products (SIC 249) & 13.6 \\
\hline
\end{tabular}

Table1.2: Billion \$ Shipments - 1997 [35]

\subsubsection{Labor Productivity}

Technological improvements in the wood products sector have not been as pronounced as in other sectors. As a result, labor productivity statistics in the lumber and wood products sector have been either declining or relatively stable during the 1987-1996 time frame. As can be seen in the Figure1.2 below which shows the labor output per hour for the years 1987-1996.

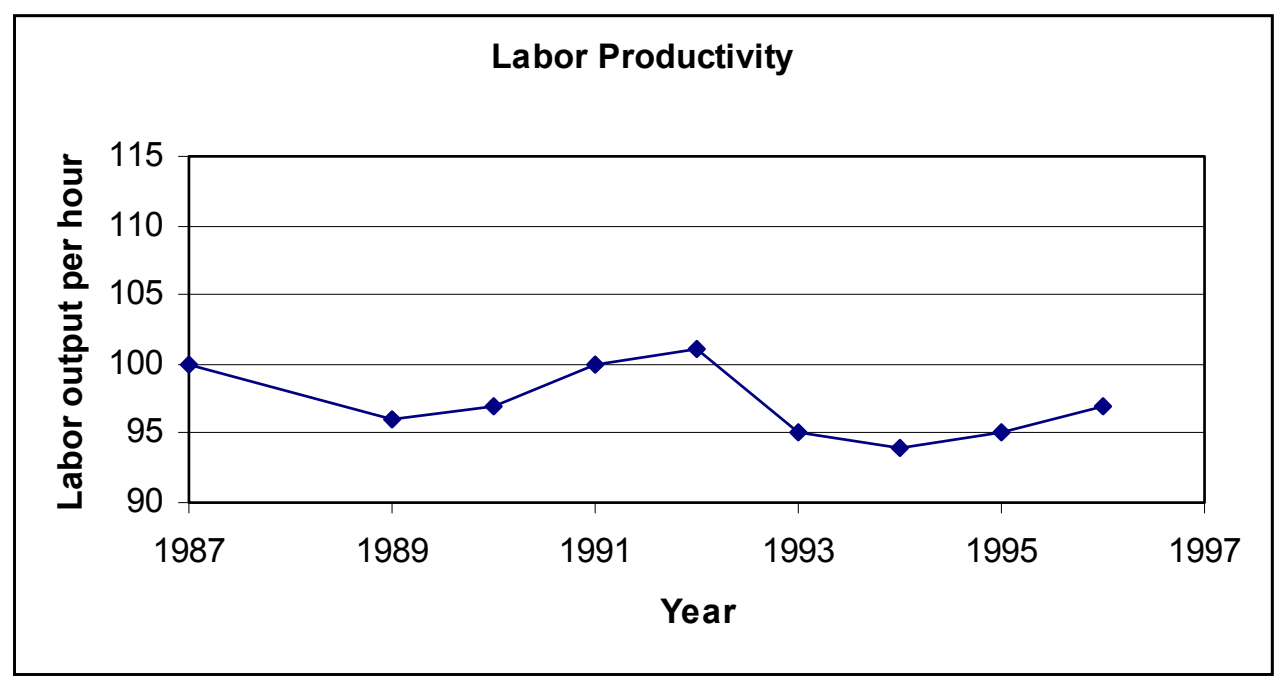

Figure1.2: Labor Productivity [35] 


\subsection{Energy Use in Forest and Wood products industry}

The forest products industry consumed more than 3.1 quads of energy in 1994. This represents about $14 \%$ of domestic manufacturing energy use, making the forest products industry as a whole the third largest industrial consumer of energy, behind only petroleum and chemicals. Within the forest products industry, the pulp and paper industry (SIC 26) uses the vast majority of the energy, 2.66 quads, while the lumber and wood products industry uses only 0.491 quad. The total energy usage for SIC 24 can be seen in the following Table 1.3.

\begin{tabular}{|c|c|}
\hline Year & $\begin{array}{c}\text { Total Energy Use } \\
\text { (trillion Btu) }\end{array}$ \\
\hline 1985 & 325 \\
\hline 1988 & 407 \\
\hline 1991 & 451 \\
\hline 1994 & 491 \\
\hline 1998 & 584 \\
\hline
\end{tabular}

Table 1.3: Annual energy use for SIC $24[35,36]$

\subsubsection{Energy Use by Fuel}

In 1998, the lumber and wood products sector generated 387 trillion Btu, or $66 \%$ of the industry's energy needs, from wood residues. Remaining energy needs were met by electricity, natural gas, and fuel oil. A pie chart of the energy use by fuel is as seen in the Figure 1.3.

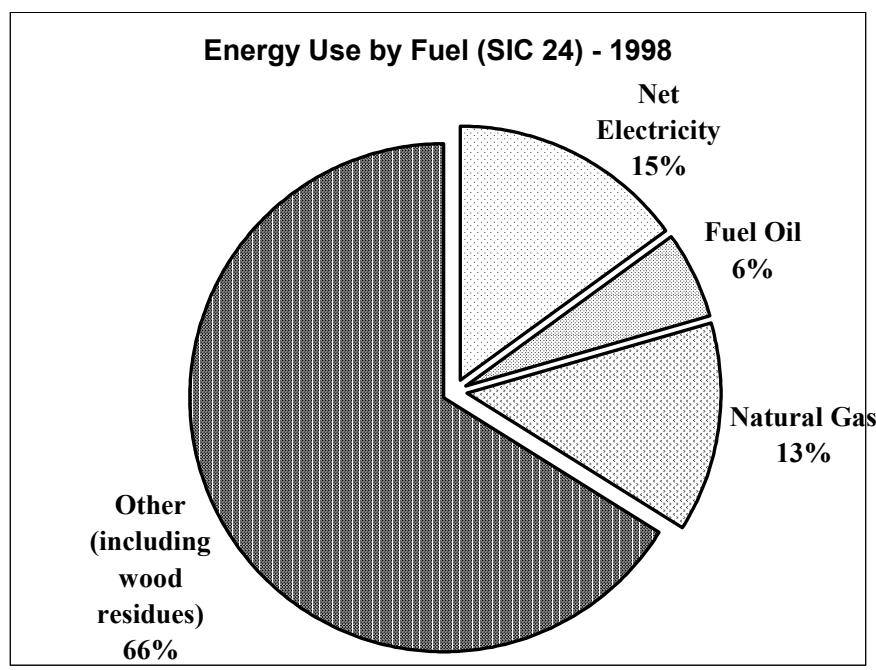

Figure 1.3: Energy Use by Fuel - 1998 [35,36] 


\subsubsection{Energy Expenditures}

The forest products industry spent $\$ 7.7$ billion on purchased energy in 1994, more than $11 \%$ of total U.S. manufacturing energy expenditures. Of this amount, about $\$ 6$ billion was spent by the pulp and paper industry and $\$ 1.7$ billion by the lumber and wood products industry. Electricity purchases represent the largest share of energy costs, almost half of the pulp and paper industry's energy expenditures and over half of lumber and wood products' purchases in 1994. Figure 1.4 below shows the distribution of the energy expenditure according to the fuel type.

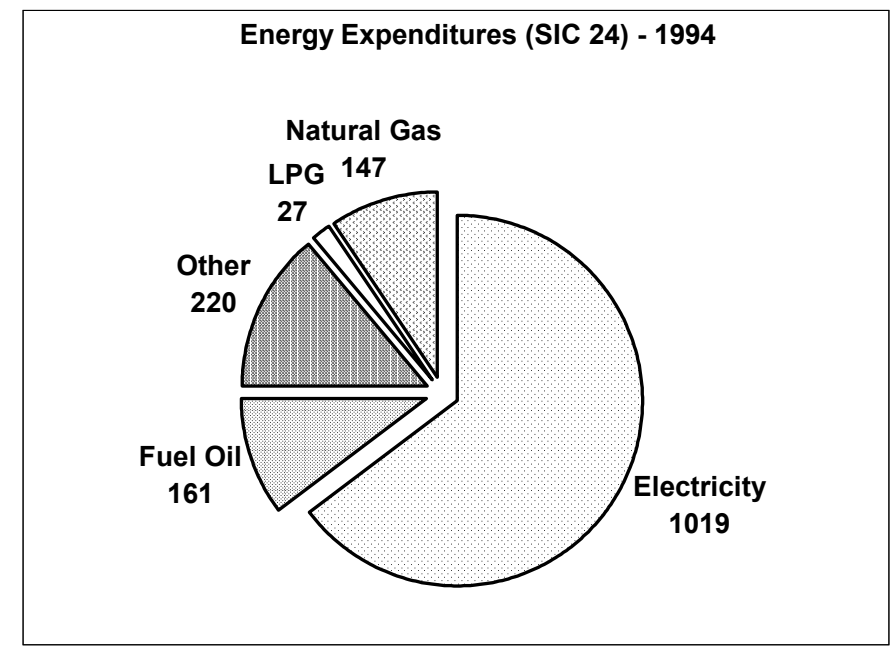

Figure 1.4: Energy Expenditures (SIC 24) - 1994 [35,36]

\subsubsection{Technologies and Equipment}

Transforming whole trees into lumber and wood products require significant physical and chemical processes that are highly energy intensive. The forest products industries alone account for over $14 \%$ of total industry demand. The technologies used by the lumber and wood products industry differ significantly from those used by pulp and paper industry. Principal processes in lumber and wood products as discussed earlier include debarking, log processing, drying, product fabrication, and finishing. The Table 1.4 shows the various major technologies used for the different unit operations carried out during the manufacturing of lumber and wood products. 


\begin{tabular}{|c|c|c|}
\hline $\begin{array}{c}\text { Unit } \\
\text { Operation }\end{array}$ & Purpose & Major Technologies \\
\hline Debarking & Removes bark from the whole log & Barking drum, ring barker \\
\hline $\log$ & $\begin{array}{l}\text { Production of round wood (poles, posts), } \\
\text { sawn wood (lumber), veneers }\end{array}$ & $\begin{array}{l}\text { Computer vision mechanical } \\
\text { sawing, cutting and chipping }\end{array}$ \\
\hline Drying & $\begin{array}{l}\text { Removing moisture from wood to facilitate } \\
\text { shipping, handling, preservation and the } \\
\text { application of treatments }\end{array}$ & Kiln or air drying \\
\hline Fabrication & $\begin{array}{l}\text { Additional processing to form desired end } \\
\text { product }\end{array}$ & $\begin{array}{l}\text { Specialized mechanical } \\
\text { sawing, drilling, sanding, high } \\
\text { pressure chemical reformation }\end{array}$ \\
\hline Finishing & Preserving and treating wood for final use & $\begin{array}{l}\text { Pressure treatment, chemical } \\
\text { treatment, coating }\end{array}$ \\
\hline $\begin{array}{l}\text { Process } \\
\text { Heating }\end{array}$ & $\begin{array}{l}\text { To drive pressure, steam and drying } \\
\text { applications }\end{array}$ & $\begin{array}{l}\text { Direct heating, furnaces, kilns, } \\
\text { dryers }\end{array}$ \\
\hline
\end{tabular}

Table 1.4: Industry specific technologies [36]

\subsubsection{Energy management activities}

Manufacturers may conduct a number of energy management activities to improve the efficiency of energy use at their facilities. The four top management techniques used by the forest products industry include energy audits, electricity load controls, power factor correction or improvement, and facility lighting. The most commonly used of these is the energy audit, employed by almost 2,500 facilities in 1994. The different activities and the number of establishments doing them can be seen in the following Table 1.5. 


\begin{tabular}{|l|c|c|}
\hline \multicolumn{1}{|c|}{ Activities } & Number of establishments & $\begin{array}{c}\text { \% Consumed energy for } \\
\text { heat and power }\end{array}$ \\
\hline Energy Audits & 1,413 & $24.6 \%$ \\
\hline $\begin{array}{l}\text { Power Factor Correction of } \\
\text { Improvement }\end{array}$ & 1,068 & $21.4 \%$ \\
\hline Electricity load control & 1,021 & $19.8 \%$ \\
\hline Facility lighting & 736 & $11.3 \%$ \\
\hline
\end{tabular}

Table 1.5: Energy Management Activities - 1994 [36]

\subsection{Wood Industry in West Virginia}

The wood products industry is of growing importance to West Virginia's economy. According to the West Virginia Forest Association, the Forestry Industry provides the state with more than 30,000 full time jobs. The wood industry supported the following list of operations [37]:

$\begin{array}{ll}\text { Sawmills } & 181 \\ \text { Veneer mills } & 3 \\ \text { Rustic fencing mills } & 18 \\ \text { Dry kilns } & 58 \\ \text { Pressure treating plants } & 11 \\ \text { Concentration yards } & 46 \\ \text { Manufacturers of wood products } & 181 \\ \text { Engineered wood products } & 3 \\ \text { Firewood producers } & 2\end{array}$

With 11.6 million acres of timberland and 75 billion board feet of inventory, the forest resources of West Virginia seem endless. The state sits at the geographic center of the worldrenowned Appalachian Hardwood belt. Climate and soils combine to provide an ideal growing 
environment for hardwoods. The species type and percent quantity of the total inventory are shown in the Table 1.6.

\begin{tabular}{|c|c|}
\hline Species & \% Of total Inventory \\
\hline Red Oak & $26 \%$ \\
\hline White Oak & $24 \%$ \\
\hline Yellow Poplar & $21 \%$ \\
\hline Maple & $10 \%$ \\
\hline Black Cherry & $4 \%$ \\
\hline Other & $15 \%$ \\
\hline
\end{tabular}

Table 1.6: Volume by species of Saw timber - 2001 [37]

\subsection{Need for Research}

This research work is concerned with the energy analysis and diagnostics in wood manufacturing industry in West Virginia. The need for this research work stems from the fact that energy conservation is being considered as a vital issue for the future, considering the steady increase in primary energy costs, the inability of supplies and predicted limitations. Energy conservation will allow the earth's limited resource base of high quality fuels to be stretched further. It will also allow a portion of the fossil fuel base to be reserved for non-energy purposes. The fact is that we may be faced with a continuing shortage of fuel and power unless new sources are developed in the future. Part of the shortage can be compensated for by conservation measures. Otherwise major dislocations and even catastrophe may be in store for the companies and institutions.

\subsection{Energy research in West Virginia}

The Appalachian Hardwood Center at West Virginia University was created by the West Virginia legislature to assist in the orderly expansion of the hardwood industry in West Virginia. The West Virginia Development Office has utilized the Center and the College of Engineering and Mineral Resource's (CEMR), Industrial and Management Systems Engineering department to provide information to the industry on marketing opportunities for 
wood residue and overall process efficiency opportunities. The intent of this project and research is to take further advantage of the technical resources to improve operational efficiency and energy performance of forest industry businesses.

Wood industry in general has not seen much technical improvement over the years in terms of productivity and energy efficiency as can be seen in the labor productivity data from the Manufacturing Consumption of Energy 1998. Wood industry in West Virginia is a major contributor to the state. With recent crisis in the Energy sector, it becomes important to concentrate our efforts on energy conservation and energy management. Energy costs contribute to the manufacturing cost of the products. The need for research is justified because several opportunities have been overlooked by the wood manufacturing industries. To understand the potential for industrial energy conservation, consider the industrial plant as a system. We can observe that on one side we have inputs of energy raw materials and labor and on the other side, the output of goods, waste energy and waste materials. In order to maximize profits the energy manager attempts to keep the costs of inputs to a minimum. In the past in many cases, since the cost of energy was low in relation to the other inputs, it was ignored. However, with today's spiraling energy prices, more attention is being given to energy input. Energy savings can occur either by improving the energy conversion process, by recycling the waste energy or by reusing the waste materials. Many opportunities exist for the application of the existing technology to yield large energy savings, which in turn means large cost savings for the company. For this to occur, however, answers must be found for two major questions:

1. What are the areas of activity in which there may be significant potential for better use of energy?

2. Within these areas, what are the specific measures or alternative options that could lead to better and more efficient use of energy?

Usually in an energy management program, the answers to these questions are sought in specific terms by means of energy audits. This is a phase in the energy management program, which involves the determination of where and how the energy is being used in the facility. 


\subsection{Research objectives}

The objectives of this work are to actually conduct site audits at several lumber and wood manufacturing plants in West Virginia, using the collected data, determine energy conservation opportunities and recommendations. We need to understand the potential for these assessment recommendations with respect to the parameters governing them. The specific objectives of the research were:

1) To identify potential recommendations in the field of energy conservation and energy management.

2) To collect data on site regarding to various potential opportunities available on site. This might include extensive measurements on major energy consuming equipment related to electrical consumption, hours of operation, load factor and other data. The data collection would involve use of data recording devices such as electrical power analyzers, digital stroboscopes, and temperature guns.

3) Analyze the measured and collected data with respect to the other recommendation for the plant and get preliminary results. Make extensive use of decision tools such as Motor Master for better understanding of the collected data especially on the plant motors. Identify the opportunities for downsizing and replacement of motors in the plant.

4) Identify the major parameters governing the recommendations. Measure and analyze the impact of each of these parameters on the resulting savings potential. Do a thorough diagnosis and sensitivity analysis for all of these major factors governing the recommendation. Perform a thorough analysis of the plant motors using Motor Master software.

5) Gain better insight into the various operating parameters, which govern the recommendations and report them.

\subsection{Conclusions}

This chapter discussed the nature of energy crisis, highlighted the problem areas and projected the importance of energy efficiency improvements. It also discussed the wood and lumber manufacturing industry in general and also in West Virginia. It is proposed to carry 
out energy assessments at several wood and lumber manufacturing facilities in West Virginia and do exhaustive measurements and analysis of the data collected. It is proposed to do a sensitivity analysis for all the recommendations and the major parameters governing them. 


\section{Chapter 2}

\section{Literature Review}

Although much literature has not been cited in the area of energy management in the wood manufacturing industry especially under SIC 24, there are some publications in the pulp and paper industry and forest products industry that are discussed in the following sections.

\subsection{Energy Analysis in Forest products industry}

Various recommendations made during IAC audits of over 200 pulp and paper industries are discussed in [1]. This paper covers the wood products sector (SIC 24) and paper product sector (SIC 26) and includes the most common energy conservation opportunities and waste minimization opportunities cited during these assessments. These assessments contain recommendations for reducing energy use in all forms (oil, natural gas, electricity, etc.) The energy efficiency of existing dust collection systems in wood furniture manufacturing plants is investigated in [2]. It is observed that these dust collection systems are in general running at lower efficiencies. The characteristics, which contribute to this situation, are identified and discussed in [2]. A wood dust collection system based on energyefficient concepts utilizing readily available technology is proposed in [2]. The proposed system is estimated to be nearly 30 to $35 \%$ more efficient than the existing conventional systems.

The use of Motor Master (DOS format) by many within the pulp and paper and other industries to evaluate and select motors for energy efficiency and lowest life cycle cost, is discussed in [3]. It also covers Motor Master+, an enhanced version of motor master, presented in Windows format. The discussion covers Motor Master's motor and motor driven

system energy management capabilities, the determination of motor load and efficiency from field-testing measurements, energy savings determination and life cycle costing., use of utility rate information, and the types of motor selection are also addressed in the paper.

The author discusses a method for estimating motor efficiency and analyzing the conditions in pulp and paper industry in [4]. Load management measures in a carpentry factory in Sweden are discussed in detail in [5]. It describes the use of electricity and heat in 
a carpentry factory. The results show that energy conservation measures and load management might be of significant importance in order to make the company more profitable. Even small savings can make the difference between survival and bankruptcy. The study finds that much of the equipment for heating purposes is in poor state. The steam system, which could be useful for decreasing the use of electricity heating, suffers from leaking steam traps and other imperfections, which lead to severe loss in both kilowatt-hours and money.

Spreadsheet based decision support system for wood panel manufacturing is discussed in [6]. It describes an MS Excel - based decision support system for wood panel manufacturing. The system is easy to use and maintain and gives the shop floor personnel access to powerful optimization capabilities useful for fine tuning production processes in the face of changing supply and price situations.

Many areas of the mechanical pulping process are explored for energy saving opportunities in [7]. Typically, over $50 \%$ of the cost associated with the manufacture of mechanical pulp is energy. Improving the efficiency of energy utilization in the manufacture of mechanical pulp can result in dramatic savings. The author proposes different ideas for such improvements in this paper. Influence of lumber grade on machine productivity in the rough mill is discussed in [8]. Lumber grade effect in hardwood-part processing time is investigated with a digitally described lumber database in conjunction with a cross cut-first rough mill yield optimization simulator.

Research in the field of automatic inspection of wood, particularly focusing on computer vision techniques for improving productivity and reducing waste is discussed in [9]. The proposed methods are put into an automated visual inspection framework, which is subdivided into commonly used modules for image acquisition, image enhancement, image subdivision, feature extraction, and classification. Use of premium efficiency motors in pulp and paper industry and the resulting savings are discussed in [13]. The author says that pulp and paper industry doesn't look upon use of premium efficiency motors with doubt. They rather claim more of their benefits because their typical mill operations fit the ideal profile for premium efficiency motors. The author says that this industry requires a relatively large number of motors, most of them within the size range that shows the biggest savings and most of them running round the clock. The author also stresses that premium efficiency 
motors are highly reliable and they really pay rich dividend in processes where downtimes might be very expensive.

\subsection{Energy Technology Research and Development}

Along with this an extensive literature review on the different recommendations was done. Special emphasis was laid on electric load management, motor efficiency, motor downsizing, compressor efficiency and belt transmission.

The real costs of energy consumption and detailed description on utility bills and its various components is discussed in [10]. The author identifies significant but overlooked cost components of electric power that could allow an energy manager to determine a basic energy rate more accurately and beneficially. The author discusses the cost components of a typical quantity of electric power, which include demand, operating and maintenance related costs.

A logical, systematic and structured approach to reduce energy waste by use of motor efficiency management techniques is discussed in [11]. The author also presents a motor performance management process (MPMP), which is designed to evaluate, measure and most importantly manage electric motors. It is a logical, systematic and structured approach to reduce energy waste. Use of energy efficient motors and creating efficient motor system is demonstrated with benefits in [12]. The author says that in industrial and commercial facilities, motor-driven systems are responsible for as much as $70 \%$ of a building's electric consumption. But with energy efficient motors and motor systems, energy cost could be cut down while improving the efficiency of the systems and reducing equipment maintenance.

Energy conservation aspect of induction motors using improved design and power controllers are studied on irrigation pumps and textile motors in [14]. The author examines a motor design for energy efficient operation and compares with conventional designs. Energy conservation through adaptive variation of the supply voltage is examined. The desired voltage variation of minimum energy consumption at varying loads is obtained by mathematical modeling and computer simulation, incorporating magnetic non-linearity in the motor. Quality and reliability of energy efficient motors is tested against standard efficiency motors and various measurements are taken and discussed in [15]. The test involved two 
identical ratings, one of premium efficiency and other of standard design under the same unbalanced voltage conditions. Measurements of current, power inputs, and the power factor angles were taken for the unbalanced in voltages ranging from $0 \%$ (balanced condition) to $10 \%$ at intervals of two percentage points. Results confirmed that motors should not be operated with any significant amount of voltage unbalance, which would result to losses, noise, and vibration.

The question, whether, "Are energy- efficient motors a cure-all for energy problems?" is discussed nicely in [16]. Various challenges posed by the application of energy efficient motors in highly motor intensive industries like petrochemical, pulp and paper and food processing is discussed in [16]. The author says that using energy efficient motors instead of standard efficiency motors can conserve energy considerably. However, he stresses that application of energy-efficient motors can pose many challenges. Considering the complexity of industrial plant efficiency and design, it is vital for consultants to keep pace with the rapidly changing technology. The author says that both clients and consultants must also recognize that energy efficient motors are not the ultimate solution for an ailing system.

Impact of energy saving technologies on electric distribution system power quality is discussed in [17]. This paper contains a discussion of several energy saving technologies and their impact on electric power distribution systems. The reduced power demand of these energy saving devices reduces the peak system demand. However, there are increased distribution transformer and distribution network losses due to the distorted load current wave shape. These losses, when integrated over many services and over the year, represent a significant cost due to fuel costs and higher peak.

Review of metering plans for demand side management savings verification is discussed well in [18]. It discusses various load monitoring systems and ways to document actual savings from demand side management programs. Increasingly, utility commissions are requiring documentation of actual savings from DSM programs. For constant loads, such as lighting and constantly loaded motors, this can be done by taking instantaneous before and after readings and multiplying the difference in $\mathrm{kW}$ by a run-hour meter reading to obtain $\mathrm{kWh}$ savings. In varying load applications, however, documenting savings is not simple. 
Energy saving with pump's AC adjustable speed drives is discussed in [19]. A detailed description, benefits and capabilities of Motor Master + are described in [20]. The author discusses several models and capabilities of Motor Master + such as motor inventory control, field measurements and operating data storage repository, batch analysis capabilities and life cycle costing. Several tips for fitting the perfect motor for a silk screen-printing application is presented by the author in [21]. The motor's speed and torque requirements by the application and consequent approximation of load's continuous and peak requirements are discussed in [21]. The author says that special consideration should be given to the selection of motor type and speed reducer, as well as the optimum motor size.

Application of compound fuzzy control in the power saving of motor is discussed in [22]. Here the author solves the problem of optimal control while the dynamic plants are under varying loads. Reducing the cost of compressed air in industrial facilities is described at length in [23]. The authors evaluated and quantified the energy losses associated with compresses air systems and their costs to manufacturers. Among the measures investigated in reducing the cost of compressed air were repairing air leaks, reducing the pressure setting if a lower pressure setting is inadequate, using a smaller compressor at full load instead of large one at part load, reducing average inlet temperature using outside air, using waste heat from the cooling fluid to heat the facility in winter, using high efficiency motors, turning off the compressor at night and during lunch breaks and using an after cooler.

Energy efficiency in air handling applications and use of variable speed drives is discussed in [24]. A comparative study of energy saving benefits in soft starters for threephase induction motors is investigated in [25]. Modern soft starters have both soft starter capability and energy saving functions, which are especially useful when the motor runs at low load. This paper investigates modern soft starters for induction motors at three different power levels. The investigation includes efficiency measurements, start-up measurements and measurement of the grid current harmonics at different loads to investigate the soft starter's performance against new regulations. The measurements are compared with an induction motor without soft starters. It is concluded that soft starters have energy saving capabilities at low load up to $4 \%$ of rated power for small motors, but it also concluded that the payback time would be long. Finally they conclude soft starters have problems with new grid disturbance regulations at low load operation. A survey of characteristics of different 
belt types, with a particular emphasis on their energy efficiency, cost effectiveness and field of application is done in [26].

The energy efficient electric motor selection handbook [27] contains a discussion on the characteristics, economics, and benefits of standard versus high efficiency motors in the 1 to 500-horse power range. This handbook shows how to assess energy savings and cost effectiveness when making motor purchase decisions. It also discusses field data acquisition techniques, high efficiency motor speed/load characteristics, performance under part-load conditions, and operation with an abnormal power supply.

A fact sheet developed by a program of the U.S. Department of Energy, discusses the reasons to determine motor loading [28]. It discusses the various methods of testing motor loads. It also discusses various issues in motor efficiency testing. Another fact sheet [29] describes the term power factor and shows how to correct low power factors. Reference [30] is a bulletin developed by Industrial Electrotechnology Laboratory that outlines a policy for cost effective management of motor purchase and repair. It also provides a checklist for motor maintenance and repairs. Guidance on using the US DOE developed software MM + is available in [31], which is a User Guide for the Motor Master + program. It discusses the various modules in the Motor Master + software and also describes how to create a motors database, and how to use the "batch" module and the "compare" module in making motor replacement and repair decisions.

\subsection{Wood manufacturing industry}

The manufacturing process for lumber manufacturing and the various equipment involved is discussed here. Also the recent trends in the energy consumption in wood manufacturing industry are discussed. In [32] the lumber manufacturing industry is described in detail. The lumber manufacturing process and various components involved are discussed. In [33], the design and operations of sawmills is discussed. The major manufacturing equipment and machinery involved in manufacturing wood products is discussed. In [34] the modern saw mill techniques are discussed. The modern productive systems on various saw mill equipment is discussed in detail.

The manufacturing consumption of energy 1994 and 1998 is found in [35]. All the relevant details like amount of MMBtu used and the dollars spend on different types of fuel 
in wood manufacturing industry can be found here. Various data like, total value of shipments, labor productivity in the wood manufacturing industry in U.S. can be found here. The Industries of Future (IOF) program and the various initiatives taken in the forest products area are presented in [36]. The vision, roadmap, implementation and new technology strategy for forest products industry is reported. The directory for the forest industry of West Virginia is found in [37]. The different species of wood available and produced in the state of West Virginia are reported here. It has an overview of the forest industry of West Virginia.

\subsection{Conclusion}

The above literature gives an idea about the work done in the field of energy conservation. Many issues related to energy efficiency in industry are discussed. But there is very little literature found on energy analysis and diagnostics specifically in the wood manufacturing industry. Most of the efforts have been concentrated on the forest industry as a whole. The pulp and paper industry has been given special attention all throughout the literature with very little emphasis on the SIC 24 category, which is wood products industry. Specifically research in the area of energy conservation and energy analysis and diagnostics in wood manufacturing industry and especially in a state like West Virginia would be of immense help to the industry as well as the state. 


\section{Chapter 3 \\ Utility Bill Analysis}

\subsection{Data Collection}

The utility bills of all the wood plants visited under the project were collected. The historic data of the past twelve months at the minimum was collected for further analysis and evaluation. The utility rate schedule for each plant was carefully analyzed so as to understand the rate structure and how the electricity charges are obtained. Each plant visited has its own rate structure with the utility service and therefore each structure is required to be analyzed separately. Also it is seen in all the visits that electrical energy dominates the energy bill in most of the wood industries in West Virginia. Other sources of energy like natural gas constitute a very small percent of the total energy bill. A brief introduction to electrical cost distribution followed by the analysis of electricity charges for each plant visited is discussed in this chapter. Various plots are obtained and the load profile of each plant is also obtained.

\subsection{Electric Cost Distribution}

The analysis of the electrical costs of a facility involves the contribution of the various components of the electricity bill towards the total cost of electricity. Following is an example of the utility bill analysis of facility A. The utility bill analysis for the other plants audited can be seen in Appendix I. As can be seen in the Table 3.1, the various components used for analysis are $\mathrm{kWh}$ used, the demand $\mathrm{kW}$ on the plant, the RKVA demand on the plant, the kWh charge, RKVA charge and the total electricity charge. The electricity billing information for 15 months is shown in the Table 3.1. It also shows calculation of apparent power, power factor, load factor, and demand charge as percent of total bill. Detailed discussion on power factor and load factor is done in the recommendations on the following pages. Here we only discuss the demand as a percentage of the total cost. The demand $\mathrm{kW}$ for each month is obtained from the electricity bill. Also the demand charge is mentioned in the schedule $15-\mathrm{D}$, which is presently $\$ 9.45 / \mathrm{kW}$ of demand. The total charge of the electricity is obtained from the bill and the calculation of demand charge as a percent of total charge is done. 


\subsubsection{Sample Calculation}

Please refer to the Table 3.1. As can be seen in the $11^{\text {th }}$ row, the $\mathrm{kW}$ demand is 348.8 for the period from $1 / 19 / 01$ to $2 / 21 / 01$.

So demand or $\mathrm{kW}$ charge $=$ Demand $\mathrm{kW} X \$ / \mathrm{kW}$

$$
\begin{aligned}
& =349 \times 9.45 \\
& =\$ 3,297
\end{aligned}
$$

Also it can be seen that the total charge for this period is $\$ 5,654.27$.

So demand as a percent of total charge $=3297 / 5,654 * 100$

$$
=58.3 \%
$$

The marginal cost of electricity per MMBtu is calculated by dividing the total cost of electricity for all the months by the total MMBtu of electricity consumed in all those months. The average cost of MMBtu is $\$ 21.95 / \mathrm{MMBtu}$. The plot of various cost components of the bill is plotted against the months as seen in Figure 3.1. It shows a clear distinction between the various charge components of the electricity bill and their contribution towards the total electric charges. It can be seen that demand charge dominates the electricity charges, average percentage demand charge being around 60\%. Also it is seen that the average total electric cost of electricity hovers around $\$ 5,000$ for most of the months. It should be also noticed that the demand charge is greater than the usage or the kWh charge in all the months. Appearance of RKVA charge in the plot shows that the power factor of the plant is very low for that month and hence this excess charge. 


\begin{tabular}{|c|c|c|c|c|c|c|c|c|c|c|c|c|c|c|}
\hline Months & $\begin{array}{l}\text { From } \\
\text { Date }\end{array}$ & $\begin{array}{c}\text { To } \\
\text { Date }\end{array}$ & $\begin{array}{l}\text { No. of } \\
\text { Days }\end{array}$ & $\begin{array}{l}\text { kWh } \\
\text { Used }\end{array}$ & $\begin{array}{c}\text { kW } \\
\text { Demand }\end{array}$ & $\begin{array}{c}\text { RKVA } \\
\text { Demand }\end{array}$ & $\begin{array}{c}\text { kWh } \\
\text { charge } \\
(\$)\end{array}$ & $\begin{array}{c}\text { kW } \\
\text { Charge } \\
\text { (\$) }\end{array}$ & $\begin{array}{c}\text { RKVA } \\
\text { Charge } \\
\text { (\$) }\end{array}$ & $\begin{array}{c}\text { Total } \\
\text { Charge } \\
\text { (\$) }\end{array}$ & $\begin{array}{c}\text { Apparent } \\
\text { Power }\end{array}$ & $\begin{array}{l}\text { Power } \\
\text { Factor }\end{array}$ & $\begin{array}{c}\text { Load } \\
\text { Factor }\end{array}$ & \begin{tabular}{|c|} 
Demand \\
as $\%$ of \\
Total charge
\end{tabular} \\
\hline Mar & $3 / 18 / 2000$ & $4 / 15 / 2000$ & 28 & 61,800 & 323 & 588 & 1711 & 3022 & 190 & 4924 & 671 & 0.48 & 0.28 & 61 \\
\hline Apr & $4 / 15 / 2000$ & $5 / 20 / 2000$ & 35 & 79,200 & 319 & 589 & 2193 & 2982 & 191 & 5366 & 669 & 0.48 & 0.30 & 56 \\
\hline May & $5 / 20 / 2000$ & $6 / 21 / 2000$ & 32 & 71,400 & 323 & 593 & 1977 & 3022 & 192 & 5191 & 675 & 0.48 & 0.29 & 58 \\
\hline Jun & \begin{tabular}{|l}
$6 / 21 / 2000$ \\
\end{tabular} & $7 / 21 / 2000$ & 30 & 59,400 & 314 & 587 & 1664 & 2970 & 191 & 4825 & 666 & 0.47 & 0.26 & 62 \\
\hline Jul & 7/21/2000 & $8 / 22 / 2000$ & 32 & 72,600 & 318 & 589 & 2034 & 3000 & 191 & 5225 & 669 & 0.47 & 0.30 & 57 \\
\hline Aug & $8 / 22 / 2000$ & $9 / 20 / 2000$ & 29 & 66,600 & 313 & 592 & 1865 & 2960 & 193 & 5018 & 670 & 0.47 & 0.31 & 59 \\
\hline Sep & 9/20/2000 & $10 / 19 / 2000$ & 29 & 71,400 & 339 & 336 & 2000 & 3204 & 87 & 5292 & 478 & 0.71 & 0.30 & 61 \\
\hline Oct & $10 / 19 / 2000$ & $11 / 18 / 2000$ & 30 & 76,800 & 337 & 325 & 2151 & 3185 & 83 & 5419 & 468 & 0.72 & 0.32 & 59 \\
\hline Nov & $11 / 18 / 2000$ & \begin{tabular}{|l|}
$12 / 20 / 2000$ \\
\end{tabular} & 32 & 67,200 & 351 & 364 & 1882 & 3317 & 97 & 5296 & 506 & 0.69 & 0.25 & 63 \\
\hline Dec & $12 / 20 / 2000$ & $1 / 19 / 2001$ & 30 & 70,800 & 356 & 345 & 1983 & 3368 & 88 & 5439 & 496 & 0.72 & 0.28 & 62 \\
\hline Jan & \begin{tabular}{|l|}
$1 / 19 / 2001$ \\
\end{tabular} & $2 / 21 / 2001$ & 33 & 81,600 & 349 & 303 & 2286 & 3296 & 72 & 5654 & 462 & 0.75 & 0.30 & 58 \\
\hline Feb & $2 / 21 / 2001$ & $3 / 20 / 2001$ & 27 & 71,400 & 362 & 346 & 2000 & 3419 & 88 & 5507 & 500 & 0.72 & 0.30 & 62 \\
\hline Mar & $3 / 20 / 2001$ & $4 / 23 / 2001$ & 34 & 81,000 & 349 & 312 & 2269 & 3296 & 76 & 5641 & 468 & 0.75 & 0.28 & 58 \\
\hline Apr & $4 / 23 / 2001$ & $5 / 22 / 2001$ & 29 & 65,400 & 355 & 373 & 1832 & 3358 & 100 & 5289 & 515 & 0.69 & 0.26 & 63 \\
\hline \multirow[t]{2}{*}{ May } & $5 / 22 / 2001$ & $6 / 22 / 2001$ & 31 & 57,800 & 335 & 1063 & 1619 & 3164 & 378 & 5161 & 1114 & 0.30 & 0.23 & 61 \\
\hline & & & Total & $1,054,400$ & 5,042 & 7,305 & 29,466 & 47,563 & 2,216 & 79,245 & Average & 0.59 & 0.28 & 60.00 \\
\hline
\end{tabular}

Table 3.1 Utility bill analysis for facility $A$ 


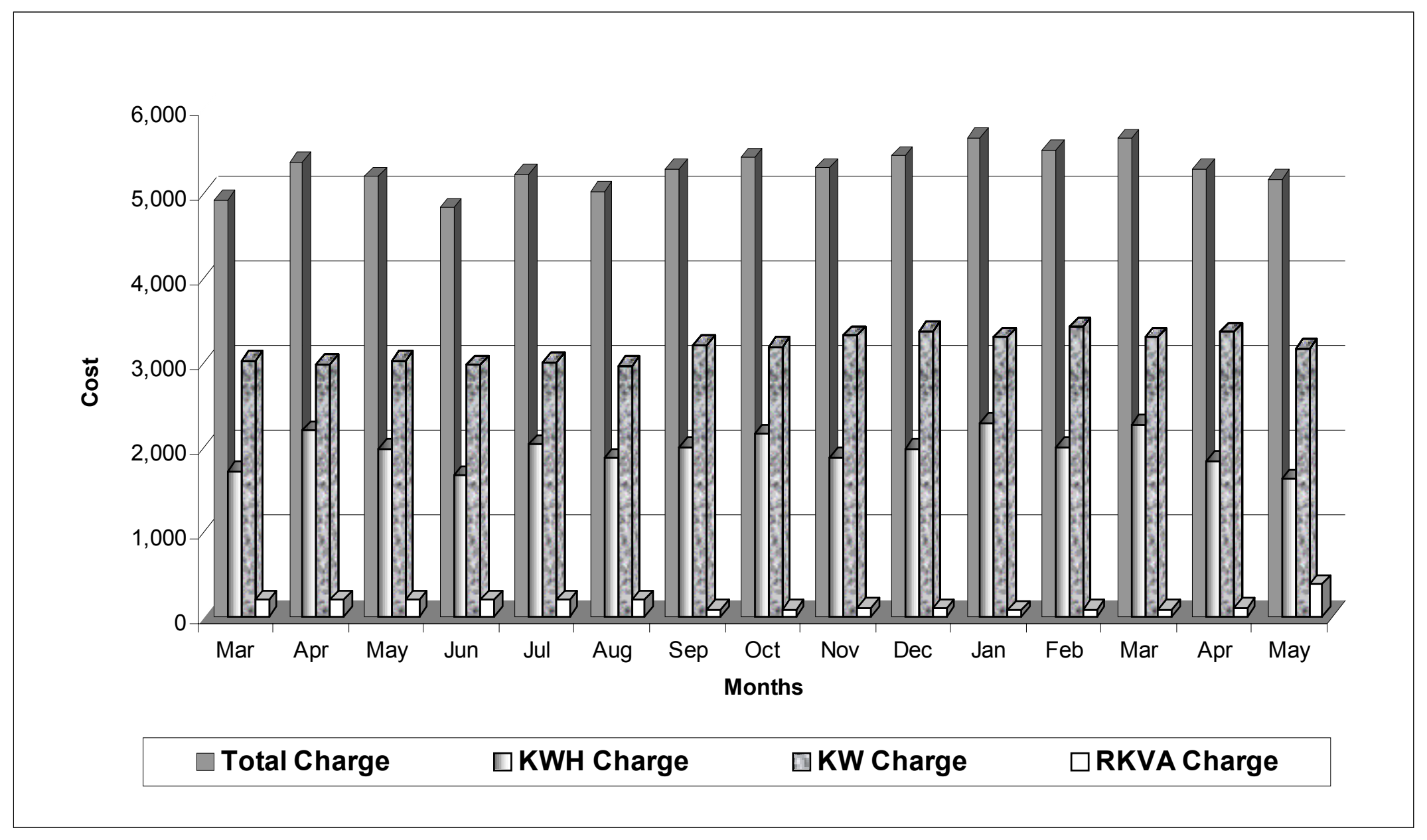

Figure 3.1 Electricity cost distribution for facility A 


\subsubsection{Load Factor Sample Calculation}

Please refer to the Table 3.1 and to the first entry in table. It shows the electrical summary for the month of March 2000. As seen in the table, energy usage is $61,800 \mathrm{kWh}$, billed demand is $323 \mathrm{~kW}$ and usage cost is $\$ 1,711$.

With the above data the load factor is calculated as follows:

Load factor $=61,800 /(323 * 24 * 30)$

$$
=0.28
$$

Similarly the load factor is calculated for all the remaining months.

\subsection{Power Factor}

Power factor (PF) quantifies the reaction of alternating current (AC) electricity to various types of electrical loads. Inductive loads, as found in motors, drives and fluorescent lamp ballast's, cause the voltage and current to shift out of phase. Electrical utilities must then supply additional power, measured in kilovolt-amps (KVA), to compensate for phase shifting. To see why, power must be examined as a combination of two individual elements. The total power requirement constituents can be broken down into the resistive, also known as the real component, and reactive component. Useful work performance comes from the resistive component, measured in kilowatts $(\mathrm{kW})$ by wattmeter. The different components of electrical power are show in the Figure 3.2. The reactive component, measured in reactive kilovolt-amps (KVAR), represents current needed to produce the magnetic field for the operation of a motor, drive or other inductive device but performs no useful work, does not register on measurement equipment such as the watt meter. The reactive components significantly contribute to the undesirable heating of electrical generation and transmission equipment formulating real power losses to the utility.

Power factor derives from the ratio of real, usable power $(\mathrm{kW})$, to apparent power (KVAR). Assessment recommendations towards reduction of the power factor in fact indicate reduction of reactive losses. To accomplish this goal, the industrial electricity user must increase the power factor to a value as close to unity as practical for the entire facility. The supplying utility should be consulted for the determination of the requisite amount of 
capacitance necessary for correction to the desired power factor. The number in the Table 3.2 is multiplied by the current demand ( $\mathrm{kW}$ ) to get the amount of capacitors (KVAR) needed to correct from the existing to the desired power factor. This number can be chosen from the Table 3.2 as follows [29]. First determine the current power factor in the first column and then determine the new power factor in the first row. The number corresponding to that row and column is then multiplied by the current demand. Mathematically, power factor is expressed as

$$
\mathrm{PF}=\mathrm{kW} / \mathrm{KVA}
$$

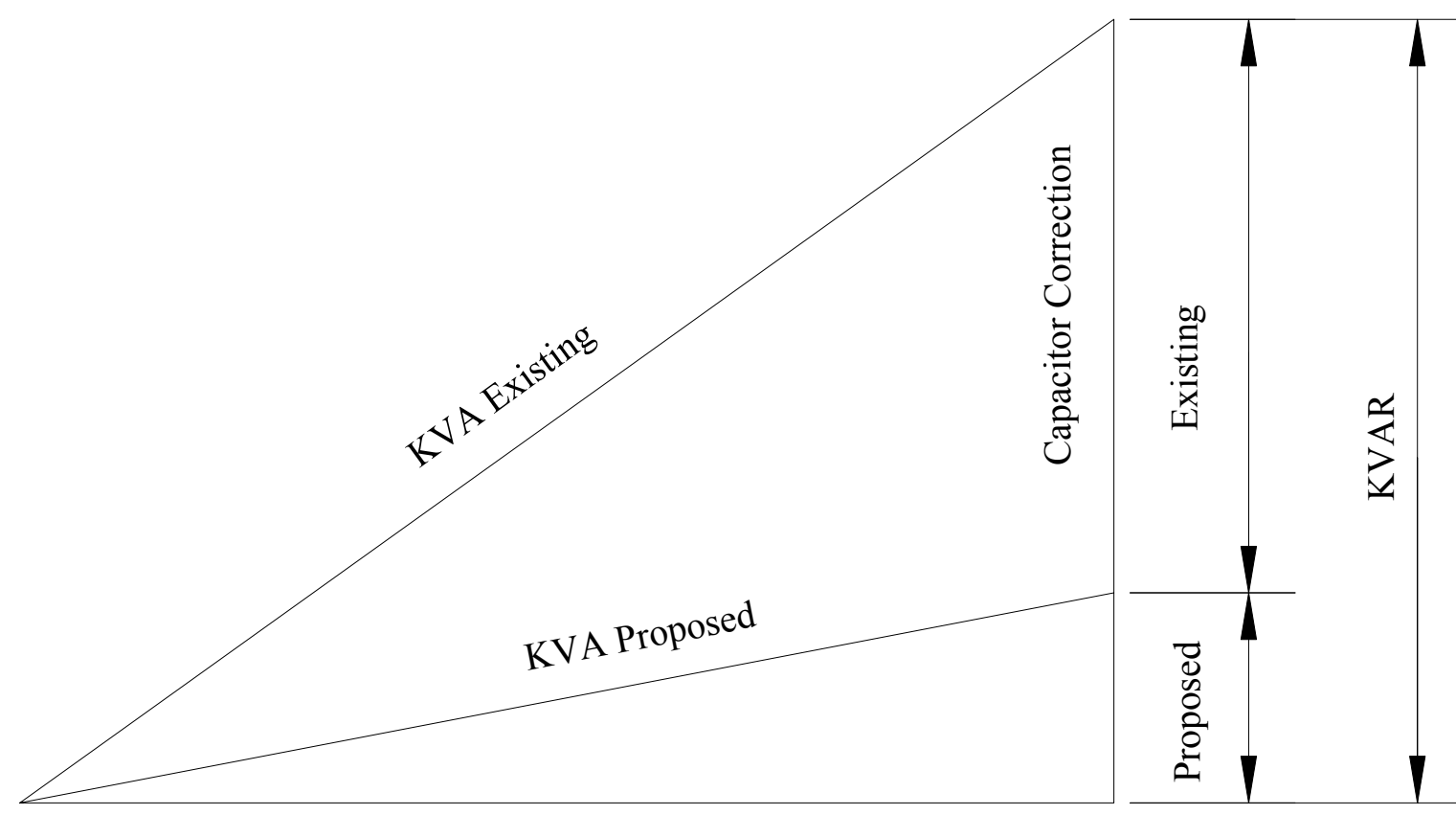

KW

Figure 3.2: Components of Electrical Power [29]

Example: Consider a 480-volt 3-phase system with an assumed load and instrument readings as follows: the ammeter indicates $200 \mathrm{amps}$ and wattmeter reads $120 \mathrm{~kW}$. The power factor of the load can be expressed as follows:

The apparent power for a 3-phase circuit is given by the expression 


$$
\begin{aligned}
\mathrm{KVA} & =\mathrm{E} \times \mathrm{I} \times(3)^{1 / 2} / 1000 \\
& =480 \text { volts } \times 20 \mathrm{amps} \times 1.73 / 1000 \\
& =290.6 \mathrm{KVA}
\end{aligned}
$$

Therefore:

$$
\begin{aligned}
\mathrm{PF} & =\mathrm{kW} / \mathrm{KVA} \\
& =120 / 290.6 \\
& =41.2 \%
\end{aligned}
$$

From the above example it is apparent that by the decreasing power drawn from the line (KVA) the power factor can be increased.

\subsubsection{Power Factor Improvement}

Preventive measures involve selecting high-power-factor equipment. For example, when considering lighting, only high-power factor ballast's should be used for fluorescent and high intensity discharge (HID) lighting. Power factor of so-called normal-power factor ballasts is notoriously low, on the order of 40 to 55 percent [29].

When induction motors are being selected, the manufacturer's motor data should be investigated to determine the motor power factor at full load. In the past few years, some motor manufacturers have introduced premium lines of high-efficiency, high-power-factor motors. In some cases, the savings on power factor alone can justify the premium prices charged for such motors. Motors should also be sized to operate as closely as possible to full load, because power factor of an induction motor suffers severely at light loads. Power factor decreases because the inductive component of current that provides the magnetizing force, necessary for motor operation, remain virtually constant from no load to full load, but the inphase current component that actually delivers work varies almost directly with motor loading.

Corrective measures for poor power factor involve canceling the lagging current component with current that leads the applied voltage. This cancellation can be done with power-factor-improvement capacitors, or by using synchronous motors. Capacitors have the effect of absorbing reactive current on a one-to-one basis, because almost all of the current flowing through a capacitor leads the applied voltage by 90 degrees. A capacitor rated at 100 
kilovolt-amperes capacitive (KVAC) will, therefore cancel 100 kilovolt-amperes reactive (KVAR).

Synchronous motors provide an effective method of improving power factor because they can be operated at leading power factor. This improvement at the load center contributes to an improvement in overall plant power factor, thereby reducing the power factor penalty on the plant electricity cost. For example, if a synchronous motor is used in place of an induction motor, the power factor improves from $85 \%$ to $89 \%$.

The Table 3.2 can be also used to determine the amount of capacitors needed to correct a power factor. The amount of capacitors needed in KVAR can be determined from:

$$
\mathrm{KVAR}=\mathrm{D} \times \mathrm{CF}
$$

Where

$$
\begin{aligned}
\mathrm{D} & =\text { maximum annual demand }, \mathrm{kW} \\
\mathrm{CF} & =\text { correction factor }
\end{aligned}
$$

\subsubsection{General Considerations for Power Factor Improvements}

Power factor plays a very important role in the facility. If it is maintained at a good value say above 0.95 then one can say that the plant is in good condition with regards to power factor. But a lower power factor cause many problems to the plant. It not only creates problems for the user but also the utility provider. So the utility service company often makes it mandatory for the plant to maintain a good power factor. Poor power factor penalizes the user in three ways.

* It robs the distribution system of capacity that could be used to handle the workperforming load.

* It results in currents higher than necessary to perform a given job, thereby contributing to higher voltage drop and electrical system losses.

* It can result in electric power billing penalties depending on the schedule terms. 


\begin{tabular}{|c|c|c|c|c|c|c|}
\hline $\begin{array}{c}\text { EXISTING } \\
\text { POWER } \\
\text { FACTOR }\end{array}$ & \multicolumn{7}{|l|}{ NEW POWER FACTOR } \\
\hline & $\mathbf{1 . 0 0}$ & $\mathbf{0 . 9 5}$ & $\mathbf{0 . 9 0}$ & $\mathbf{0 . 8 5}$ & $\mathbf{0 . 8 0}$ & $\mathbf{0 . 7 5}$ \\
\hline 0.66 & 1.138 & 0.810 & 0.654 & 0.519 & 0.388 & 0.256 \\
\hline 0.68 & 1.078 & 0.750 & 0.594 & 0.459 & 0.328 & 0.196 \\
\hline 0.70 & 1.020 & 0.692 & 0.536 & 0.400 & 0.270 & 0.138 \\
\hline 0.72 & 0.964 & 0.635 & 0.480 & 0.344 & 0.214 & 0.082 \\
\hline 0.74 & 0.909 & 0.580 & 0.425 & 0.289 & 0.159 & 0.027 \\
\hline 0.76 & 0.855 & 0.526 & 0.371 & 0.235 & 0.105 & \\
\hline 0.78 & 0.802 & 0.474 & 0.318 & 0.183 & 0.052 & \\
\hline 0.80 & 0.750 & 0.421 & 0.266 & 0.130 & & \\
\hline 0.82 & 0.698 & 0.369 & 0.214 & 0.078 & & \\
\hline 0.84 & 0.646 & 0.317 & 0.162 & 0.026 & & \\
\hline 0.86 & 0.593 & 0.265 & 0.109 & & & \\
\hline 0.88 & 0.540 & 0.211 & 0.055 & & & \\
\hline 0.90 & 0.484 & 0.156 & & & & \\
\hline 0.92 & 0.426 & 0.097 & & & & \\
\hline 0.94 & 0.363 & 0.034 & & & & \\
\hline 0.96 & 0.292 & & & & & \\
\hline 0.98 & 0.203 & & & & & \\
\hline 0.99 & 0.142 & & & & \\
\hline
\end{tabular}

Table 3.2: Power Factor Correction [29]

A plant's power factor penalty can be determined from the monthly utility bills. The method of billing for low power factor varies widely among utilities. Often no penalty is imposed unless the power factor falls below a certain minimum, typically 85 percent to 90 percent. In other situations, a penalty is involved for any reduction below 100 percent. For this reason, each rate schedule must be studied separately to determine the potential savings involved for improving power factor. 
Some equipment, such as high power factor lighting ballast's or synchronous motors, has inherent power factor improvement. With other equipment, notably induction motors, power factor is a function of the mode of operation. Operation of an induction motor below full load will significantly reduce the power factor of the motor. Therefore, motors should be operated close to full load for the best power factor. Power factor also becomes progressively lower for slower speed motors. For example, the decline in power factor below 90 percent for a 1,200 RPM motor is 1.5 times greater than for a 1,800 RPM motor; for a 900 RPM motor, the decrease is more than double that for a 1,800 RPM motor.

The use of power factor improvement capacitors is the simplest and most direct method of power factor improvement. Capacitors can be bought in blocks and combined to provide the required amount of capacitive reactance or individual capacitors can be installed at each motor. Capacitors already in use should be checked annually to ensure all units are operating. Inoperative capacitors negate the power factor improvement for which their installation was intended. Diminishing returns are realized as power factor approaches 100 percent. Generally, 95 percent (based on normal full load) is the economic break-even point in a power factor improvement program; up to this point, improvements usually show a good return on investment [27].

\subsubsection{Power factor at facility $A$}

Power factor calculations at facility A are shown in the Table 3.1. The table contains the values for $\mathrm{kW}$ and KVAR for all the months shown in the table. The power factor is calculated using the formula

$$
\mathrm{PF} \quad=\mathrm{kW} / \mathrm{KVAR}
$$

\subsubsection{Sample Calculation}

Consider the first entry in the table. The entries in the row for the month of March are as follows:

Demand $=323 \mathrm{~kW}$

Apparent Power $=671 \mathrm{KVAR}$ 
Power Factor $=323 / 671$

$$
=0.48
$$

Similarly, the power factor for all other months is calculated and the average is calculated. The average power factor is 0.59 .

\subsubsection{Anticipated savings obtained from Power factor improvement}

The excess KVAR charge paid by facility A is the result of lower power factor. If the power factor is improved considerably, this excess charge in the electric bill will reduce. The total excess charge paid by facility A from the billing information is around $\$ 1,835$ /year. Please refer to the Table 3.1 for the excess charge. Also refer Table 3.2 for selection the correction factor. The correction factor is calculated by interpolation to be 0.885 .

Present Average power factor $=0.59$

Maximum kW demand

$=361.8 \mathrm{~kW}$

Required Power Factor after correction

$=0.90$

Additional KVAR required for correction $=0.885 \times 361.8$

$=320.19 \mathrm{KVAR}$

\subsubsection{Implementation and payback}

Average cost of Capacitor bank required for power factor correction is $\$ 15 / \mathrm{KVAR}$. So total implementation cost of the capacitor bank is as follows:

$$
\begin{aligned}
& =320.19 \mathrm{KVAR} X \$ 15 \\
& =\$ 4,802 .
\end{aligned}
$$

So the simple payback obtained is as follows:

$$
\begin{aligned}
& =4,802 / 1,835 \\
& =2.6 \text { Years } .
\end{aligned}
$$




\subsection{Conclusions}

The utility bill analysis was performed for all the wood manufacturing facilities in West Virginia. The utility bill analysis for facility A along with the opportunity for power factor improvements are discussed in detail in this chapter. The utility bill analyses of the remaining plants can be referred to in Appendix I. Also the power factor recommendations for other plants where they were cited during the assessment are presented in Appendix I. This preliminary analysis of the utility bills for the wood manufacturing plants in West Virginia shows that electricity charges contribute to around $85 \%$ of the total energy charges. Also it is seen from this analysis that, demand charge of electricity is up to $70 \%$ of the total electricity charges for this type of industry.

This analysis emphasizes the need for attacking the demand charges of these plants so as to reduce the overall electricity charges and eventually the total energy charges for these plants. Thus this chapter on utility bill analysis gives us an insight into as to what component of the electricity charges needs to be attacked in order to obtain better results in terms of energy conservation and reduction of total energy bill. So, the electrical demand reduction is the topic of analysis in the next chapter, in order to explore different ways in which electrical demand can be reduced and what will be the impact of the reduction on the total energy charges. 


\section{Chapter 4}

\section{Electrical Demand Reduction}

The analysis in the chapter 3 on the utility bills for the wood manufacturing plants visited in West Virginia emphasizes the need for concentration of more efforts on reduction of the total electric demand of these plants. This chapter will discuss in detail and will answer the following questions: what exactly is this demand charge? How is this demand recorded in the plants? What is the load factor of a plant? What are the various ways in which one can reduce this demand? This chapter also includes a detailed sensitivity analysis on the electrical demand reduction and its impact on the annual energy charges and proves its importance in a plant wide energy assessment program.

\subsection{The Demand Charge}

This charge component of the electricity bill compensates the utility company for the capital investment required to serve peak loads, even if that the peak load is only used for a few hours per week or month. The demand is measured in kilowatts $(\mathrm{kW})$ or kilovolt amperes (KVA). These units are directly related to the amounts of energy consumed in a given time interval of the billing period. The demand periods vary with the type of energy demand, the high fluctuating demand has a short demand period, which can be as short as five minutes, but generally demand periods are of 15 or 30 minutes. The period with the highest demand is the one used for billing demand charges. Demand charges can be a significant portion of the total electricity charges. In some cases, demand charges can amount to as much as $80 \%$ of the total electricity charges. This is referred from [40].

\subsubsection{Recording of demand}

The demand mentioned above is calculated at 15 -minute intervals. During each interval, a weighted average of the demand is taken for those 15 minutes. The recording procedure is as discussed using the following example. Suppose demand is recorded after every 15 minutes, then the level of demand and the time interval for which it exists is measured. Suppose the demand was $50 \mathrm{~kW}$ for the first four minutes of the interval followed by $75 \mathrm{~kW}$ for next seven minutes, $60 \mathrm{~kW}$ for next two minutes and $0 \mathrm{~kW}$ for the last two 
minutes of the interval. Then the weighted average of all recorded demand in this interval is taken and the weighted demand for that 15 -minute interval is calculated.

So weighted average $=\underline{(50 * 4)+(75 * 7)+(60 * 2)+(0 * 2)}$

\section{5}

$$
\begin{aligned}
& =\underline{845} \\
& =56.33 \mathrm{~kW}
\end{aligned}
$$

So $56.33 \mathrm{~kW}$ is the recorded demand for the 15 -minute interval. Same procedure is used to record demand over the whole month. The highest value of these 15-minute intervals is the value that is reflected on the monthly electricity bill from the utility. The demand charge is then obtained by multiplying the utility demand rate obtained from the rate schedule for that particular plant. So if the demand rate is say $\$ 9.5 / \mathrm{kW}$ in the schedule, then this rate is multiplied by the peak demand value which is the maximum value of the 15 minute intervals in which demand is recorded.

\subsubsection{Potential Savings}

The potential savings in terms of demand reduction depend on such factors as

* The plant's profile (variations in $\mathrm{kW}$ demand)

* Ability to shed loads

* The rate schedule

Together these factors determine the relative importance of the demand charge to the plant's total electric bill. Controlling demand becomes more important if the schedule includes a ratchet clause that involves payment based on the highest peak occurring in the previous 12 months. 


\subsubsection{Plant load factor}

The plant's load factor should be analyzed to determine the opportunity for improvement. Load factor improvement is synonymous with demand control. Load factor is the ratio of the average $\mathrm{kW}$ load over a billing period to the peak demand. For example, if a facility consumed $800,000 \mathrm{kWh}$ during a 30-day billing period and had a peak demand of $2,000 \mathrm{~kW}$, the Load factor is:

Load factor $=(800,000 \mathrm{kWh} / 720 \mathrm{hrs}) / 2,000 \mathrm{~kW}=0.55$ or $55 \%$.

A high load factor usually indicates that less opportunity exists for improvement because the load is already relatively constant. This means that with a high load factor, the variance between the lower and higher value of the peak $\mathrm{kW}$ demand on the load profile is less and it is almost equal to average $\mathrm{kW}$ demand. As a result there is a small opportunity for peak demand reduction and hence downsizing [27].

\subsection{System Analysis}

The user will obtain the lowest electric cost by operating as close to a constant load as possible (load factor $100 \%$ in case of a 3 shift operation). The closer a plant can approach this ideal situation, lower the monthly demand charge will be. The key to high load factor and corresponding lower demand charge is to even out the peaks and valleys of energy consumption. To analyze the opportunity for demand reduction, it is necessary to obtain data on the plant's demand profile. The demand profile is best obtained from the utility's records of the $\mathrm{kW}$ demand for each 15-30 minute interval. If no demand recording is made as a routine part of the billing procedure, the utility will usually install an instrument temporarily to provide the customer with this information. A plot of this data will show the extent of the

peaks and valleys and indicate the potential for limiting demand. If sharp peaks or an unusually high demand for one shift or short period occur, the opportunity for demand control should be investigated further. If the demand curve is relatively level, little opportunity exists for reducing demand charges by peak shaving. In order to level out the peaks in the demand profile, it is necessary to identify the various loads that could be reduced during periods of high demand. The major users of electricity will provide the most likely 
sources for limiting demand. Accordingly, a list of the largest users, their loads, and their operating schedules should be prepared. The smaller loads can be ignored, as they will not be able to affect the demand materially. An examination of this list will often suggest which loads do contribute or are likely to peak demands. When the load pattern is not easily determined, an energy meter can be installed at individual loads to provide a more detailed record of load variations.

\subsection{Ways to reduce demand}

The plants demand charge can be reduced in various ways. These vary from staggering startup loads to increasing local plant generation. Also oversized motors and any other form of electrical equipment generate an opportunity for possible downsizing and hence reduce the overall demand. All these measures are discussed in the following paragraphs. One thing, which is common to all these different ways, is that each of them requires a lot of data collection and a constant tracking of the demand parameters. These methods can be used to reduce demand only after a thorough analysis of the situation is performed considering all other plant operating factors and as well as other business aspects [28].

\subsubsection{Stagger Startup Loads}

A few utilities base their demand charge on a facility's instantaneous peak. In this case, short period of intense use such as a ten second start up of a motor (or start up of motors after a power outage) can significantly affect demand. Eliminate spikes by sequencing the startup loads of large motors so that their peak demands are staggered. Peaks in demand are caused by a number of different factors. The two most important of these are the starting of large motors and the starting of many motors of any size in a single 15-minute period and sustaining their operation over a significant period. Electric motors can draw between five and seven times their full load currents during start-ups. These current spikes will last until the motor has reached nearly full operating speed. For fully loaded motors this is typically between 30 seconds and two minutes.

Demand spikes from electric motors can be reduced in a number of ways. In general it is suggested that the starting of small motors be staggered and that of large motors be 
electronically controlled. Some startup problems have a hardware solution such as the placement of sequencers on air conditioning system will prevent more than one air conditioner from coming on at once. The sequencer will cycle through the units allowing 15 minutes for each unit to cool its respective area. Slow, or soft, start devices will control spikes in demand by limiting the amount of current that a large motor can draw. They will slowly increase, or ramp, the current to its operating level. Another problem with high inrush currents is the voltage imbalance created at the start up. When all the motors are started at one instant, the voltage across all the other equipment in the plant goes down momentarily and this might have a very adverse effect on the some equipment, which is sensitive to voltage imbalance. Proper provision and safety devices must be installed to tackle this problem of high inrush currents when all the motors are started at same time.

\subsubsection{Reschedule Loads}

Most of the utility companies offer different electricity rates during the daytime and the night shifts. Also the weekend rates are lower than the normal weekdays in many cases. So here lies an opportunity for the plant to reschedule some of its loads during these off peak periods. All the high power equipment can be rescheduled to work in the night shift or in the weekends, if it doesn't hamper the process in any form during the normal working hours. Such a rescheduling of high power equipment will significantly reduce the peak load during the daytime. Some of the problems with demand can be solved through procedural changes rather than the installation of hardware. Peak demands are usually established at particular times during the day shift. A review of the operating schedule may show individual loads can be rescheduled to other items or shifts to even out the demand. This technique can provide significant gains at little or no cost. For example, operation of an electric oven might be rescheduled to the evening shift or on weekends, if the oven is not needed full time. Another example is conducting routine testing of the fire pump periods when the peak demands are not likely to occur.

The determination of when a demand spike occurs is typically a difficult job. It is suggested that a demand meter be installed. This would enable plant personnel to examine the demand. A determination of when peak demand occurs could then be made. Once the time of peak demand is found, it is usually easy to determine what is causing it and what 
must be changed to reduce it. We can get this information on the peak demand from the utility service company.

\subsubsection{Increase Local plant Generation}

When the plant generates some electricity, plant generation can be temporarily increased to limit demand. In some cases, any venting of excess low-pressure steam from the turbo generator for short periods may represent a lesser penalty than the increased demand charge. Plant generation is a good solution for supplying power to those rare times when we have the peaks in demand. Power generation at the plant site can be done by using some onsite waste as the fuel for burning and producing the steam to run the turbine. Also portable onsite power generators are available these days. With an on site generation possible, the company can reduce their electric demand on the utility service. As a result, considerable cost savings can be achieved which often justify the big investment in cogeneration. In the wood industry the sawdust, which is obtained as waste from almost every stage of the process, can be used as a fuel for a boiler, which can generate steam to run a turbine.

\subsection{Motors and demand}

Motors represent the largest single use of electricity in most plants. The function of an electric motor is to convert electrical energy into mechanical energy. In a typical three phase AC motor, current passes through the motor windings and creates a rotating magnetic field. The magnetic field in turn causes the motor shaft to turn. Motors are designed to perform this function efficiently; the opportunity for savings with the motors rests primarily in their selection and use [27].

\subsubsection{Idle Running}

The most direct power savings can be obtained by shutting off idling motors, thereby eliminating no-load losses. While the approach is simple, in practice it calls for constant supervision or automatic control. Often no load power consumption is considered unimportant. However, the idle no load current is frequently about the same as the full load current. 


\subsubsection{Efficiency at Low Load}

When a motor has a greater rating than the unit it is driving requires, the motor operates at only partial load. In this state, the efficiency of the motor is reduced. The use of oversized motors is fairly common because of the following conditions: [27]

Personnel may not know the actual load; and to be conservative, select a motor larger than necessary.

The designer or supplier wants to ensure his unit will have ample power, therefore, he suggests a driver that is substantially larger than the real requirements. The maximum load is rarely developed in real service. Furthermore, most integral horsepower motors can be safely operated above the full load rating for short periods. (This problem may be magnified if there are several intermediaries).

When a replacement is needed and a motor with correct rating is not available, personnel install the next larger motor. Rather than replace the motor when one with the correct rating becomes available, the oversized unit continues in use.

* A larger motor is selected for some unexpected increase in driven equipment load has not materialized.

Process requirements have been reduced.

* For some loads, the starting or breakaway torque is substantially greater than the running torque; thus, over sizing of the motor is a frequent consequence, with penalties in the running operation.

Motor is "De-rated due to poor operating conditions": If a motor is used under extreme duty conditions, such as high altitude or poor power quality, over sizing the motor allows it to operate cooler and thus more reliably. However, there may be 
other, more efficient strategies to maintain reliability, such as improving power quality or providing better cooling.

Variable Loads: Motors should be sized to accommodate the greatest expected load. If a motor is sized for a peak that seldom or never occurs, it may operate inefficiently most of the time. Pumps and fans that operate with load factors less than $80 \%$ are good candidates for adjustable speed drives or other speed control strategy to improve efficiency.

Plant personnel should be sure that none of the above procedures are contributing to the use of oversized motors and resulting in inefficient operation. Replacement of under loaded motors with smaller motors will allow a fully loaded smaller motor to operate at higher efficiency. This arrangement is generally most economical for larger motors, and only when they are operating at less than $50 \%$ capacity, depending on their size.

\subsection{Load profile of the plant}

A load profile of the plant is plotted for every plant visited. The peak $\mathrm{kW}$ demand for the plant is plotted for all the months available and a load profile of the connected load obtained. This is a very important plot with respect to the amount of load variation, and the opportunities for reduction of demand charges at the plant. The demand data in $\mathrm{kW}$ is obtained from the plants utility service provider. As discussed earlier the load profile for facility A is discussed here. The plots for the other plants visited can be found in Appendix II. Please refer Table 3.1 for the data starting from Mar 2000 to May 2001. Also the Figure 4.1 shows the plot of the plant demand in $\mathrm{kW}$ against the months of the year 2000-2001. As seen in the plot, the load curve appears to be non homogeneous. There is a lot of variation on the load on the plant and doesn't appear to be stable at all. This is an indication of good potential for demand reduction in the plant. The average demand on the curve is $336 \mathrm{~kW}$, the upper limit is $362 \mathrm{~kW}$ and the lower limit is $313 \mathrm{~kW}$. Thus there is an opportunity for demand reduction and leveling the load profile. 


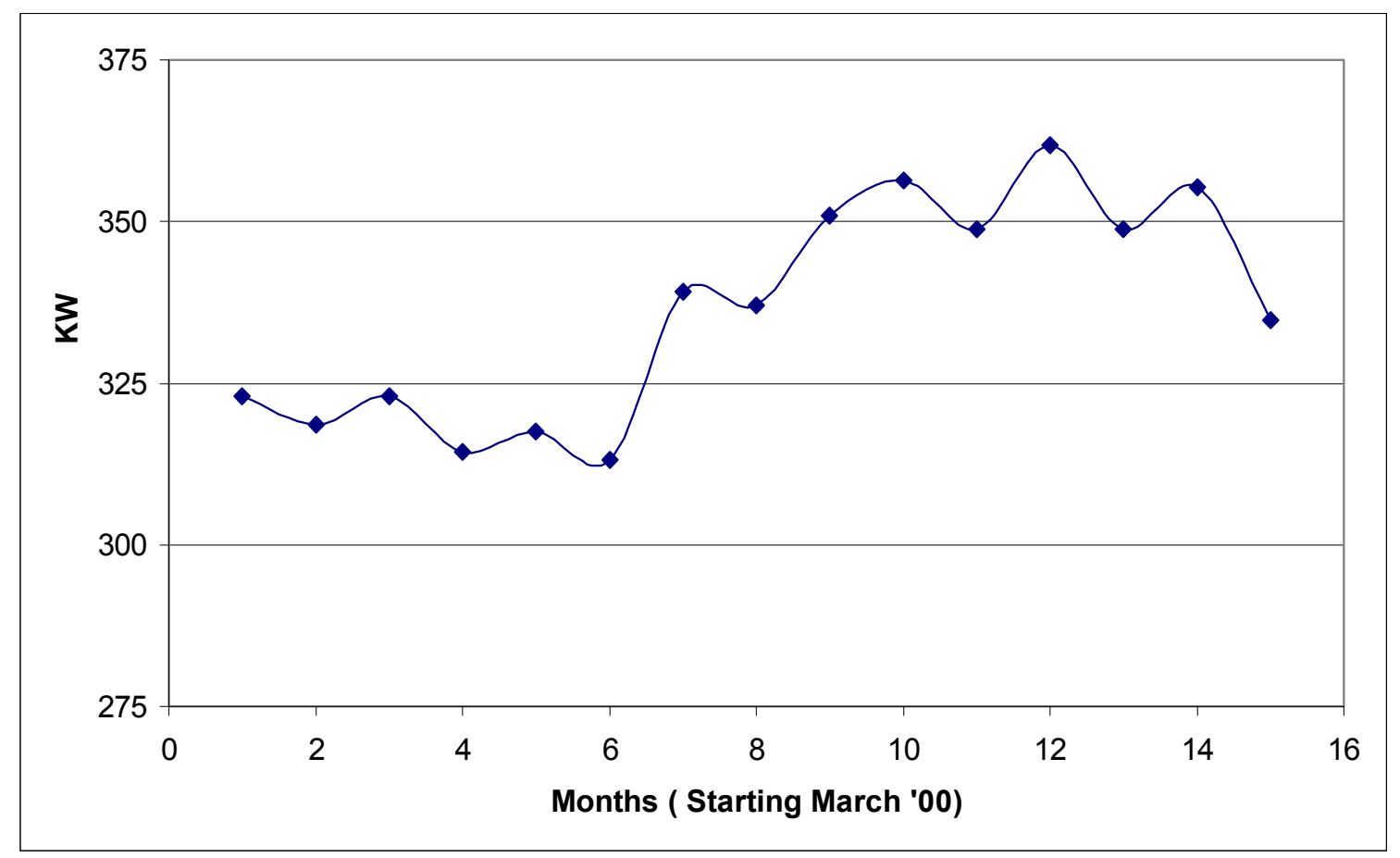

Figure 4.1: Load profile of facility A

\subsubsection{Recommendation Action}

As discussed above, we can estimate a reduction of $10 \%$ of the existing demand at facility A. Estimated savings in the total electricity charges are $\$ 3,165$ per year as can be seen in the calculations in Table 4.0. This reduction in the existing demand can be achieved by the following actions :

* Downsize the under loaded motors

* Reschedule the loads

* Onsite power generation

The downsizing of under-loaded motors is very crucial in implementation of the recommendation. The motor load test should be done to figure out the existing load pattern on the motor. This test should be done over a shift or longer time period so that the exact load conditions imposed by the process on the motor can be examined. After identifying the under-loaded motors, replacing them with a properly sized motor at the next available opportunity is essential in bringing down the demand. The opportunity for replacement with 
an under sized motor appears when the present motor fails or is sent for rewinding. This is the time when a close look at the load requirements of the process and proper sizing of the equipment should be looked into. The oversized motors can be identified by a series of electrical tests, which are also called load tests. Rescheduling of loads and onsite power generation are also available alternatives, which can be considered here for reducing the demand on the plant. But motor downsizing is the most attractive, as motors constitute about $80 \%$ of the total demand on the plant.

\subsubsection{Implementation Cost}

The implementation cost for the above recommendation depends on the strategy adopted to reduce the demand. If the company decides to downsize all their under loaded motors, then it accounts for a big investment. But proper sizing of motors and other electrical load will definitely result in lower energy costs. The stagger start up loads or reschedule loads doesn't require a big investment in machines, but it requires a lot of planning and decision making on part of the management. So the cost associated is with the labor cost spent in planning. The increase local plant generation strategy again calls for a huge investment of time and money, but the results or the savings obtained from this investment are also huge, i.e. if the company decides to go for onsite generation, then the reduction in demand might also be $20 \%$, which corresponds to a annual saving of $\$ 6,340$. So the selection of strategy and implementation is the decision of the management. The total savings achieved will also vary accordingly. So a sensitivity analysis of the demand reduction is done and discussed in the next section, which gives us an insight into the level of savings obtained because of demand reduction.

\subsection{Sensitivity Analysis for Demand Reduction}

A sensitivity analysis for the reduction of $\mathrm{kW}$ demand is performed so as to have a better understanding of the demand cost reduction in the plant. This analysis is performed for the overall plant. The peak demand for every month appears on the utility electricity bill. If this peak demand would be reduced, what would be the effect on the total electricity charges each year? The answer to this question is obtained from this analysis. The range for reduction in peak demand for a plant is considered from $0 \%$ reduction to $20 \%$ reduction in the peak 
demand from the current demand. The demand sensitivity analysis performed for facility A can be seen in the Table 4.1. The table shows the annual cost savings obtained for facility A for different levels of reduction in demand. Also the percentage change in the total electricity charge over the current annual charge is calculated. The results obtained from the table are also plotted and can be seen in the Figure 4.2. The slope of the line in the plot is calculated. This slope corresponds to the cost savings in annual total electricity charges for one percent reduction in demand. It is seen that for every one percent reduction in $\mathrm{kW}$ demand for facility A, the total electricity charge will come down by approximately $\$ 317$ /year. Thus the control over the demand of the plant will play a crucial role in the energy efficiency program undertaken by the management.

Every plant has its own specific utility structure, so the utility rate structure for each plant was studied differently for identifying the impact of demand reduction on the overall electricity charge of the company. Some plants had the demand charge as a separate charge in the rate structure, while in others this charge was hidden in the other components of the structure. Similar demand analysis was performed on all the other wood manufacturing plants visited in West Virginia and the analysis tables and the plots and comments for each plant can be found in Appendix II. 


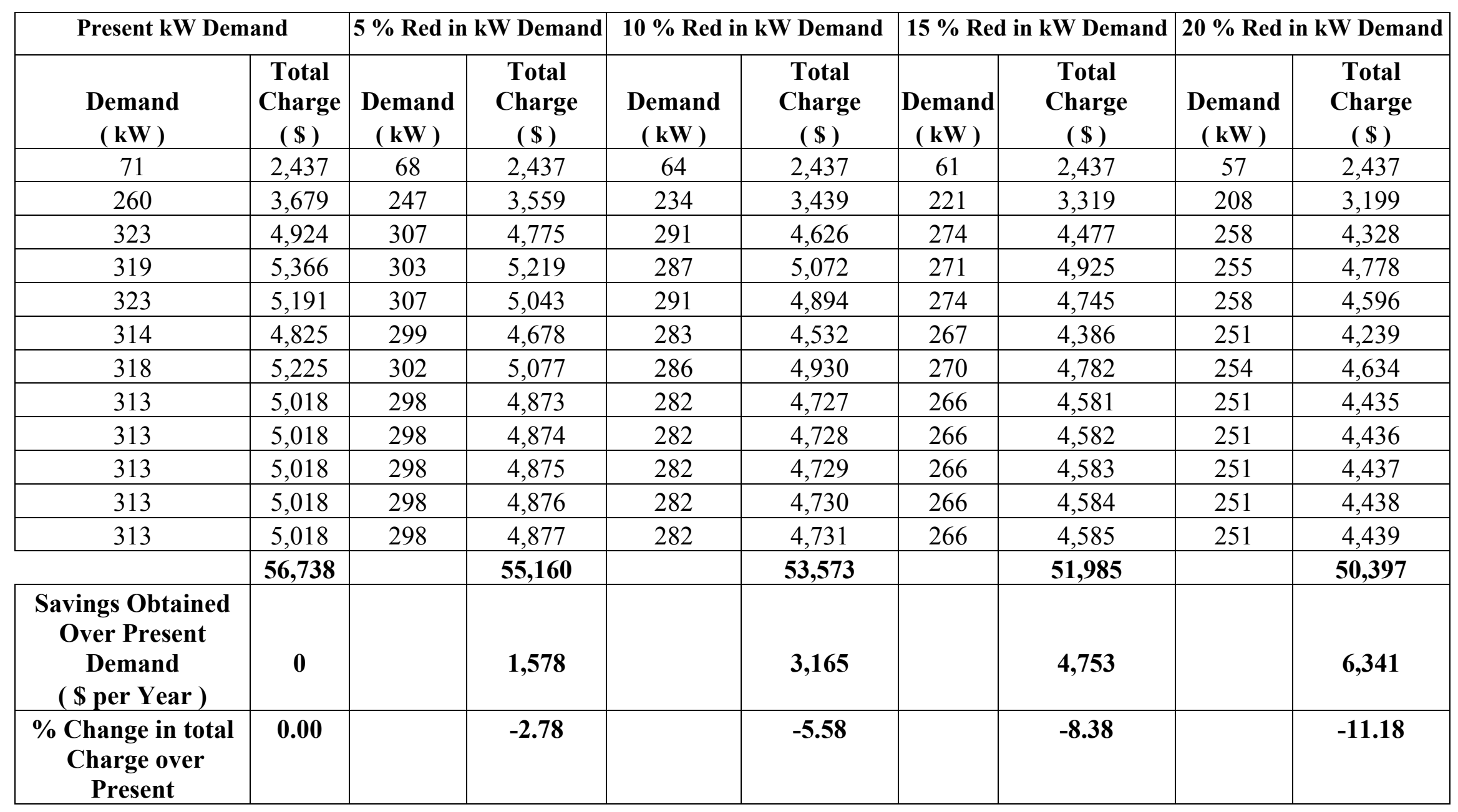

Table 4.1: Demand sensitivity analysis for facility A 


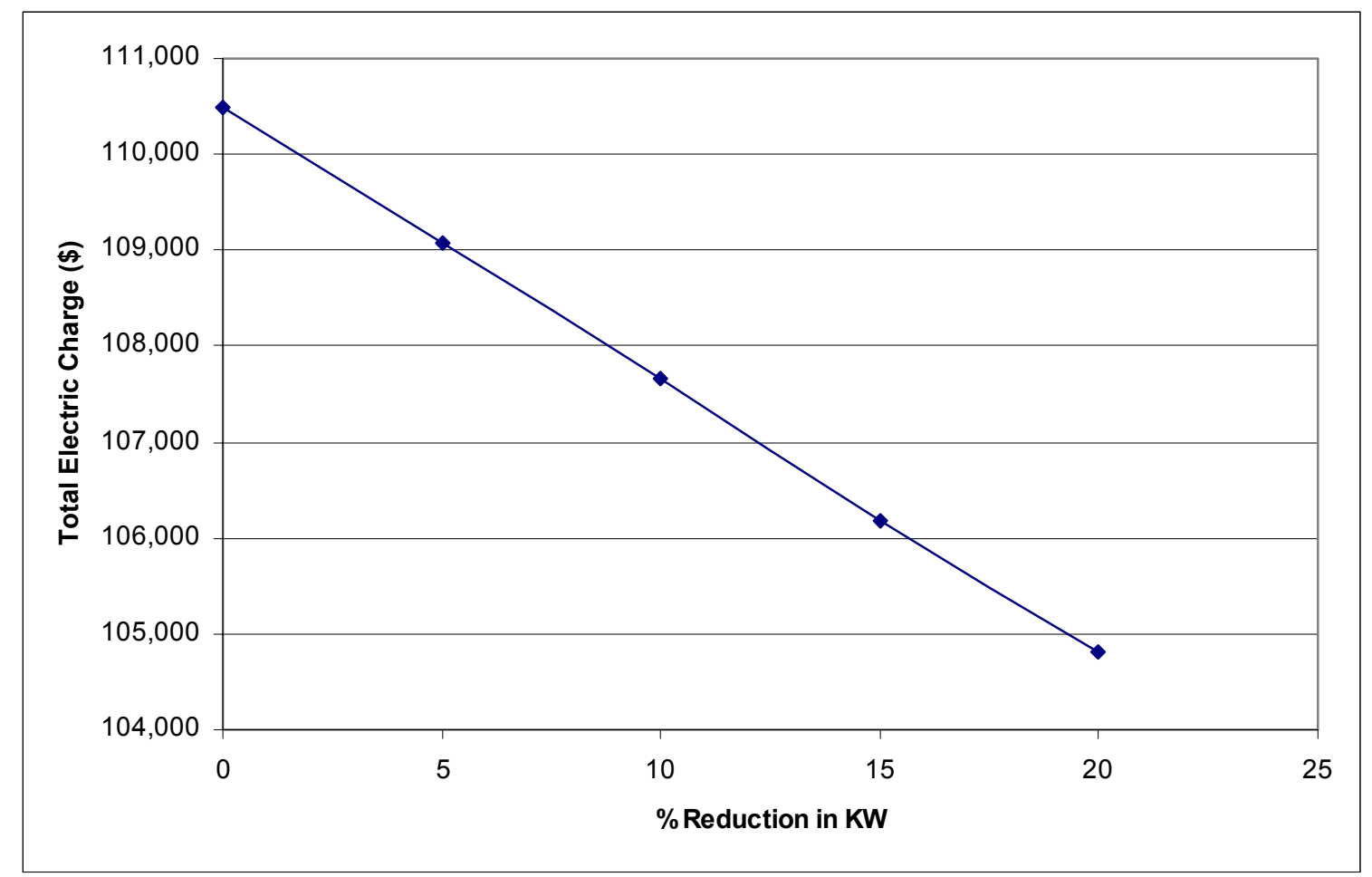

Figure 4.2: Plot for demand sensitivity analysis for facility A

\subsection{Conclusions}

This chapter discussed the various opportunities for reducing demand in the plant. Reduction in demand does have a very significant impact on annual energy bill for these plants. The sensitivity analysis on the demand reduction gives an insight into the magnitude of cost savings, which can be obtained for different levels of reduction in demand over the present peak demand. Also discussed in this chapter are the various possible ways in which demand can be reduced. One of these ways is downsizing motors. As the wood manufacturing industry is highly motor intensive, downsizing motors to appropriate sizes will contribute significantly to the overall reduction on peak demand of the plant. But to identify these motors for downsizing, a motor load test needs to be performed. This motor load test is described in the next chapter in detail, along with the potential of downsizing oversized motors to their appropriate size. 


\section{Chapter 5}

\section{Motor Load Test}

Reduction in overall plant demand can give significant reduction in annual energy bill. Also the wood manufacturing industry is highly motor intensive. The preliminary results from the utility bill analysis and the load curves for the plant show that there is some potential for reduction in demand. Oversized motors in the plants can be downsized to the required appropriate size so as to reduce the energy as well as the demand charges of the plant. This chapter emphasizes the need for downsizing motors and also discusses the type of motor load test used during assessments and the results obtained therewith.

\subsection{Reasons to determine motor loading}

Most electric motors are designed to run at $50 \%$ to $100 \%$ of rated load. Maximum efficiency is usually near $75 \%$ of rated load. Thus, a $10 \mathrm{hp}$ motor has an acceptable load range of 5 to $10 \mathrm{hp}$, with the peak efficiency at $7.5 \mathrm{hp}$. A motor's efficiency tends to decrease dramatically below about $50 \%$ load. A motor is considered under loaded when it is in the range where efficiency drops significantly with the decreasing load. With decreasing load on the motor, the power factor also drops down drastically. The power factor tends to drop off sooner, but less steeply than efficiency, as load decreases. Over loaded motors can overheat and lose efficiency. Many motors are designed with a service factor that allows occasional overloading. Service factor is a multiplier that indicates how much a motor can be overloaded under ideal ambient conditions. Although many motors have service factors of 1.15 , running the motor continuously above rated load reduces efficiency and motor life. Determining if your motors are properly loaded enables you to make informed decisions about when to replace motors and which replacements to choose. Measuring motor loads is relative quick and easy when the proper techniques are used [27].

It is recommended that a survey and test of all the motors operating over 1000 hours per year should be made. Using the analysis results, the motors can be divided into following categories: 
Motors that are significantly oversized and under loaded - replace with more efficient, properly sized models at the next opportunity, such as scheduled plant down time.

- Motors that are moderately oversized and under loaded - replace with more efficient, properly sized models, when they fail.

Motors that are properly sized and but standard efficiency - replace most of these with energy efficient models when they fail.

\subsubsection{Motor downsizing example}

An example [27] will be valuable in appreciating the concept of downsizing motors. As can be seen in the Table 5.1, an analysis of downsizing a lightly loaded, existing $75 \mathrm{hp}$ motor is shown. A careful check of the motor load by the electrician reveals that the maximum (peak) load encountered is $30 \mathrm{hp}$. The peak load is short in duration (one hour per day). The potential replacement motor ( $40 \mathrm{hp}$, energy efficient) is forecast to operate at $75 \%$ load.

\begin{tabular}{|c|l|c|c|c|}
\hline No & \multicolumn{1}{|c|}{ Description } & $\begin{array}{c}\text { Existing motor } \\
\mathbf{7 5} \mathbf{~ h p}\end{array}$ & $\begin{array}{c}\text { Replacement } \\
\text { motor } \\
\mathbf{4 0} \mathbf{~ h p}\end{array}$ & Units \\
\hline 1 & Load imposed on motor & $40.0 \%$ & $75.0 \%$ & $\%$ \\
\hline 2 & Average volts & 476.0 & 476.0 & Volts \\
\hline 3 & Average current I & 44.2 & 33.9 & Amps \\
\hline 4 & Power factor - pf at load point & $69.9 \%$ & $85.0 \%$ & $\%$ \\
\hline 5 & Input power - Pin & 25.5 & 23.8 & $\mathrm{~kW}$ \\
\hline 6 & Motor efficiency - at load point & $87.9 \%$ & $94.1 \%$ & $\%$ \\
\hline 7 & Output power - Pout & 22.4 & 22.4 & $\mathrm{~kW}$ \\
\hline 8 & Motor losses $\left(\mathrm{P}_{\text {in }}-\mathrm{P}_{\text {out }}\right)$ & 3.1 & 1.4 & $\mathrm{~kW}$ \\
\hline 9 & Power savings & 0 & $\mathbf{1 . 7}$ & $\mathrm{kW}$ \\
\hline
\end{tabular}

Table 5.1: Motor downsizing example [27] 
The values of efficiency and power factor have been selected to reflect the load. Also it can be seen from this example that there was a net saving of $1.7 \mathrm{~kW}$ of demand because of downsizing. An additional energy saving is obtained which can also be substantial of the operating hours for this particular motor are above 1,000 hours. Thus the total savings obtained might justify the investment of replacing the present motor with an energy efficient undersized motor.

\subsubsection{Two speed Motors}

Two-speed motors are another option to downsizing in case of applications like chipper motor in wood manufacturing plants, where the motor runs at no load for some time and only when there is a load or wood particle, the motor is highly loaded. The two-speed motor can be used along with a sensor unit, which senses the wood coming on the belt towards the chipper motor. When the sensor detects something on the belt, the motor can be switched to a higher power mode and the operation conducted successfully.

The above concept can be explained with an example. Assume that a facility has a chipper motor of $150 \mathrm{hp}$, which operates continuously. From the assessment experience, it is seen that this chipper not operating at full load much of the time. So, this chipper motor can be replaced with a 2 -speed motor. By using a 2 -speed motor, the chipper will run at $150 \mathrm{hp}$ when actually chipping operation takes place, and at say 50hp when idling (no chipping operation performed). This will result in energy savings, as the chipper does not operate at $150 \mathrm{hp}$ at all times. From audit experience, it is estimated that the chipper is idle for $30 \%$ of the time. The energy cost savings are calculated as follows:

$\mathrm{ES}=\mathrm{CEU}-\mathrm{PEU}$

The current and proposed energy usage values can be estimated as follows:

$\mathrm{CEU}=\mathrm{hp} 1 \times \mathrm{H} \times \mathrm{LF} 1 \times \mathrm{C} / \mathrm{EFF} 1 \quad$ (for 150hp operation)

$\mathrm{PEU}=\mathrm{hp} 1 \times 0.70 \mathrm{H} \times \mathrm{LF} 1 \times \mathrm{C} / \mathrm{EFF} 1+\quad$ (for 150hp operation)

hp2 x 0.30H x LF2 x C / EFF2 (for 50hp operation)

Where

$\mathrm{CEU}=$ Annual energy consumption under current conditions.

$\mathrm{PEU}=$ Annual energy consumption under proposed conditions. 
1 corresponds to $150 \mathrm{hp}, 2$ corresponds to $50 \mathrm{hp}$

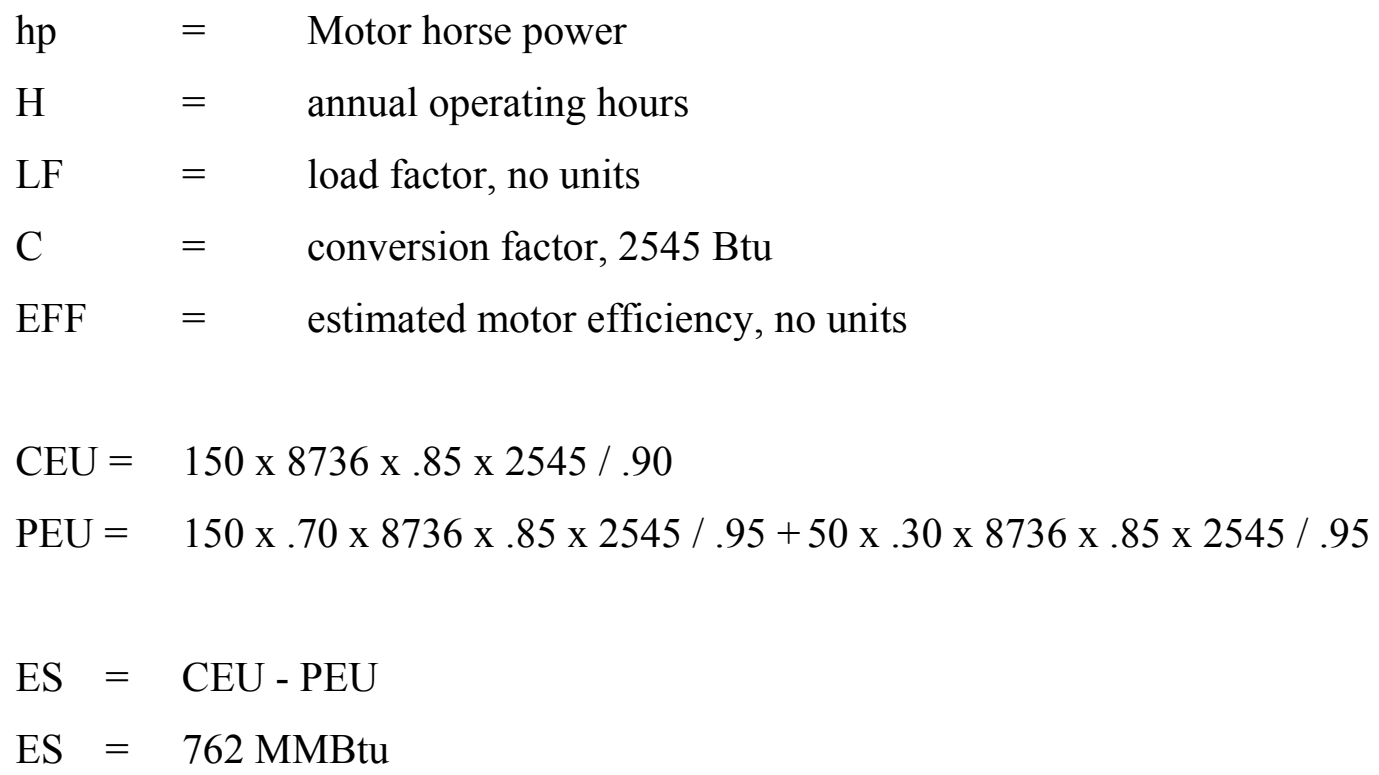

Assuming $\$ / \mathrm{Mmbtu}$ is $\$ 6.47 / \mathrm{MMBtu}$ and the demand cost is $\$ 7.34 / \mathrm{kW}$, annual Electricity Cost Savings, CS, are estimated as:

$$
\begin{array}{lll}
\mathrm{CS} & = & \mathrm{ES} \times(\text { average unit cost of electricity }) \\
\mathrm{CS} & =(762 \mathrm{MMBtu} / \mathrm{yr})(\$ 6.47 / \mathrm{MMBtu}) \\
\mathrm{CS} & =\$ 4,930 / \mathrm{yr}
\end{array}
$$

Annual Demand Savings DS can be estimated as:

$$
\text { DS } \quad \begin{aligned}
& =(\text { MMBtu } / \mathrm{y}) \times 10^{6} \mathrm{Btu} / \mathrm{MMBtu} \times 12 \mathrm{month} / \mathrm{y} \div(\mathrm{YOH} \times 3412 \mathrm{Btu} / \mathrm{kWh}) \\
& =\left(1256 \times 10^{6} \times 12\right) \div(8736 \times 3412) \\
& =465 \mathrm{~kW}-\mathrm{mo}
\end{aligned}
$$

Annual Demand Cost Savings, DCS, are estimated as:

$$
\begin{array}{ll}
\text { DCS } & =\text { DS } x \text { Demand Rate } \$ / \mathrm{kW} \text {-mo } \\
\text { DCS } & =465 \mathrm{~kW} \text {-mo x } 7.34 \$ / \mathrm{kW} \text {-mo }
\end{array}
$$




$$
\mathrm{DCS} \quad=\$ 3413 / \mathrm{yr}
$$

$$
\begin{aligned}
\text { Total Annual Cost Savings } & =\mathrm{CS}+\mathrm{DCS} \\
& =4,930+3,413 \\
& =\$ 8,343 / \mathrm{yr}
\end{aligned}
$$

The total cost to replace $150 \mathrm{hp}$ single speed motor with $150 \mathrm{hp}$ two speed / variable speed motor and corresponding control can be estimated:

New Variable Speed Motor \& Controls $=\$ 9,000$

Labor Cost $=\$ 90$

$$
\begin{array}{ll}
\text { Labor Rate } & =\$ 18 / \mathrm{hr} \\
\text { Labor Time } & =5 \mathrm{hr}
\end{array}
$$

Total implementation cost $=\$ 9,090$

The cost savings of $\$ 8,343 / \mathrm{yr}$ pay for the implementation cost of $\$ 9,090$ in about 14 months.

If the same analysis is performed for downsizing the same chipper motor to a lower size motor of say $100 \mathrm{hp}$, the resulting savings for the same usage and demand rates as obtained from Motor Master + software are as follows:

Total energy savings $=\$ 735 / \mathrm{yr}$

Total Implementation cost $=\$ 4,779$

Payback period $=6.5$ years.

\subsubsection{Comparison between downsizing and two-speed motor option}

As can be seen in the above example, it is really necessary to perform a load factor test on the motor to take a wise decision on whether to downsize motors like chipper or to replace them with a two speed- motor and control unit. The two-speed motors option may not be applicable in each and every operation in the wood industry. Some processes where the load is pretty constant and low, then downsizing would be a wise option to consider. The two- speed option should be carefully evaluated for the different load conditions on the motor and also a load profile of the motor would be of advantage to find the percentage of time, the motor is idle and motor is running at full load. 


\subsection{Determining motor load factor}

It is important to determine the load factor of the motors in order to ensure that the motor is properly sized for the application and to identify potential problems. Field tests are performed in order to determine the load of the motors in wood manufacturing plants. There are two types of motor load testing techniques used in the field. They are the electrical method of load testing (Use of line current measurements) and the slip method.

\subsubsection{Use of line current measurements}

The amperage draw of a motor varies approximately linearly with respect to load down to about $50 \%$ of full load. Below the $50 \%$ load point, due to reactive magnetizing current requirements, power factor degrades, and the amperage curve becomes increasingly non-linear and is no longer a useful indicator of load. The no load or idle amperage for most motors is typically on the order of 25 to 40 percent of the nameplate full load current while the power draw or no load loss is only 4 to $8 \%$ of the name plate horsepower.

Advantages of using the current based load estimation technique are that NEMA MG 1-12.47 allows a tolerance of only $10 \%$ when reporting nameplate full load current. In addition, motor terminal voltages only affect current to the first power, while slip varies with the square of the voltage. Finally, a motor's current draw is not directly related to operating temperature. The equation that related motor load to measured current values is [28]:

$$
\text { Motor load }=\frac{\text { Amps measured X Volts measured }}{\text { Amps full load, nameplate X Volts nameplate }}
$$

\subsubsection{The Slip method}

The synchronous speed of an induction motor depends on the frequency of the power supply and on the number of poles for which the motor is wound. The higher the frequency, the faster a motor runs. The more poles the motor has, the slower it runs. The synchronous speed (Ns) for a squirrel cage induction motor is given by $[27,28]$ :

$$
\mathrm{Ns}=\frac{120 \mathrm{Xf}}{\mathrm{P}}
$$


Where:

$\mathrm{f}=$ frequency of the power supply

$\mathrm{p}=$ poles for which the motor is wound

The actual speed of the motor is less than its synchronous speed with the difference between the synchronous and actual speed referred as slip. The amount of slip present is proportional to the load imposed upon the motor by the driven equipment. Slip is typically expressed as a percentage where:

Percent slip $=\underline{(\text { synchronous speed }- \text { actual speed })} \times 100$

synchronous speed

The motor load can be estimated with slip measurement as follows:

Slip $=\mathrm{RPM}_{\text {sync }}-\mathrm{RPM}_{\text {measured }}$

Motor load $=$

Slip

$\mathrm{RPM}_{\text {sync }}-\mathrm{RPM}_{\text {full load (nameplate) }}$

For example:

Given : RPM $_{\text {sync }}=1,800$

$\mathrm{RPM}_{\text {measured }}=1,770$

$\mathrm{RPM}_{\text {nameplate }}=1,750$

Nameplate hp $=25$

Then: Slip $=1,800-1,770$

$$
=30
$$

Motor load $=$ 30

$$
\begin{aligned}
& \overline{1,800-1,750} \\
= & 30 / 50 \\
= & 0.6
\end{aligned}
$$

The speed / slip technique for determining motor load has been favored due to its simplicity and safety advantages. The two most easily measured motor operating parameters are temperature and speed. Most motors are constructed such that the shaft is accessible to a tachometer or a strobe light. 


\subsection{Field testing}

This slip method of load testing was used for testing the load of the motors in the wood manufacturing facilities visited in West Virginia. The information on the motor input data was obtained during the assessment and a motor load test was performed using a digital stroboscope. This method is very simple and fairly accurate in an industry like wood manufacturing. The electrical method is very time consuming and is risky in the sense that you need to work with the currents and voltages directly. While in the slip method the field test can be performed standing at some safe distance away from the running motor. Also the operation need not be stopped or there is no modification in the set up required to perform this test. Thus it is completely hassle free and doesn't interfere with the working of the plant equipment.

Advantage of using a digital stroboscope is that one doesn't require a reflective tape to be put on the motor shaft and then measure the rpm. The digital stroboscope flashes in unison with the monitored object, and the speed of the object or the motor shaft is equal to the flash rate. The schematic of the motor load test set up can be seen in the Figure 5.1 below. The figure shows the variable frequency source, which is the supply for the unit. A battery pack can also be used to provide the AC supply to the stroboscope. The frequency scalar is used to change the frequency of the flashlight so as to meet the rpm pf the motor shaft. There is also a digital display, which shows the flashes per minute. The flashing unit produces the flashlight through a Xenon flasher, which is directly incident on the rotating shaft of the motor. When the rotating shaft of the motor appears stationary to the eyes of the user, than the flash per minute equals the rpm of the motor. 


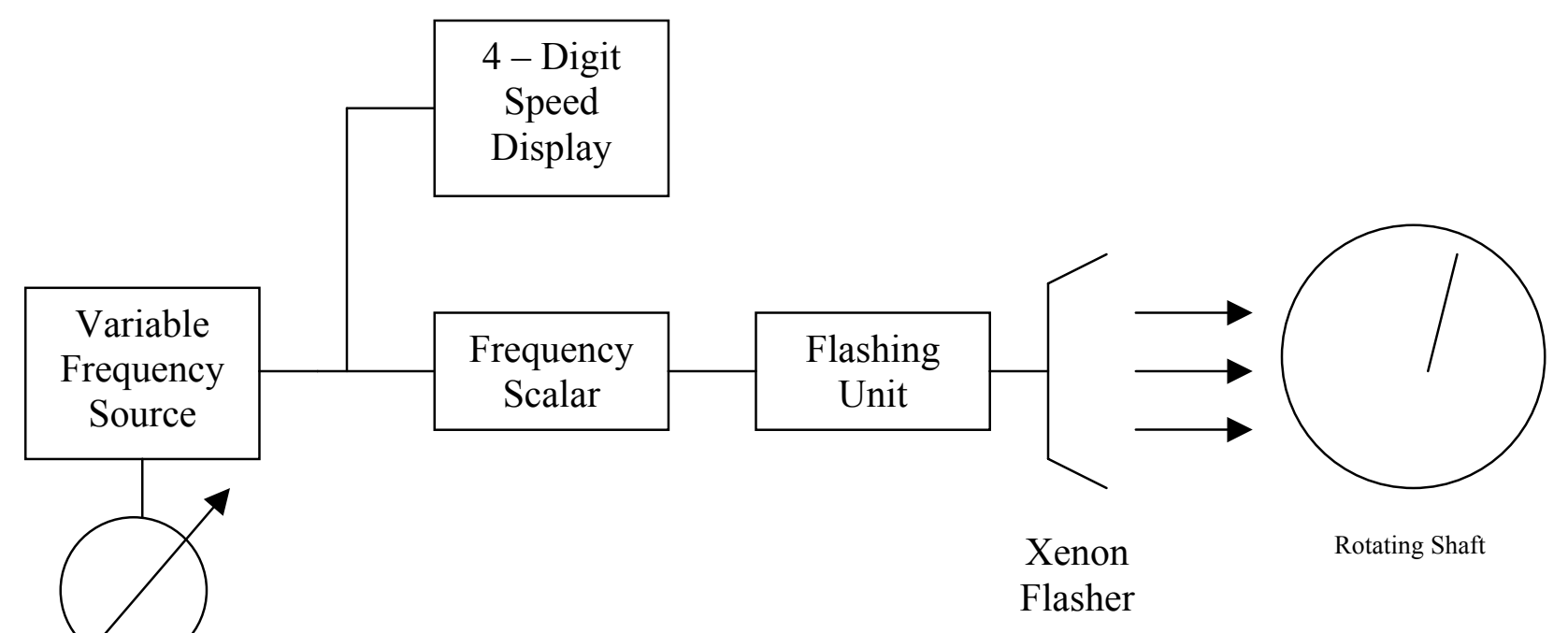

Figure 5.1: Schematic diagram for the motor load test

\subsection{Example of the field test}

The motor load test was performed in various plants during the assessments. During the test, care was taken that the load test was performed when the motor was aptly loaded. The motor load test data of on one of the chipper motors encountered during the assessment can be seen in the Table 5.1. It is seen that the synchronous speed of the motor, the full load rpm of the motor and the other details of the motor are noted from the motor nameplate data. The operating speed of the motor is determined using a digital stroboscope.

\begin{tabular}{|l|l|l|l|}
\hline Company & Facility G & Location & Spencer, WV \\
\hline Date & $04 / 18 / 2002$ & Process & Chipper \\
\hline \multicolumn{4}{|c|}{ Motor Name Plate Data } \\
\hline Manufacturer & Lincoln Motors & $\begin{array}{l}\text { Synchronous } \\
\text { speed }\end{array}$ & $1800 \mathrm{rpm}$ \\
\hline Full load speed & $1760 \mathrm{rpm}$ & Voltage rating & $460 \mathrm{~V}$ \\
\hline Size & $150 \mathrm{hp}$ & $\begin{array}{l}\text { Enclosure } \\
\text { type }\end{array}$ & TEFC \\
\hline Operating speed & $1785 \mathrm{rpm}$ & \multicolumn{3}{|l}{} \\
\hline
\end{tabular}

Table 5.2: Motor load test data for a chipper 


\subsubsection{Calculations for the field test}

The data collected from the load test performed on the chipper motor during the assessment is further used to find the load factor of the motor. The calculations of the motor load test data are shown as follows:

$$
\begin{aligned}
\text { Slip } & =\mathrm{RPM}_{\text {sync }}-\mathrm{RPM} \text { measured } \\
\text { Slip } & =1800-1785 \\
& =15
\end{aligned}
$$

$$
\begin{aligned}
\text { Motor load } & =\frac{\text { Slip }}{\text { RPM }_{\text {sync }}-\mathrm{RPM}_{\text {full load (nameplate) }}} \\
& =\frac{15}{1800-1760} \\
& =0.375
\end{aligned}
$$

Thus from the calculations it can be seen that the instantaneous load of the chipper motor is 0.375 . Similar tests are carried out on different motors in the plants on different assessments. The collected data on these motors and the calculation of the motor load is done for each of these motors and can be seen in the Appendix III. It should be noted that the operating rpm, which is measured, always lies in between the synchronous and the full load rpm of the motor. Even though the range or the difference between the synchronous and full load rpm is small still the measured operating rpm will lie within that range. A summary of some of the load test conducted at different plants can be seen in the Table 5.3.

\begin{tabular}{|c|c|c|c|c|c|}
\hline Motor Type & $\begin{array}{c}\text { Motor size } \\
(\mathbf{h p})\end{array}$ & $\begin{array}{c}\text { Measured } \\
\text { rpm }\end{array}$ & $\begin{array}{c}\text { Full load } \\
\text { rpm }\end{array}$ & $\begin{array}{c}\text { Synchronous } \\
\text { rpm }\end{array}$ & $\begin{array}{c}\text { Motor } \\
\text { load }\end{array}$ \\
\hline Chipper shaker & $\mathbf{4 0}$ & 1780 & 1760 & 1800 & 0.50 \\
\hline Treatment plant & $\mathbf{4 0}$ & 1762 & 1760 & 1800 & 0.95 \\
\hline Trimmer & 10 & 1774 & 1745 & 1800 & 0.47 \\
\hline
\end{tabular}

Table 5.3: Summary of some of the load test calculations 


\subsection{Conclusion}

As can be seen in the section 5.4.1 and the Appendix III, the motor load test carried out on the motors in the wood manufacturing plants indeed show that the load factor of the motor is smaller than optimal. This shows that there is an opportunity for downsizing the motors to there appropriate size and thus reduce demand as well as energy for the plant. This load test is only an instantaneous load test carried out during the field visits of these plants. Before coming to a final decision on the downsizing, a continuous load test needs to be performed on the candidate motors at different time intervals so as to make sure of the downsizing possibility. After the load factor on the motor is obtained, the efficiency for the motor can be obtained from the Motor Master database. These load and efficiency values of the motor then can be used for detailed economic analysis using the Motor Master software. Motor Master will give a better insight into the replacement and downsizing decisions and will help justify the investment from the economics of the decision. The features of the Motor Master and how the different variables in the Motor Master software affect the replacement decision are discussed in the next chapter. 


\section{Chapter 6}

\section{Motor Master Analysis}

The motor load test performed on the motors in the wood manufacturing plants visited suggest that the motors are indeed over loaded for the application and there is immense potential for downsizing them to the appropriate size. After determining the load factor, the efficiency values of the motors can be obtained from Motor Master software for those loads. This chapter will discuss the Motor Master analysis of the various replacement decisions. A detailed justification on the motor replacement decision can be obtained. Also a thorough sensitivity analysis of the replacement decision is made by changing the various parameters that govern the investment decision.

\subsection{Introduction to Motor Master}

Motor Master is a motor management software designed by the US Department of Energy to support motor management functions at medium sized and large industrial facilities. It supports motor and motor systems improvement planning through identifying the most efficient motors for a given repair or motor purchase decision. It can be used to identify inefficient or oversized inventory motors and compute the energy and demand savings associated with selection of a replacement energy efficient model. Motor Master + contains a field data module, a motor price and performance database, energy conservation analysis, life cycle costing, and energy accounting capabilities [31].

The compare module of the software calculates the annual energy consumption and energy costs for particular motors in a specific application. It predicts expected energy and cost savings for replacing an existing motor with an energy efficient model, and shows the simple payback from energy cost savings. The comparison of two motors can be done in the following three scenarios:

- New: Compare two new motors from the motor catalog.

* Rewind: Compare rewinding an existing motor with purchase of a new energy efficient motor. 
* Replace existing: Compare an existing motor with a new energy efficient replacement.

These three scenarios are discussed in detail in the following passages. The motor data collected from the site visits and also the load test results will be used to analyze the different replacement decisions in detail.

\subsection{Compare new motors}

This scenario compares the costs of acquiring and operating a standard motor with those of an energy efficient model. Motor Master + determines the energy and cost savings possible with the energy efficient model. Then, assuming that the energy efficient motor is also more expensive to purchase, it calculates the simple payback. The time it takes for the savings to pay back the difference or premium in the new motor purchase price. The major parameters, which govern this type of decision, are the purchase price of the standard and energy efficient model and the operating efficiencies of these motors [31].

As can be seen in the Figure 6.1, the analysis is performed for a $10 \mathrm{hp}$ motor, which runs for 3 shifts, 8760 hours annually. The load factor for the analysis is assumed to be 0.80 . The enclosure type for the motors under comparison is assumed to be of TEFC type. The energy cost used in the analysis is obtained from the rate schedule for facility A, which is $0.02801 \$ / \mathrm{kWh}$. The demand cost obtained from the schedule is $9.45 \$ / \mathrm{kW}$. This analysis is performed on motors in the range from $7.5 \mathrm{hp}$ to $200 \mathrm{hp}$. It was found during the assessments that the motors in wood manufacturing plants lie in this range. The payback for this analysis is obtained on the investment, which is the difference of the capital cost of purchasing and installing a standard motor and an energy efficient model. The Figure 6.2 shows the savings obtained by making such an investment comparison for new motors. The energy saved and the demand saved and also the cost savings related to them can be seen here. The simple payback, which is calculated, can also be seen in this window. The value for the motor premium is obtained as a difference of the purchase cost of the standard efficiency and the energy efficient models. 


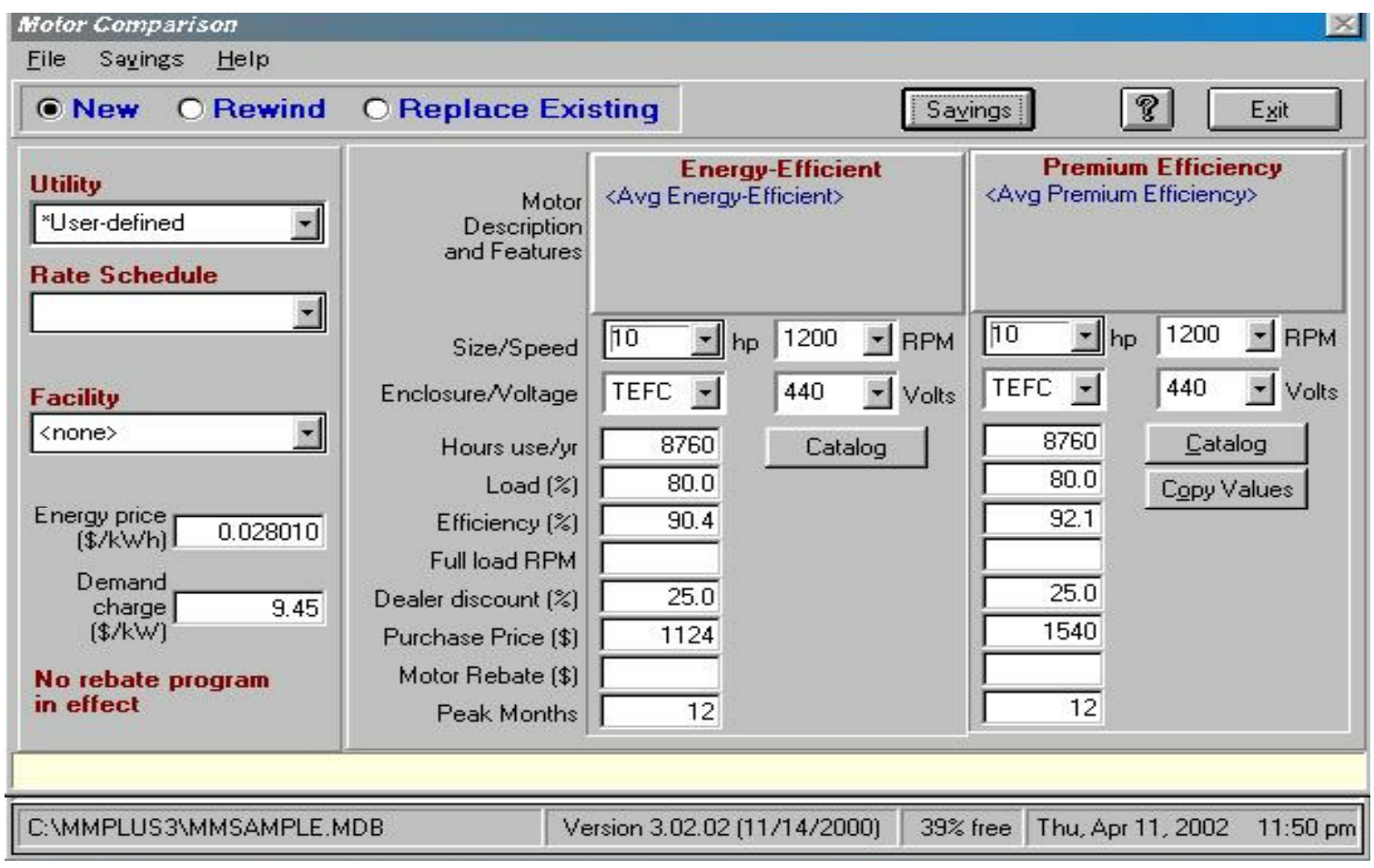

Figure 6.1: Compare module - Compare new motors

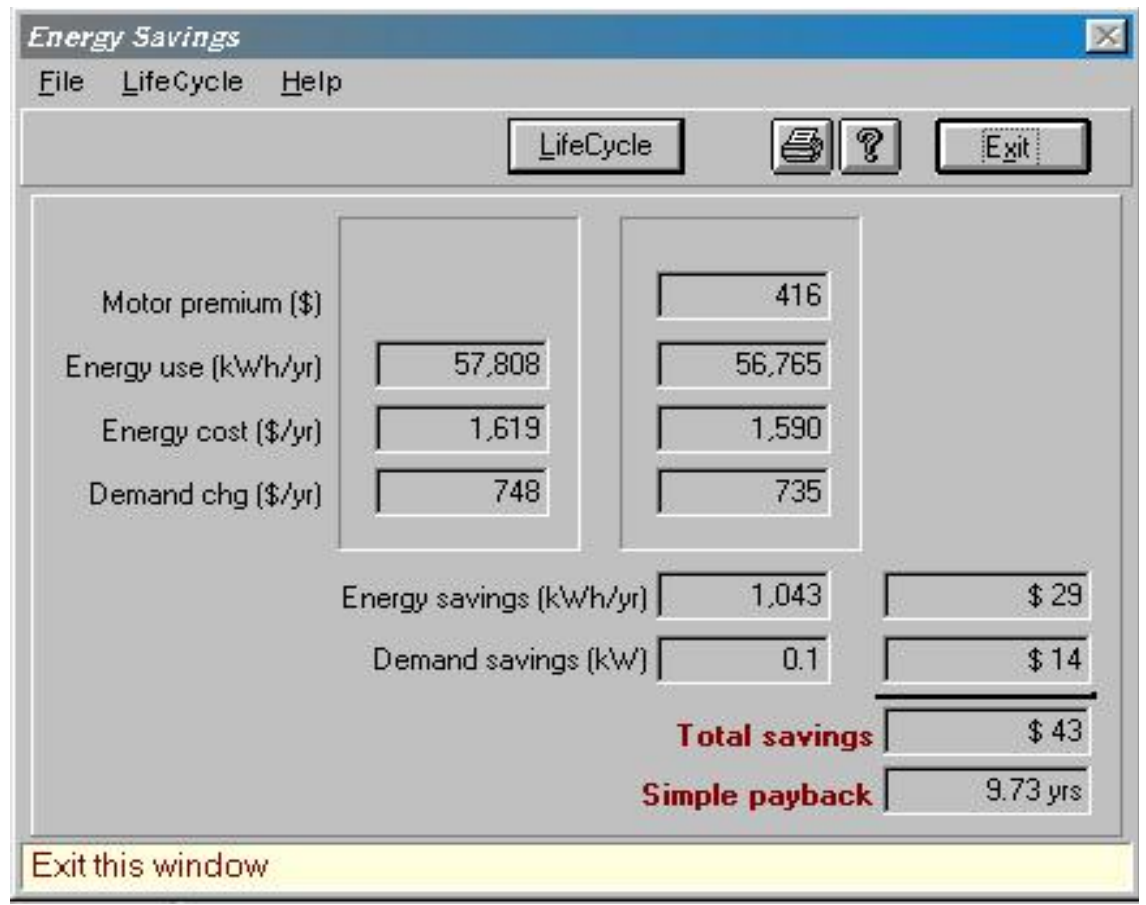

Figure 6.2: Savings window - Compare new motors 


\subsubsection{Analysis of the results}

The compare new module of the Motor Master was used to compare the new motor investment decisions from $7.5 \mathrm{hp}$ to $200 \mathrm{hp}$. The Table 6.1 shows the results of that analysis. These results are based on the energy and demand cost obtained from the rate schedule for facility A. As can be seen in the table, the payback period is significantly high in the analysis for a $10 \mathrm{hp}$ motor. This is because the motor premium for this size of motor is high. This high motor premium is not justified by a smaller payback, as the total annual energy savings obtained are very small.

Other wise a there is no specific trend observed in the simple pay back as the size of the motors is increased from $7.5 \mathrm{hp}$ to $200 \mathrm{hp}$. There is no such trend because the motor premium for each size is different and it does not vary in the proportion. Also it can be seen that the there is not much difference in the standard and premium energy efficiency values for the bigger sized motors. Overall this analysis shows that one should always opt for a premium efficiency motor as compared to a standard efficiency motor when making a new motor purchasing decision.

TEFC Enclosure

$1200 \mathrm{rpm}$

25\% Dealer Discount 12 months peak

\begin{tabular}{|c|c|c|c|c|c|c|c|c|c|c|c|c|}
\hline \multicolumn{5}{|c|}{ Energy Efficient } & \multicolumn{5}{|c|}{ Premium Efficiency } & \multicolumn{3}{|c|}{ Analysis } \\
\hline hp & Hours & $\begin{array}{l}\text { Load } \\
\text { factor }\end{array}$ & Eff & Investment & hp & Hours & $\begin{array}{l}\text { Load } \\
\text { factor }\end{array}$ & Eff & Investment & $\begin{array}{c}\text { Energy } \\
\text { sav }\end{array}$ & $\begin{array}{l}\text { Dem } \\
\text { sav }\end{array}$ & $\begin{array}{l}\text { Pay } \\
\text { back }\end{array}$ \\
\hline 7.5 & 8,760 & 0.8 & 90.3 & 1011 & 7.5 & 8,760 & 0.8 & 91.7 & 1020 & 19 & 9 & 0.32 \\
\hline 10 & 8,760 & 0.8 & 90.4 & 1124 & 10 & 8,760 & 0.8 & 92.1 & 1540 & 29 & 14 & 9.73 \\
\hline 15 & 8,760 & 0.8 & 91.3 & 1586 & 15 & 8,760 & 0.8 & 92.5 & 1661 & 32 & 15 & 1.59 \\
\hline 20 & 8,760 & 0.8 & 91.4 & 1878 & 20 & 8,760 & 0.8 & 92.8 & 1931 & 49 & 23 & 0.74 \\
\hline 25 & 8,760 & 0.8 & 92.4 & 2194 & 25 & 8,760 & 0.8 & 93.4 & 2437 & 42 & 19 & 3.93 \\
\hline 30 & 8,760 & 0.8 & 92.6 & 2634 & 30 & 8,760 & 0.8 & 93.9 & 2755 & 68 & 32 & 1.2 \\
\hline 40 & 8,760 & 0.8 & 93.4 & 3344 & 40 & 8,760 & 0.8 & 94.5 & 3944 & 69 & 32 & 5.96 \\
\hline 50 & 8,760 & 0.8 & 93.5 & 4005 & 50 & 8,760 & 0.8 & 94.5 & 4437 & 81 & 37 & 3.66 \\
\hline 60 & 8,760 & 0.8 & 93.9 & 4860 & 60 & 8,760 & 0.8 & 95 & 5086 & 99 & 46 & 1.56 \\
\hline 75 & 8,760 & 0.8 & 94.1 & 5643 & 75 & 8,760 & 0.8 & 95.2 & 6056 & 130 & 60 & 2.17 \\
\hline 100 & 8,760 & 0.8 & 94.5 & 7268 & 100 & 8,760 & 0.8 & 95.4 & 8193 & 148 & 68 & 4.28 \\
\hline 125 & 8,760 & 0.8 & 94.6 & 8723 & 125 & 8,760 & 0.8 & 95.7 & 9950 & 219 & 101 & 3.82 \\
\hline 150 & 8,760 & 0.8 & 95.2 & 9748 & 150 & 8,760 & 0.8 & 96.1 & 11469 & 202 & 94 & 5.81 \\
\hline 200 & 8,760 & 0.8 & 95.2 & 12014 & 200 & 8,760 & 0.8 & 95.9 & 13018 & 224 & 104 & 3.06 \\
\hline
\end{tabular}

Table 6.1: New motors investment analysis 
The user might want to check the premiums for $10 \mathrm{hp}$ motor and recalculate the savings if he gets a better price for the premium efficiency model. The results for the comparison are plotted as can be seen in the Figure 6.3 below. The payback period obtained is plotted against the motor size. It can be seen that there is a spike in the plot for the $10 \mathrm{hp}$ motor, because of its high premium. Other wise the plot appears to have no specific pattern.

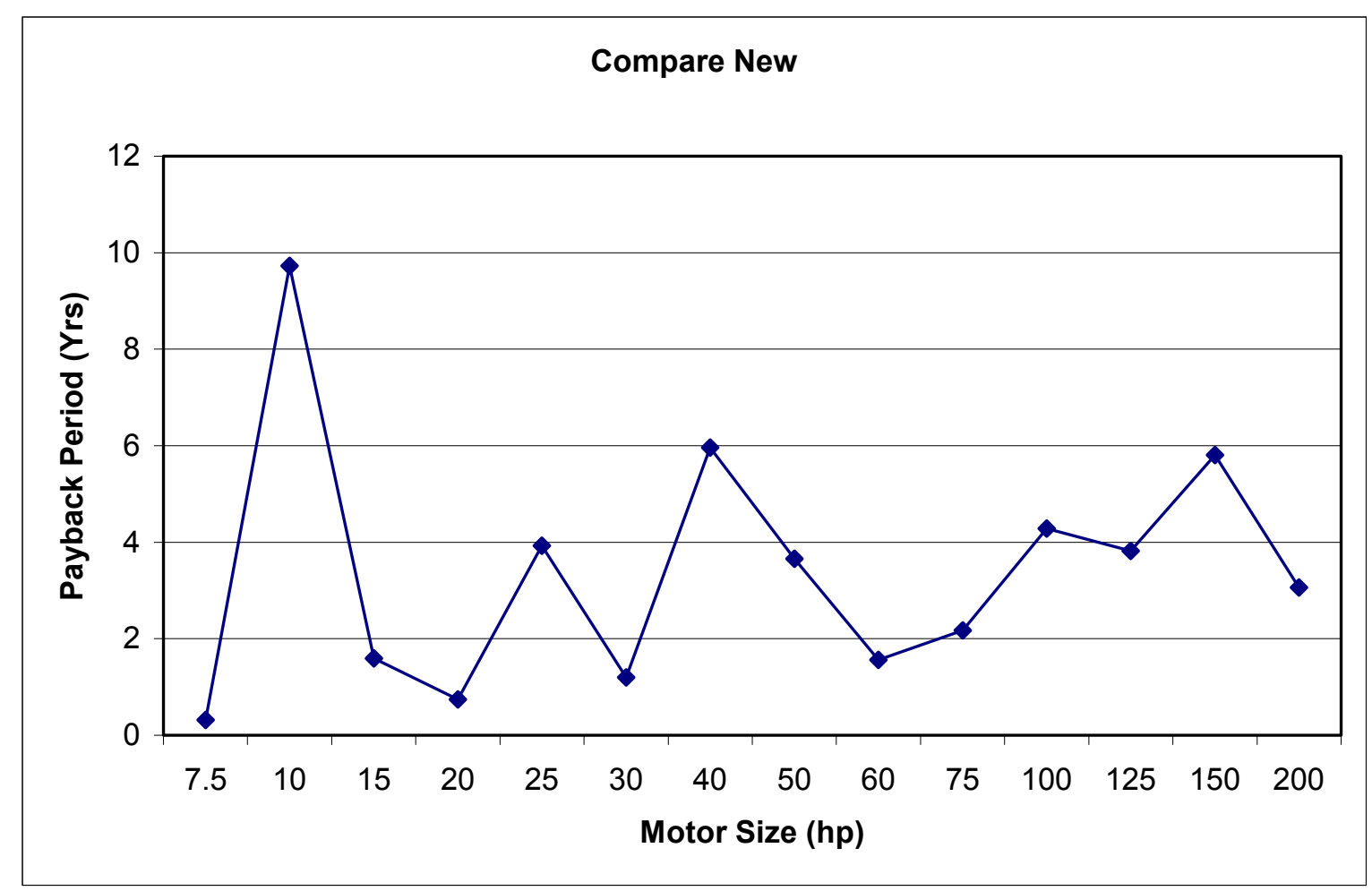

Figure 6.3: Comparison for different sizes of the motors with respect to the payback

\subsection{Rewind Vs new efficiency motor purchase decision}

This compares the cost effectiveness of rewinding a failed motor with the cost of purchasing a new standard efficiency or energy efficient model. This comparison takes into account the reduced efficiency for the rewound motor attributable to age and rewind losses. To perform this analysis the user must select the rewind option in the motor master compare module. As can be seen in the Figure 6.4 some additional information is required for this type of analysis. There is additional information required on the rewinding charge for the existing standard efficiency motor. Also the loss in the efficiency of the standard motor is another 
important variable considered here. The default value for this loss is $1 \%$ for motors above 40 $\mathrm{hp}$, and for those below $40 \mathrm{hp}$ this default value is $2 \%$. Normally old motors might have a chance to lose more efficiency after rewinding then as compared to new motors. In this case again, the load factor of the motor and the efficiency of the motor play a crucial role in the analysis. The comparison is shown in Figure 6.4 for a $50 \mathrm{hp}$ motor. The savings obtained from such an option can be seen in the Figure 6.5. The analysis is again performed using the energy and demand cost values obtained from the utility rate schedule for facility A. Again here the enclosure type of the motors is assumed to be TEFC and the load factor is assumed to be 0.8 .

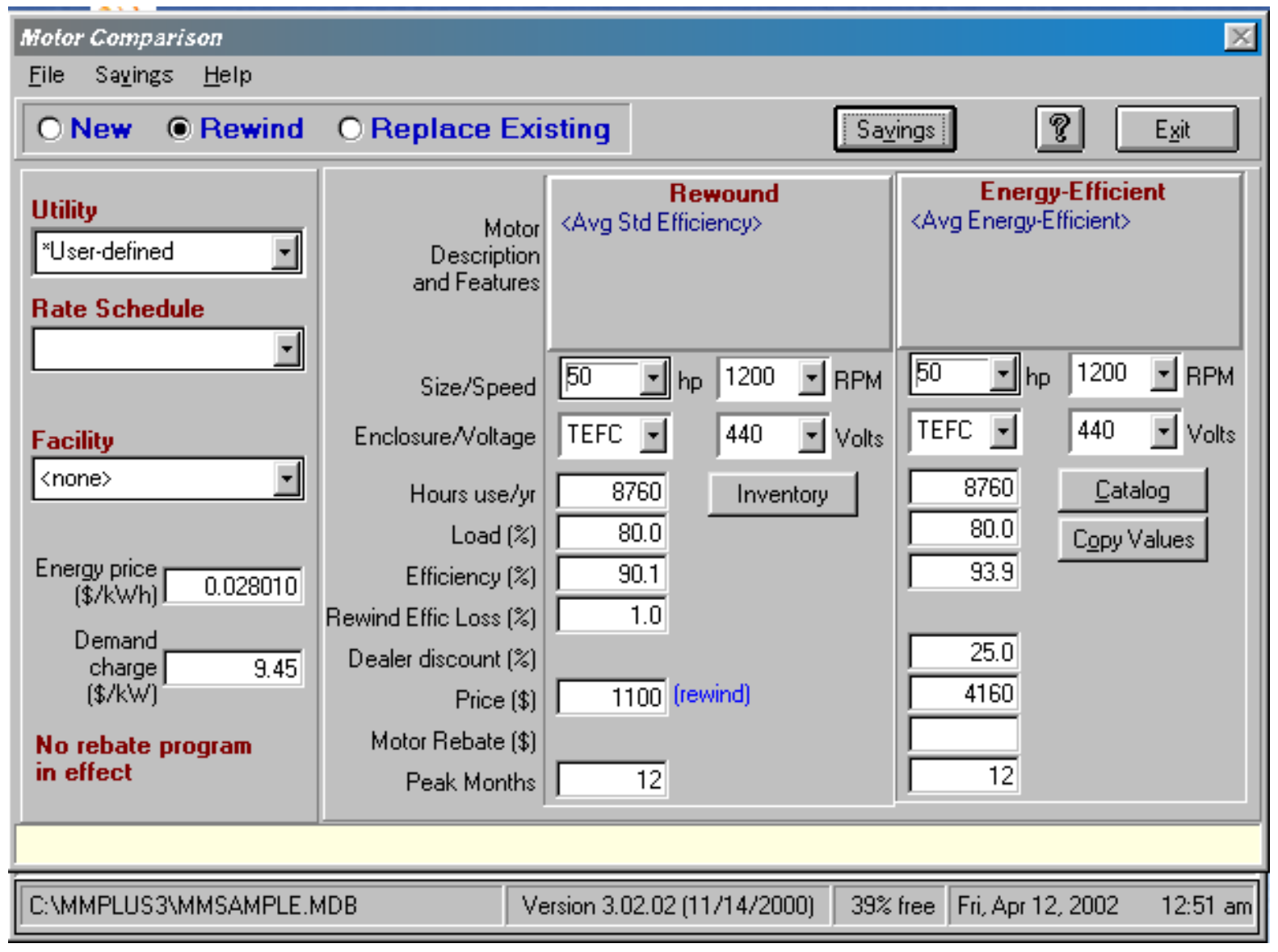

Figure 6.4: Compare module - Rewind Vs New efficiency motor purchase decision 


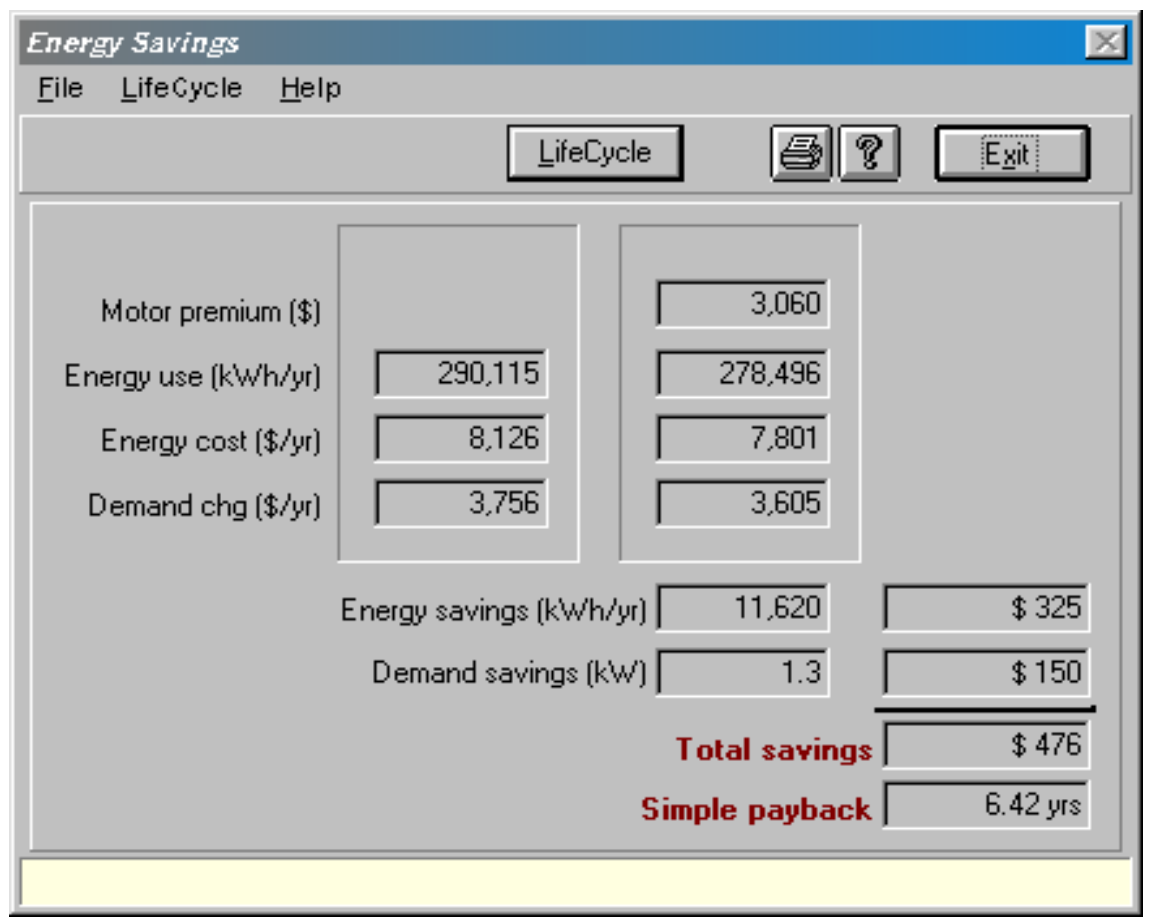

\section{Figure 6.5: Savings window - Rewind Vs New efficiency motor purchase decision}

\subsubsection{Analysis of the results}

The comparison of the cost effectiveness of rewinding a failed motor with the cost of purchasing a new standard efficiency or energy efficient model was performed from $7.5 \mathrm{hp}$ to $200 \mathrm{hp}$ range of motors. The Table 6.2 shows the results of that analysis. These results are based on the energy and demand cost obtained from the rate schedule for facility $\mathrm{A}$. The table shows that purchasing a new energy efficient motor might be more economical up to 40 hp size of the motors. The payback for the energy efficient motor purchase is above 5 years for motors above $40 \mathrm{hp}$. This is because as the size of the motors increase, the cost of the energy efficient models increases rapidly as compared to the increase in cost of rewinding motors. For the bigger size motors the motor premium is very high as compared to smaller size motors up to $40 \mathrm{hp}$. Also the efficiency of the current motors, which are supposed to be rewound on failure, plays a very crucial role in the decision. If the current motors are old motors and if they are going to be rewound a second or third time, then the efficiency values might be lower then what is assumed here in the analysis. In that case the purchase of energy 


TEFC Enclosure 1200 rpm
\begin{tabular}{|c|c|c|c|c|c|c|c|c|c|c|c|c|}
\hline \multicolumn{3}{|c|}{ Existing } & \multicolumn{1}{c|}{$25 \%$ Dealer Discount 12 months peak } \\
\hline hp & Hours & $\begin{array}{c}\text { Load } \\
\text { factor }\end{array}$ & Eff & $\begin{array}{c}\text { Rewinding } \\
\text { Cost }\end{array}$ & hp & Hours & $\begin{array}{c}\text { Load } \\
\text { factor }\end{array}$ & Eff & Investment & $\begin{array}{c}\text { Anergy } \\
\text { Enalysis } \\
\text { sav }\end{array}$ & $\begin{array}{c}\text { Dem } \\
\text { sav }\end{array}$ & $\begin{array}{l}\text { Pay } \\
\text { back }\end{array}$ \\
\hline 7.5 & 8,760 & 0.8 & 82.5 & 500 & 7.5 & 8,760 & 0.8 & 90.5 & 1,012 & 118 & 54 & 2.97 \\
\hline 10 & 8,760 & 0.8 & 83.7 & 550 & 10 & 8,760 & 0.8 & 90.9 & 1,209 & 138 & 64 & 3.27 \\
\hline 15 & 8,760 & 0.8 & 85.2 & 600 & 15 & 8,760 & 0.8 & 91.5 & 1,604 & 180 & 83 & 3.82 \\
\hline 20 & 8,760 & 0.8 & 86.6 & 660 & 20 & 8,760 & 0.8 & 91.8 & 1,893 & 192 & 89 & 4.38 \\
\hline 25 & 8,760 & 0.8 & 87.4 & 760 & 25 & 8,760 & 0.8 & 92.8 & 2,286 & 244 & 113 & 4.28 \\
\hline 30 & 8,760 & 0.8 & 88.2 & 800 & 30 & 8,760 & 0.8 & 93 & 2,660 & 255 & 118 & 4.76 \\
\hline 40 & 8,760 & 0.8 & 88.3 & 980 & 40 & 8,760 & 0.8 & 93.8 & 3,579 & 390 & 180 & 4.55 \\
\hline 50 & 8,760 & 0.8 & 90.1 & 1100 & 50 & 8,760 & 0.8 & 93.9 & 4,160 & 325 & 150 & 6.43 \\
\hline 60 & 8,760 & 0.8 & 90.0 & 1320 & 60 & 8,760 & 0.8 & 94.3 & 4,943 & 449 & 207 & 5.52 \\
\hline 75 & 8,760 & 0.8 & 90.6 & 1650 & 75 & 8,760 & 0.8 & 94.4 & 5,763 & 483 & 223 & 5.82 \\
\hline 100 & 8,760 & 0.8 & 90.6 & 2200 & 100 & 8,760 & 0.8 & 94.8 & 7,581 & 720 & 333 & 5.11 \\
\hline 125 & 8,760 & 0.8 & 91.1 & 2400 & 125 & 8,760 & 0.8 & 94.9 & 9,174 & 823 & 381 & 5.62 \\
\hline 150 & 8,760 & 0.8 & 92.3 & 2650 & 150 & 8,760 & 0.8 & 95.5 & 10,405 & 811 & 375 & 6.53 \\
\hline 200 & 8,760 & 0.8 & 92.0 & 2860 & 200 & 8,760 & 0.8 & 95.4 & 12,363 & 1124 & 519 & 5.78 \\
\hline
\end{tabular}

Table 6.2: Rewind Vs new efficiency motor purchase decision

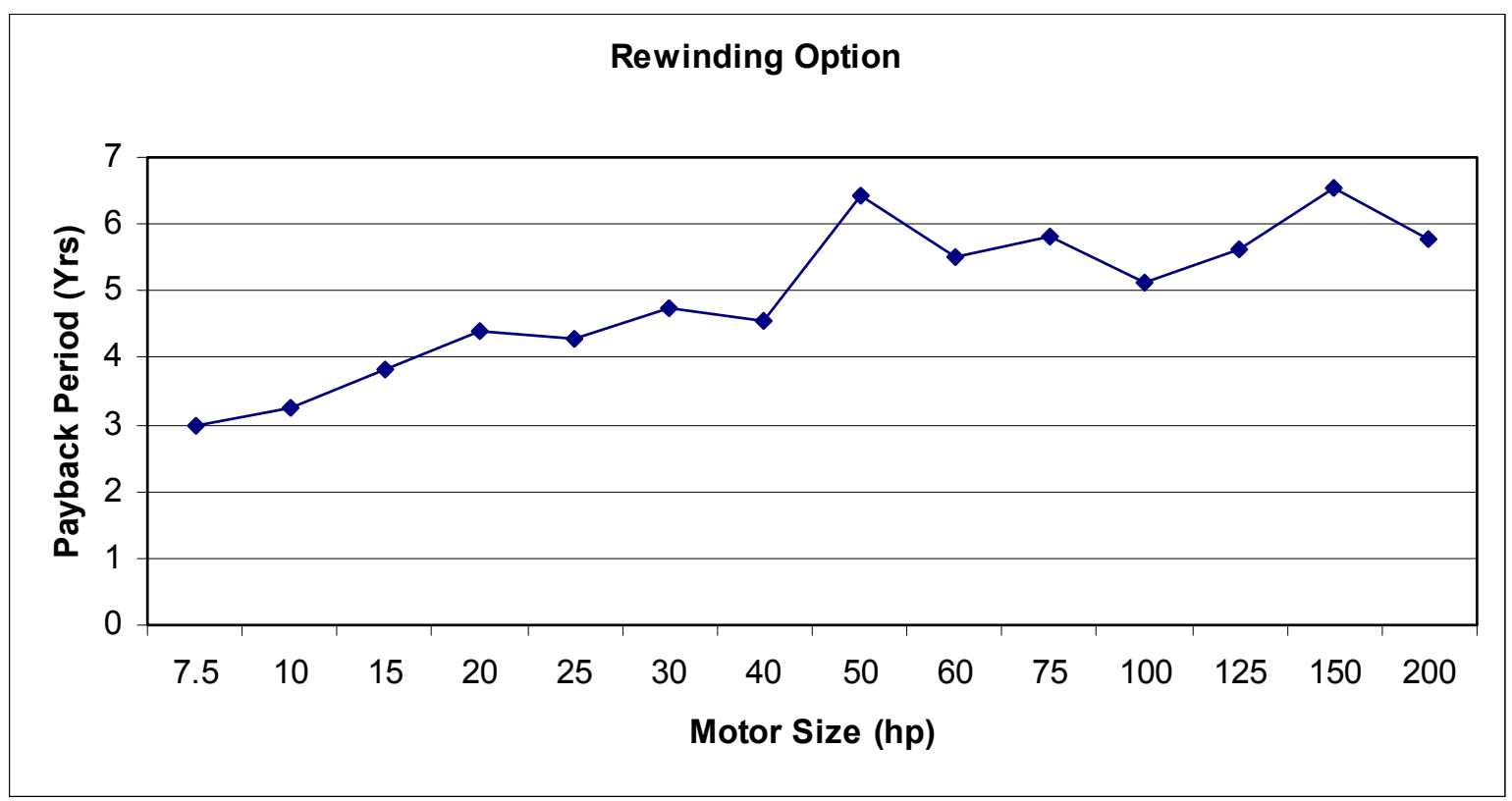

Figure 6.6: Analysis of the Rewind Vs new efficiency motor purchase decision 
efficient motor option might be even more favorable. The Figure 6.6 shows the plot of the payback period against the motor size. It can be seen that, the energy efficient motor purchase decision instead of the rewinding decision may not be really favorable as the motor size increases.

\subsection{Replace existing}

This analyzes the cost effectiveness of replacing an operable standard efficiency motor with a new energy efficiency motor model of the same size. This calculation is useful for deciding whether to replace older, low efficiency, and rewound motors. This analysis considers the entire purchase price and installation costs as the motor premium in determining the simple payback. In this option various cases are considered for the analysis. This analysis is again performed for the energy and demand costs obtained from the rate schedule for facility A. The comparison can be seen in the Figure 6.7.

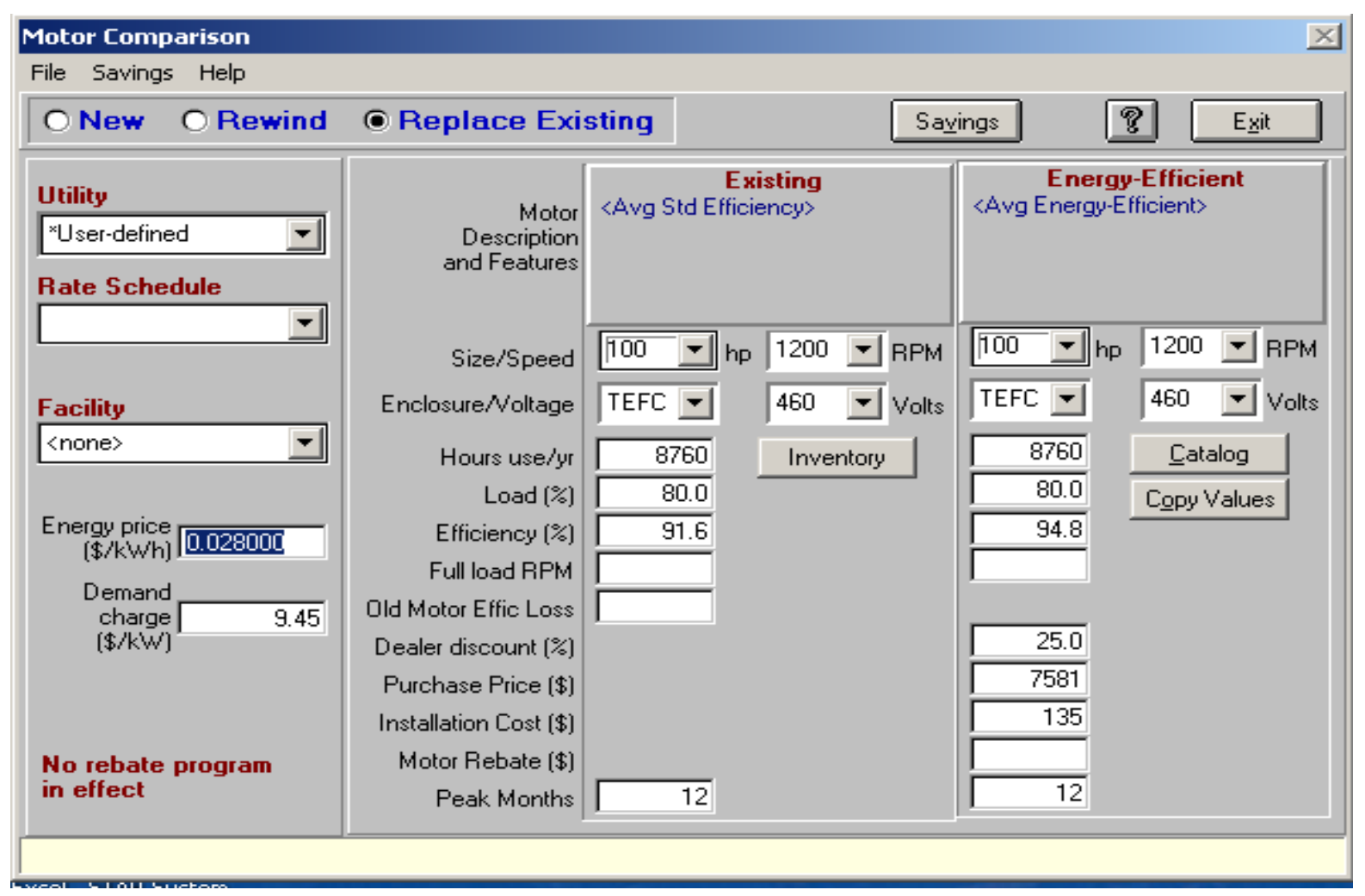

Figure 6.7: Compare module - Replace existing option 


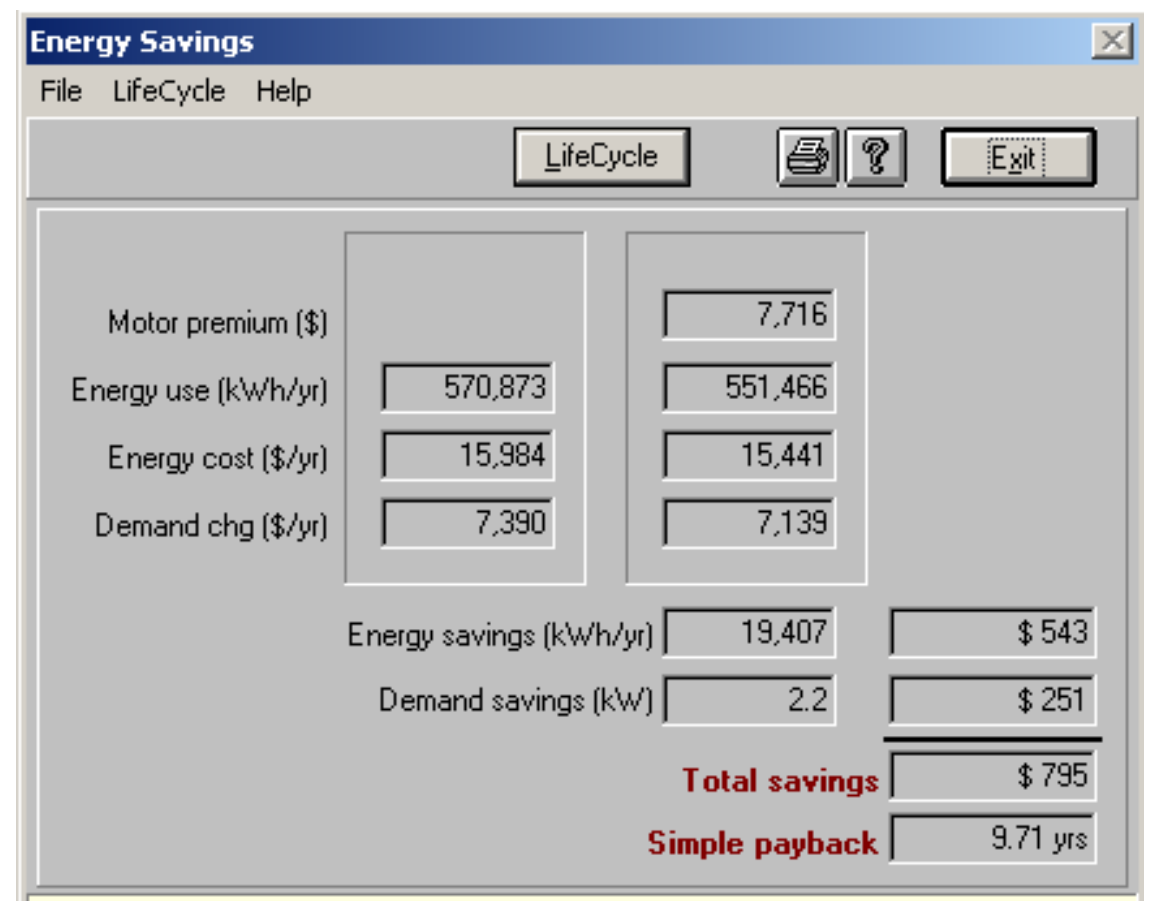

Figure 6.8: Savings window - Replace existing option

As seen in the Figure 6.8, the savings obtained from a replace existing option can be seen. This example show in the Figure 6.7 and Figure 6.8 is for replacing an existing standard efficiency motor with an energy efficient motor of the same size. The motor shown in the example is a $100 \mathrm{hp}$ motor. There are various parameters here in the replacement analysis, which affect the outcome or the payback period for the investment decision. The parameters are:

\footnotetext{
* Type of motor enclosure

Number of operating hours of the motor

* Efficiency of the existing standard efficiency motor
}

\subsubsection{Analysis for the replace existing option}

In this analysis following different scenarios are considered and the Motor Master is run for each scenario to get an insight into various situations, which affect the decisionmaking and also the payback period. These different scenarios are as mentioned below: 
* Replace existing standard efficiency motor with a same size energy efficient motor for different enclosure types for the motor - this analysis will show the impact of the enclosure type on the replacement analysis.

* Replace existing standard efficiency motor with a same size energy efficient motor for different number of hours in operation - this analysis which is performed for 2 shift operating hours and 3 shift operating hours, shows the impact of the operating hours on the payback of the investment.

* Replace existing standard efficiency motor with a same size energy efficient motor for different values of current standard efficiencies - this analysis shows the impact of efficiency of the existing standard motor on the replacement decision.

* Replace existing standard efficiency motor with a smaller size energy efficient motor (downsizing) - this analysis is also performed for different values for efficiency of the existing standard motors.

\subsubsection{Analysis to measure the impact of the enclosure type of the motor}

Many type of motor enclosures are available. Some of them are open, open drip proof (ODP), guarded, splash proof, totally enclosed non-ventilated (TENV), totally enclosed fan cooled (TEFC), explosion proof, etc. The enclosure types, which really affect the decisionmaking in terms of payback and energy saved, are the TEFC and the ODP enclosures. So this analysis is performed for these two types of enclosures assuming a three-shift operation and a load factor of 0.8 in both the cases. The analysis is performed and the results are as seen in the Table 6.3 and Table 6.4. It is evident from the analysis that the TEFC enclosure motors are expensive as compared to the ODP type. So consequently the payback for the TEFC enclosure option is higher than the ODP option. Also it can be seen that the efficiency of the ODP type enclosure is a little better than the TEFC type enclosures for the motors. The Figure 6.9 shows the plot for such an analysis and it is clear from this plot that the user should opt for the TEFC enclosure only if the process demands it. Unnecessary use of TEFC enclosure will result in higher paybacks and also loss of some efficiency. The ODP type of enclosure should be given preference over the TEFC type of course depending on the process requirements. 


TEFC Enclosure 1200 rpm
\begin{tabular}{|c|c|c|c|c|c|c|c|c|c|c|c|}
\hline \multicolumn{3}{|c|}{ Existing } & \multicolumn{6}{c|}{$\mathbf{2 5 \%}$ Dealer Discount } & \multicolumn{3}{c|}{12 months peak } \\
\hline hp & Hours & $\begin{array}{c}\text { Load } \\
\text { factor }\end{array}$ & Eff. & hp & Hours & $\begin{array}{c}\text { Load } \\
\text { factor }\end{array}$ & Eff & $\begin{array}{c}\text { Investment + } \\
\text { Installation }\end{array}$ & $\begin{array}{c}\text { Energy } \\
\text { sav. }\end{array}$ & $\begin{array}{c}\text { Dem } \\
\text { sav. }\end{array}$ & $\begin{array}{c}\text { Pay } \\
\text { back }\end{array}$ \\
\hline 7.5 & 8,760 & 0.8 & 84.5 & 7.5 & 8,760 & 0.8 & 90.5 & 1,087 & 86 & 40 & 8.63 \\
\hline 10 & 8,760 & 0.8 & 85.7 & 10 & 8,760 & 0.8 & 90.9 & 1,289 & 97 & 45 & 9.09 \\
\hline 15 & 8,760 & 0.8 & 87.2 & 15 & 8,760 & 0.8 & 91.5 & 1,689 & 120 & 56 & 9.58 \\
\hline 20 & 8,760 & 0.8 & 88.6 & 20 & 8,760 & 0.8 & 91.8 & 1,983 & 116 & 53 & 11.72 \\
\hline 25 & 8,760 & 0.8 & 89.4 & 25 & 8,760 & 0.8 & 92.8 & 2,381 & 150 & 69 & 10.84 \\
\hline 30 & 8,760 & 0.8 & 90.2 & 30 & 8,760 & 0.8 & 93 & 2,760 & 145 & 67 & 13.01 \\
\hline 40 & 8,760 & 0.8 & 90.3 & 40 & 8,760 & 0.8 & 93.8 & 3,684 & 243 & 113 & 10.35 \\
\hline 50 & 8,760 & 0.8 & 91.1 & 50 & 8,760 & 0.8 & 93.9 & 4,275 & 236 & 109 & 12.37 \\
\hline 60 & 8,760 & 0.8 & 91.0 & 60 & 8,760 & 0.8 & 94.3 & 5,068 & 341 & 158 & 10.14 \\
\hline 75 & 8,760 & 0.8 & 91.6 & 75 & 8,760 & 0.8 & 94.4 & 5,893 & 351 & 162 & 11.49 \\
\hline 100 & 8,760 & 0.8 & 91.6 & 100 & 8,760 & 0.8 & 94.8 & 7,716 & 543 & 251 & 9.71 \\
\hline 125 & 8,760 & 0.8 & 92.1 & 125 & 8,760 & 0.8 & 94.9 & 9,314 & 605 & 280 & 10.52 \\
\hline 150 & 8,760 & 0.8 & 93.3 & 150 & 8,760 & 0.8 & 95.5 & 10,555 & 556 & 257 & 12.97 \\
\hline 200 & 8,760 & 0.8 & 93.0 & 200 & 8,760 & 0.8 & 95.4 & 12,518 & 782 & 361 & 10.94 \\
\hline
\end{tabular}

Table 6.3: Analysis for TEFC enclosure type for motors

ODP Enclosure
\begin{tabular}{|c|c|c|c|c|c|c|c|c|c|c|c|}
\hline \multicolumn{3}{|c|}{ Existing } & \multicolumn{5}{c|}{$\mathbf{2 5 \%}$ Dealer Discount } & \multicolumn{3}{c|}{12 months peak } \\
\hline hp & Hours & $\begin{array}{c}\text { Load } \\
\text { factor }\end{array}$ & Eff. & hp & Hours & $\begin{array}{c}\text { Load } \\
\text { factor }\end{array}$ & Eff. & $\begin{array}{c}\text { Investment + } \\
\text { Installation }\end{array}$ & $\begin{array}{c}\text { Energy } \\
\text { sav. }\end{array}$ & $\begin{array}{c}\text { Dem } \\
\text { sav. }\end{array}$ & $\begin{array}{c}\text { Pay } \\
\text { back }\end{array}$ \\
\hline 7.5 & 8,760 & 0.8 & 85.8 & 7.5 & 8760 & 0.8 & 90.1 & 711 & 62 & 29 & 7.81 \\
\hline 10 & 8,760 & 0.8 & 87.8 & 10 & 8760 & 0.8 & 91 & 845 & 59 & 27 & 9.74 \\
\hline 15 & 8,760 & 0.8 & 87.3 & 15 & 8760 & 0.8 & 91.8 & 1,061 & 123 & 57 & 5.9 \\
\hline 20 & 8,760 & 0.8 & 88.4 & 20 & 8760 & 0.8 & 92.4 & 1,293 & 145 & 67 & 6.1 \\
\hline 25 & 8,760 & 0.8 & 89.4 & 25 & 8760 & 0.8 & 92.9 & 1,561 & 153 & 71 & 6.95 \\
\hline 30 & 8,760 & 0.8 & 90.1 & 30 & 8760 & 0.8 & 93.4 & 1,747 & 174 & 81 & 6.85 \\
\hline 40 & 8,760 & 0.8 & 89.8 & 40 & 8760 & 0.8 & 93.9 & 2,488 & 282 & 130 & 6.04 \\
\hline 50 & 8,760 & 0.8 & 89.3 & 50 & 8760 & 0.8 & 94 & 2,920 & 412 & 191 & 4.84 \\
\hline 60 & 8,760 & 0.8 & 91.3 & 60 & 8760 & 0.8 & 94.6 & 3,468 & 331 & 153 & 7.15 \\
\hline 75 & 8,760 & 0.8 & 91.7 & 75 & 8760 & 0.8 & 94.7 & 3,995 & 374 & 173 & 7.29 \\
\hline 100 & 8,760 & 0.8 & 92.5 & 100 & 8760 & 0.8 & 94.8 & 4,779 & 379 & 175 & 8.62 \\
\hline 125 & 8,760 & 0.8 & 92.4 & 125 & 8760 & 0.8 & 95 & 5,645 & 531 & 245 & 7.27 \\
\hline 150 & 8,760 & 0.8 & 93 & 150 & 8760 & 0.8 & 95.2 & 6,427 & 554 & 256 & 7.92 \\
\hline 200 & 8,760 & 0.8 & 93.1 & 200 & 8760 & 0.8 & 95.4 & 8,470 & 749 & 346 & 7.73 \\
\hline
\end{tabular}

Table 6.4: Analysis for ODP enclosure type for motors 


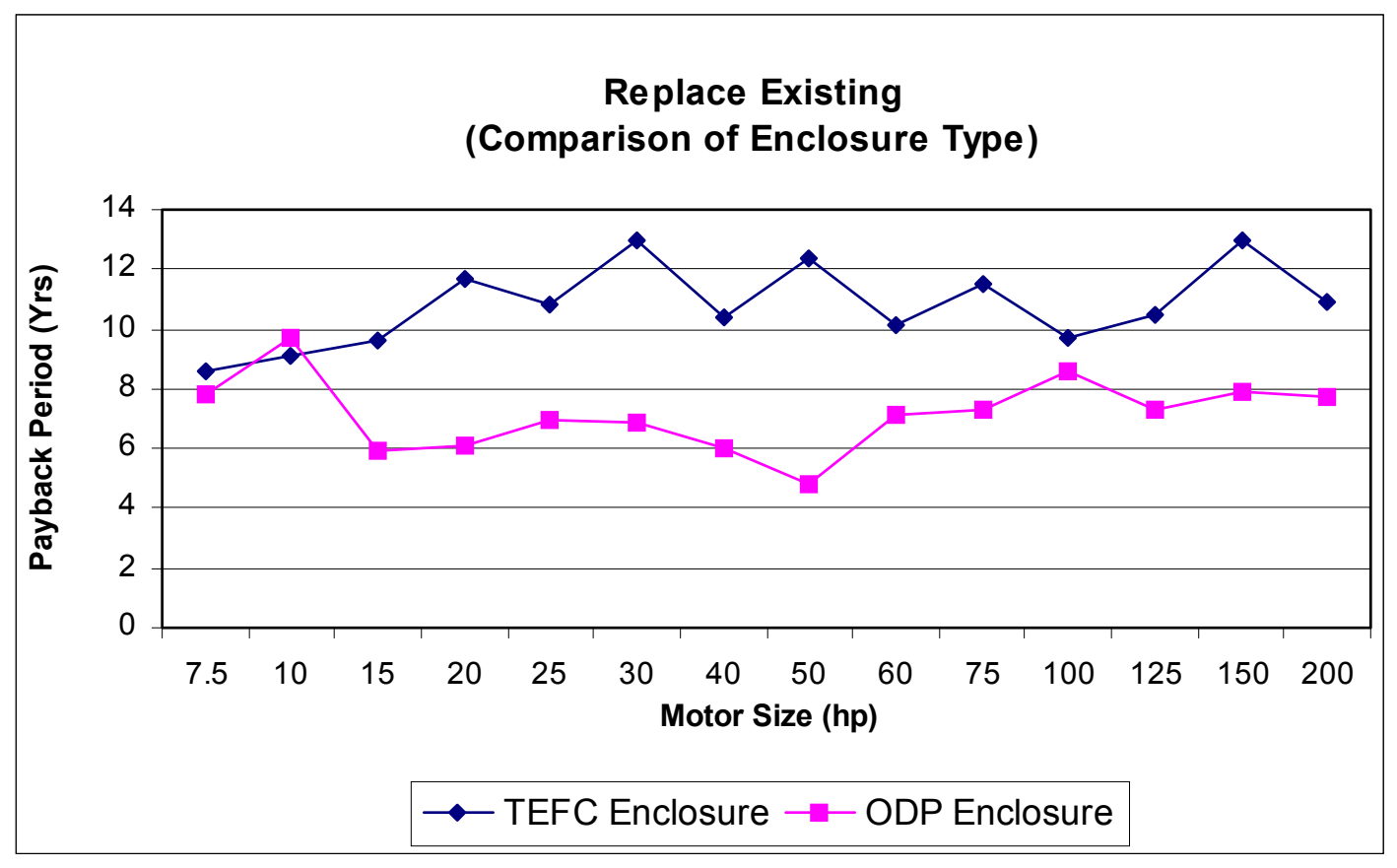

Figure 6.9: Comparison for the TEFC and ODP enclosure type

\subsubsection{Analysis to measure the impact of the operating hours of the motor}

The annual number of operating hours of the motor affects the replacement decision. This analysis is performed for 2 shift and 3 shift operations of the plant, assuming that the motors run continuously during the shift. This analysis is performed assuming the enclosure type as TEFC and a load factor of 0.8 . The results for the 3 -shift operation, i.e. 8,760 hours are same as that can be seen in the Table 6.3. The results for the 2 - shift operation can be seen in the Table 6.5 below. The analysis obviously suggests that the payback period for the 2-shift operation is definitely bigger than the 3-shift operation. The payback period reduces around 2 to 3 years for each motor size when the annual operating hours increase to 8,760 hours. The Figure 6.10 plots the results and shows the comparative payback periods obtained for the 2 shift and the 3 shift operations. This analysis gives an insight that in an energy management program, first priority should be given to those motors, which run for more number of annual operating hours. Actions on such motors will give attractive payback periods and quicker energy savings. 
TEFC Enclosure

25\% Dealer Discount 12 months peak

\begin{tabular}{|c|c|c|c|c|c|c|c|c|c|c|c|}
\hline \multicolumn{4}{|c|}{ Existing } & \multicolumn{9}{c|}{ Proposed } & \multicolumn{3}{c|}{ Analysis } \\
\hline hp & Hours & $\begin{array}{c}\text { Load } \\
\text { factor }\end{array}$ & Eff & hp & Hours & $\begin{array}{c}\text { Load } \\
\text { factor }\end{array}$ & Eff & $\begin{array}{c}\text { Investment }+ \\
\text { Installation }\end{array}$ & $\begin{array}{c}\text { Energy } \\
\text { sav }\end{array}$ & $\begin{array}{c}\text { Dem } \\
\text { sav }\end{array}$ & $\begin{array}{c}\text { Pay } \\
\text { back }\end{array}$ \\
\hline 7.5 & 5,840 & 0.8 & 84.5 & 7.5 & 5,840 & 0.8 & 90.5 & 1,087 & 57 & 40 & 11.17 \\
\hline 10 & 5,840 & 0.8 & 85.7 & 10 & 5,840 & 0.8 & 90.9 & 1,289 & 65 & 45 & 11.78 \\
\hline 15 & 5,840 & 0.8 & 87.2 & 15 & 5,840 & 0.8 & 91.5 & 1,689 & 80 & 56 & 12.42 \\
\hline 20 & 5,840 & 0.8 & 88.6 & 20 & 5,840 & 0.8 & 91.8 & 1,983 & 77 & 53 & 15.18 \\
\hline 25 & 5,840 & 0.8 & 89.4 & 25 & 5,840 & 0.8 & 92.8 & 2,381 & 100 & 69 & 14.04 \\
\hline 30 & 5,840 & 0.8 & 90.2 & 30 & 5,840 & 0.8 & 93 & 2,760 & 97 & 67 & 16.85 \\
\hline 40 & 5,840 & 0.8 & 90.3 & 40 & 5,840 & 0.8 & 93.8 & 3,684 & 162 & 113 & 13.4 \\
\hline 50 & 5,840 & 0.8 & 91.1 & 50 & 5,840 & 0.8 & 93.9 & 4,275 & 157 & 109 & 16.03 \\
\hline 60 & 5,840 & 0.8 & 91.0 & 60 & 5,840 & 0.8 & 94.3 & 5,068 & 228 & 158 & 13.14 \\
\hline 75 & 5,840 & 0.8 & 91.6 & 75 & 5,840 & 0.8 & 94.4 & 5,893 & 234 & 162 & 14.88 \\
\hline 100 & 5,840 & 0.8 & 91.6 & 100 & 5,840 & 0.8 & 94.8 & 7,716 & 362 & 251 & 12.57 \\
\hline 125 & 5,840 & 0.8 & 92.1 & 125 & 5,840 & 0.8 & 94.9 & 9,314 & 403 & 280 & 13.63 \\
\hline 150 & 5,840 & 0.8 & 93.3 & 150 & 5,840 & 0.8 & 95.5 & 10,555 & 371 & 257 & 16.8 \\
\hline 200 & 5,840 & 0.8 & 93.0 & 200 & 5,840 & 0.8 & 95.4 & 12,518 & 521 & 361 & 14.18 \\
\hline
\end{tabular}

Table 6.5: Replacement analysis for a two-shift operation

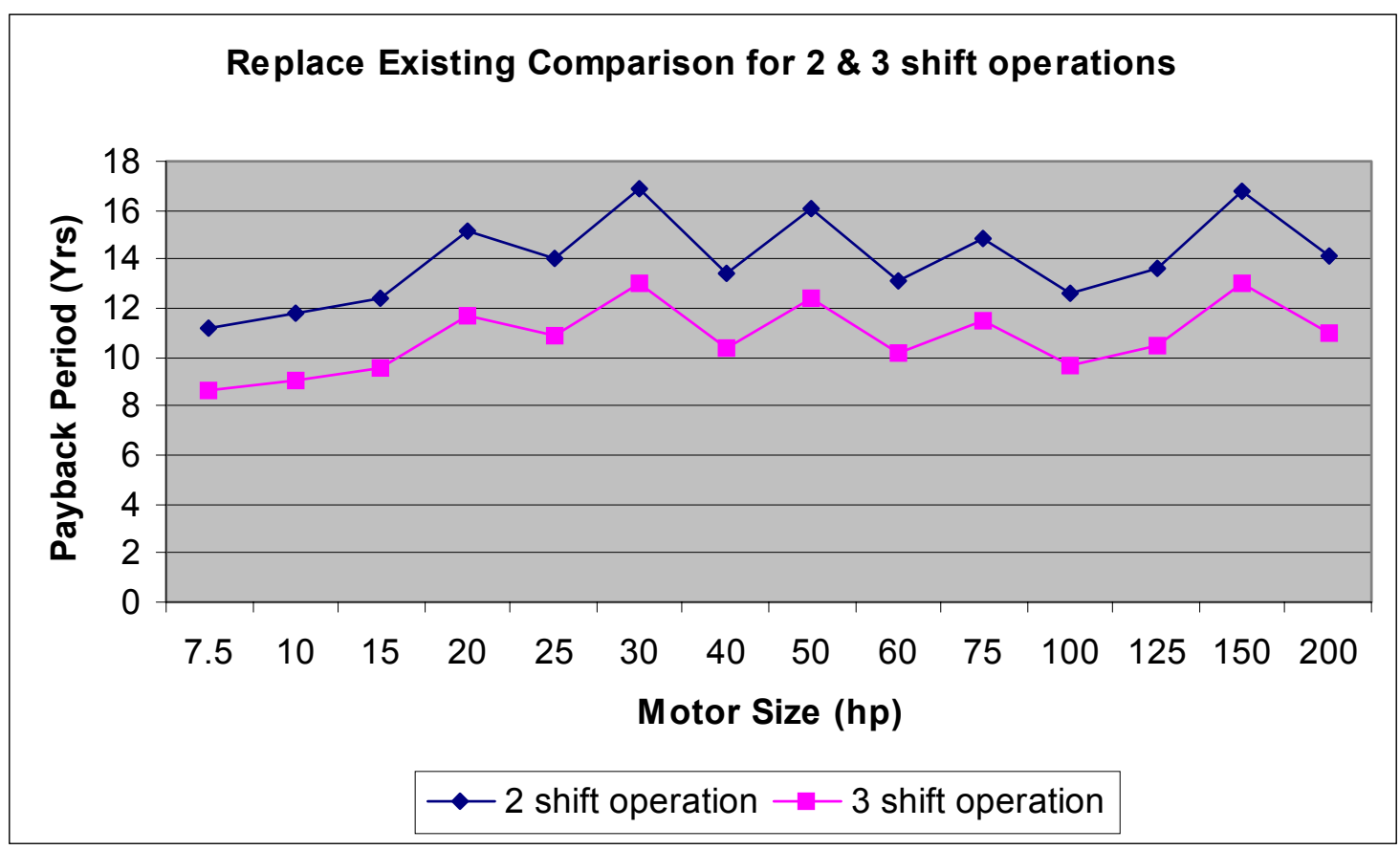

Figure 6.10: Analysis for comparing different annual operating hours 


\subsubsection{Analysis to measure the impact of the existing efficiency of the standard motor}

The Motor Master database provides the efficiency values of the standard efficiency motors at various loads. These efficiency values are obtained from the data obtained from many experiments on various sizes of the motors. In reality it is found during the assessments that most of the existing motors are very old, some may be even 20 years old. The efficiency of the existing motors decreases over their lifetime due to rewinding and also due to failures and maintenance in between. The parts of the motor wear out and reduce the efficiency over a longer period. This analysis takes this fact into consideration. It is assumed during the analysis that the motors are of TEFC enclosure type and the load factor is assumed to be 0.8 . The analysis is performed for a three-shift operation. As can be seen in the Table 6.6, the analysis is performed for the existing standard efficiency motors with a reduction in efficiency over the standard values available in Motor Master of about $3 \%$. This decrease in efficiency by $3 \%$ has a substantial impact on the motor replacement decision.

The Table 6.7 shows an analysis for the existing standard motor replacement with standard efficiency values $5 \%$ less than that what are obtained from the Motor Master database. The Figure 6.11 shows the comparison for all the three scenarios. The existing values in the Motor Master and then with $3 \%$ and $5 \%$ reduction in the standard efficiency values of the existing motors. It can be seen from the plot that the payback period decreases considerably when the existing efficiency decreases by $3 \%$ and $5 \%$. It is seen that for the 3 $\%$ decrease, the payback period reduces by around 3 years for the lower size motors and up to 6 years for the higher size motors. For the $5 \%$ decrease in standard efficiency, the payback period reduces by around 4 years for the lower size motors and up to 7 years for the higher size motors.

This analysis gives some very crucial insights into the replacement decision. It proves the efficiency of the existing motors plays a very important role in the decision making process. Older and long used motors, which are already subject to many rewinding and other maintenance operations, should be attacked first and given high priority over the other motors in the plant. Also when making a replacement decision, the older but higher sized motors should be given higher priority over the smaller sized motors, as they will payback faster if they are replaced with energy efficient motors of the same size. 
TEFC Enclosure

$25 \%$ Dealer Discount 12 months peak

\begin{tabular}{|c|c|c|c|c|c|c|c|c|c|c|c|c|}
\hline \multicolumn{4}{|c|}{ Existing } & & \multicolumn{4}{c|}{ Proposed } & \multicolumn{3}{|c|}{ Analysis } \\
\hline hp & Hours & $\begin{array}{c}\text { Load } \\
\text { factor }\end{array}$ & Eff & Eff & hp & Hours & $\begin{array}{c}\text { Load } \\
\text { factor }\end{array}$ & Eff & $\begin{array}{c}\text { Investment + } \\
\text { Installation }\end{array}$ & $\begin{array}{c}\text { Energy } \\
\text { sav }\end{array}$ & $\begin{array}{c}\text { Dem } \\
\text { sav }\end{array}$ & $\begin{array}{c}\text { Pay } \\
\text { back }\end{array}$ \\
\hline 7.5 & 8,760 & 0.8 & 84.5 & 81.5 & 7.5 & 8,760 & 0.8 & 90.5 & 1,087 & 134 & 62 & 5.54 \\
\hline 10 & 8,760 & 0.8 & 85.7 & 82.7 & 10 & 8,760 & 0.8 & 90.9 & 1,289 & 159 & 73 & 5.54 \\
\hline 15 & 8,760 & 0.8 & 87.2 & 84.2 & 15 & 8,760 & 0.8 & 91.5 & 1,689 & 209 & 97 & 5.52 \\
\hline 20 & 8,760 & 0.8 & 88.6 & 85.6 & 20 & 8,760 & 0.8 & 91.8 & 1,983 & 230 & 106 & 5.9 \\
\hline 25 & 8,760 & 0.8 & 89.4 & 86.4 & 25 & 8,760 & 0.8 & 92.8 & 2,381 & 293 & 135 & 5.56 \\
\hline 30 & 8,760 & 0.8 & 90.2 & 87.2 & 30 & 8,760 & 0.8 & 93 & 2,760 & 312 & 144 & 6.04 \\
\hline 40 & 8,760 & 0.8 & 90.3 & 87.3 & 40 & 8,760 & 0.8 & 93.8 & 3,684 & 466 & 215 & 5.41 \\
\hline 50 & 8,760 & 0.8 & 91.1 & 88.1 & 50 & 8,760 & 0.8 & 93.9 & 4,275 & 510 & 236 & 5.73 \\
\hline 60 & 8,760 & 0.8 & 91.0 & 88.0 & 60 & 8,760 & 0.8 & 94.3 & 5,068 & 668 & 309 & 5.19 \\
\hline 75 & 8,760 & 0.8 & 91.6 & 88.6 & 75 & 8,760 & 0.8 & 94.4 & 5,893 & 761 & 352 & 5.29 \\
\hline 100 & 8,760 & 0.8 & 91.6 & 88.6 & 100 & 8,760 & 0.8 & 94.8 & 7,716 & 1081 & 500 & 4.88 \\
\hline 125 & 8,760 & 0.8 & 92.1 & 89.1 & 125 & 8,760 & 0.8 & 94.9 & 9,314 & 1264 & 584 & 5.04 \\
\hline 150 & 8,760 & 0.8 & 93.3 & 90.3 & 150 & 8,760 & 0.8 & 95.5 & 10,555 & 1333 & 616 & 5.41 \\
\hline 200 & 8,760 & 0.8 & 93.0 & 90.0 & 200 & 8,760 & 0.8 & 95.4 & 12,518 & 1848 & 854 & 4.63 \\
\hline
\end{tabular}

Table 6.6: Analysis with $3 \%$ reduction in standard efficiency of the existing motors

TEFC Enclosure

$25 \%$ Dealer Discount 12 months peak

\begin{tabular}{|c|c|c|c|c|c|c|c|c|c|c|c|c|}
\hline \multicolumn{4}{|c|}{ Existing } & & \multicolumn{4}{c|}{ Proposed } & \multicolumn{3}{c|}{ Analysis } \\
\hline hp & Hours & $\begin{array}{c}\text { Load } \\
\text { factor }\end{array}$ & Eff & Eff & hp & Hours & $\begin{array}{c}\text { Load } \\
\text { factor }\end{array}$ & Eff & $\begin{array}{c}\text { Investment + } \\
\text { Installation }\end{array}$ & $\begin{array}{c}\text { Energy } \\
\text { sav }\end{array}$ & $\begin{array}{c}\text { Dem } \\
\text { sav }\end{array}$ & $\begin{array}{c}\text { Pay } \\
\text { back }\end{array}$ \\
\hline 7.5 & 8,760 & 0.8 & 84.5 & 79.5 & 7.5 & 8,760 & 0.8 & 90.5 & 1,087 & 168 & 78 & 4.42 \\
\hline 10 & 8,760 & 0.8 & 85.7 & 80.7 & 10 & 8,760 & 0.8 & 90.9 & 1,289 & 203 & 94 & 4.34 \\
\hline 15 & 8,760 & 0.8 & 87.2 & 82.2 & 15 & 8,760 & 0.8 & 91.5 & 1,689 & 272 & 126 & 4.24 \\
\hline 20 & 8,760 & 0.8 & 88.6 & 83.6 & 20 & 8,760 & 0.8 & 91.8 & 1,983 & 312 & 144 & 4.35 \\
\hline 25 & 8,760 & 0.8 & 89.4 & 84.4 & 25 & 8,760 & 0.8 & 92.8 & 2,381 & 393 & 182 & 4.14 \\
\hline 30 & 8,760 & 0.8 & 90.2 & 85.2 & 30 & 8,760 & 0.8 & 93 & 2,760 & 430 & 199 & 4.38 \\
\hline 40 & 8,760 & 0.8 & 90.3 & 85.3 & 40 & 8,760 & 0.8 & 93.8 & 3,684 & 623 & 288 & 4.04 \\
\hline 50 & 8,760 & 0.8 & 91.1 & 86.1 & 50 & 8,760 & 0.8 & 93.9 & 4,275 & 703 & 325 & 4.15 \\
\hline 60 & 8,760 & 0.8 & 91.0 & 86.0 & 60 & 8,760 & 0.8 & 94.3 & 5,068 & 900 & 416 & 3.85 \\
\hline 75 & 8,760 & 0.8 & 91.6 & 86.6 & 75 & 8,760 & 0.8 & 94.4 & 5,893 & 1048 & 484 & 3.84 \\
\hline 100 & 8,760 & 0.8 & 91.6 & 86.6 & 100 & 8,760 & 0.8 & 94.8 & 7,716 & 1462 & 676 & 3.6 \\
\hline 125 & 8,760 & 0.8 & 92.1 & 87.1 & 125 & 8,760 & 0.8 & 94.9 & 9,314 & 1735 & 802 & 3.67 \\
\hline 150 & 8,760 & 0.8 & 93.3 & 88.3 & 150 & 8,760 & 0.8 & 95.5 & 10,555 & 1883 & 871 & 3.83 \\
\hline 200 & 8,760 & 0.8 & 93.0 & 88.0 & 200 & 8,760 & 0.8 & 95.4 & 12,518 & 2587 & 1196 & 3.3 \\
\hline
\end{tabular}

Table 6.7: Analysis with $5 \%$ reduction in standard efficiency of the existing motors 


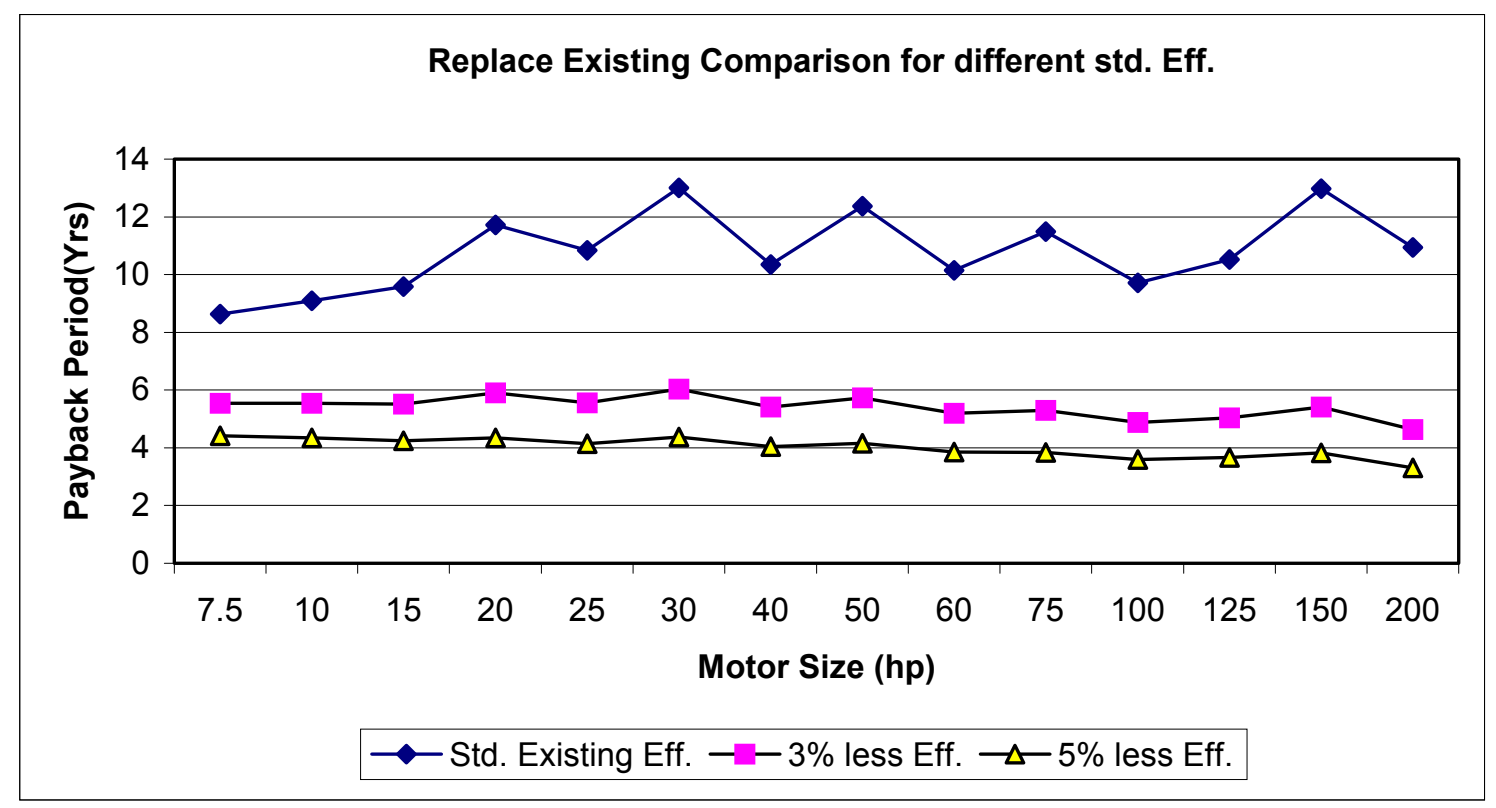

Figure 6.11: Comparison of different existing standard efficiencies

\subsubsection{Analysis for downsizing the existing motors to their appropriate required size}

This analyzes the cost effectiveness of replacing an operable standard efficiency motor with a new energy efficiency motor of smaller size. This analysis is used when there is an opportunity for downsizing that particular existing standard motor. The compare module in Motor Master is used again for the analysis, except that the value of the energy efficient motor is changed to the appropriate rating. The extent to which downsizing is required depends on the existing load conditions and also the process requirements in future. The savings are calculated on the basis of which energy efficient motor is selected for down sizing. This analysis is also performed for two values of efficiency for the existing motors. First scenario is with the default values of efficiency obtained from Motor Master and the other scenario is assuming $3 \%$ reduction in efficiency of the existing motors.

As can be seen in the Table 6.8, the analysis is performed for all the motors with a TEFC enclosure and 3-shift operation. The load factor of the existing motors which are considered for downsizing is assumed to be 0.4 , as the load - efficiency curves show a steep dissent in efficiency below $40 \%$ load. It can be seen from the Table 6.8 , that the payback period has definitely improved because of downsizing the motors to their appropriate size as compared to replacing existing motors with the same size energy efficient motors. Table 6.9 
shows the analysis for downsizing with $3 \%$ decrease in the standard efficiency of the existing motors. As earlier the impact of decreased efficiency of the existing motors can be reflected in the payback periods. The payback periods reduce by around 3 to 4 years for different sizes of the motors due to the decrease in efficiency. This fact is also seen in the plot drawn in the Figure 6.12 below. Thus it can be said that downsizing motors to their appropriate size definitely is a better option and it also improves the power factor of the motors. Another thing is that the older lower efficiency existing motors should be given higher priority over new ones when replacement decisions are to be considered. The downsizing decision should be carefully taken. The possible candidate motor should be subject to continuous load test and at different time intervals to make sure that the motor is over sized for the application. While selecting an energy efficient motor for downsizing, care should be taken with regards to the speed of the motor and the torque requirements.

\begin{tabular}{|c|c|c|c|c|c|c|c|c|c|c|c|}
\hline \multicolumn{3}{|c|}{ TEFC Enclosure } & \multicolumn{3}{|c|}{$1200 \mathrm{rpm}$} & \multicolumn{3}{|c|}{ 25\% Dealer Discount } & \multicolumn{3}{|c|}{12 months peak } \\
\hline \multicolumn{4}{|c|}{ Existing } & \multicolumn{5}{|c|}{ Proposed } & \multicolumn{3}{|c|}{ Analysis } \\
\hline $\mathrm{hp}$ & Hours & $\begin{array}{l}\text { Load } \\
\text { factor }\end{array}$ & Eff & hp & Hours & $\begin{array}{l}\text { Load } \\
\text { factor }\end{array}$ & Eff & $\begin{array}{c}\text { Investment + } \\
\text { Installation }\end{array}$ & $\begin{array}{c}\text { Energy } \\
\text { sav }\end{array}$ & $\begin{array}{l}\text { Dem } \\
\text { sav }\end{array}$ & $\begin{array}{l}\text { Pay } \\
\text { back }\end{array}$ \\
\hline 15 & 8,760 & 0.4 & 83.5 & 7.5 & 8,760 & 0.8 & 90.5 & 1,087 & 102 & 47 & 7.27 \\
\hline 20 & 8,760 & 0.4 & 86.3 & 10 & 8,760 & 0.8 & 90.9 & 1,289 & 85 & 39 & 10.42 \\
\hline 25 & 8,760 & 0.4 & 85.6 & 15 & 8,760 & 0.67 & 91.5 & 1,689 & 138 & 64 & 8.38 \\
\hline 30 & 8,760 & 0.4 & 86.9 & 15 & 8,760 & 0.8 & 91.5 & 1,689 & 129 & 59 & 8.97 \\
\hline 40 & 8,760 & 0.4 & 87.0 & 20 & 8,760 & 0.8 & 91.8 & 1,983 & 176 & 81 & 7.7 \\
\hline 50 & 8,760 & 0.4 & 88.7 & 25 & 8,760 & 0.8 & 92.8 & 2,381 & 184 & 85 & 8.85 \\
\hline 60 & 8,760 & 0.4 & 87.4 & 30 & 8,760 & 0.8 & 93 & 2,760 & 302 & 140 & 6.24 \\
\hline 75 & 8,760 & 0.4 & 89.0 & 40 & 8,760 & 0.75 & 93.9 & 3,684 & 318 & 147 & 7.91 \\
\hline 100 & 8,760 & 0.4 & 88.2 & 50 & 8,760 & 0.8 & 93.9 & 4,275 & 504 & 233 & 5.8 \\
\hline 125 & 8,760 & 0.4 & 89.5 & 60 & 8,760 & 0.83 & 94.3 & 5,068 & 514 & 238 & 6.73 \\
\hline 150 & 8,760 & 0.4 & 91.9 & 75 & 8,760 & 0.8 & 94.4 & 5,839 & 317 & 147 & 12.69 \\
\hline 200 & 8,760 & 0.4 & 90.9 & 100 & 8,760 & 0.8 & 94.8 & 7,716 & 671 & 310 & 7.85 \\
\hline
\end{tabular}

Table 6.8: Downsizing analysis for default efficiency values for existing motors 


\begin{tabular}{|c|c|c|c|c|c|c|c|c|c|c|c|}
\hline \multirow{2}{*}{\multicolumn{4}{|c|}{$\begin{array}{c}\text { TEFC Enclosure } 1200 \mathrm{rp} \\
\text { Existing }\end{array}$}} & \multirow{2}{*}{\multicolumn{5}{|c|}{$\frac{25 \% \text { Dealer Discount }}{\text { Proposed }}$}} & \multicolumn{3}{|c|}{12 months peak } \\
\hline & & & & & & & & & & alysis & \\
\hline hp & Hours & $\begin{array}{l}\text { Load } \\
\text { factor }\end{array}$ & Eff & hp & Hours & $\begin{array}{l}\text { Load } \\
\text { factor }\end{array}$ & Eff & $\begin{array}{c}\text { Investment + } \\
\text { Installation }\end{array}$ & $\begin{array}{l}\text { Energy } \\
\text { sav }\end{array}$ & $\begin{array}{l}\text { Dem } \\
\text { sav }\end{array}$ & $\begin{array}{l}\text { Pay } \\
\text { back }\end{array}$ \\
\hline 15 & 8.760 & 0.4 & 80.5 & 7.5 & 760 & 0.8 & 90.5 & 37 & 151 & 70 & 4.92 \\
\hline 20 & 8,760 & 0.4 & 83.3 & 10 & 8,760 & 0.8 & 90.9 & 289 & 146 & 68 & 6.03 \\
\hline 25 & 8,760 & 0.4 & 82.6 & 15 & 8,760 & 0.67 & 91.5 & 689 & 215 & 100 & 5.36 \\
\hline 30 & 8,760 & 0.4 & 83.9 & 15 & 8,760 & 0.8 & 91.5 & & 218 & 101 & 5.29 \\
\hline 40 & 8,760 & 0.4 & 84.0 & 20 & 8,760 & 0.8 & 91.8 & 1,983 & 295 & 136 & 4.59 \\
\hline 50 & 8,760 & 0.4 & 85.7 & 25 & 8,760 & 0.8 & 92.8 & 2,38 & 327 & 151 & 4.97 \\
\hline 60 & 8,760 & 0.4 & 84.4 & 30 & 8,760 & 0.8 & 93 & 2,760 & 479 & 222 & 3.93 \\
\hline 75 & 8,760 & 0.4 & 86.0 & 40 & 8,760 & 0.75 & 93.9 & 3,684 & 534 & 247 & 4.71 \\
\hline 100 & 8,760 & 0.4 & 85.2 & 50 & 8,760 & 0.8 & 93.9 & 4,275 & 793 & 366 & 3.68 \\
\hline 125 & 8,760 & 0.4 & 86.5 & 60 & 8,760 & 0.83 & 94.3 & 5,068 & 872 & 403 & 3.97 \\
\hline 150 & 8,760 & 0.4 & 88.9 & 75 & 8,760 & 0.8 & 94.4 & 5,839 & 720 & 333 & 5.6 \\
\hline 200 & 8,760 & 0.4 & 87.9 & 100 & 8,760 & 0.8 & 94.8 & 7,716 & 1212 & 560 & 4.35 \\
\hline
\end{tabular}

Table 6.9: Downsizing analysis for 3\% reduced efficiency values for existing motors

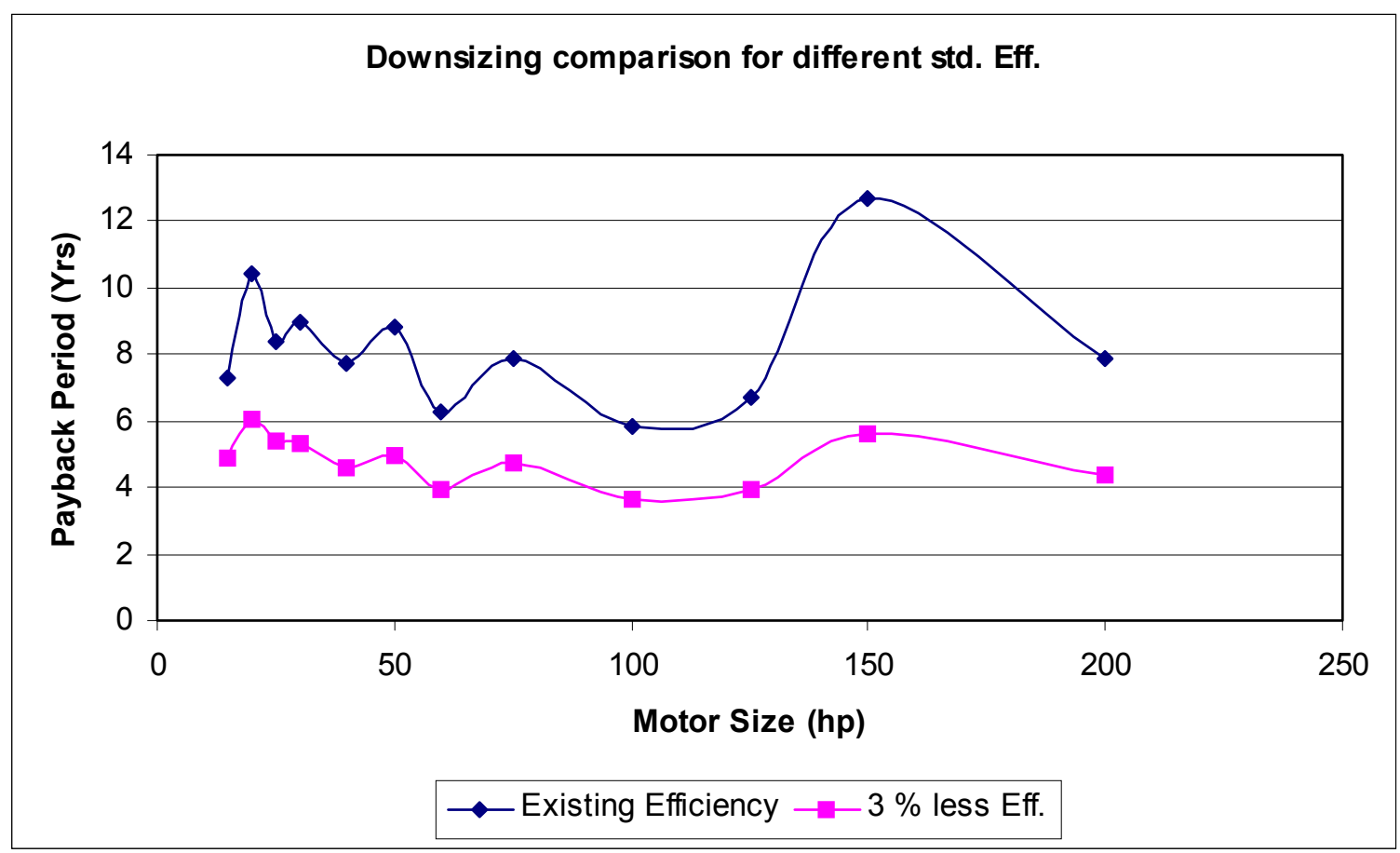

Figure 6.12: Comparison for different values of efficiency for downsizing 


\subsection{Conclusions}

This chapter gives a good insight into the various parameters in the motor replacement decision-making process. It discusses the various possibilities with new motor purchase decisions. The comparison for rewinding and new motor purchase decision is also discussed. In the replacement analysis, various parameters like annual operating hours, motor enclosure types and efficiency of the existing standard motors are subject to a sensitivity analysis and their impact on the payback period and replacement decision are made. Thus after enough load testing of the motors in the plant, the user can use the compare module of the Motor Master and run different scenarios and come to a wise decision on replacing the existing standard motor.

Another field of interest connected to the proper working of the motor systems is the drive belts on these systems. There are losses encountered during transmission of the power from the motor shaft to the other parts in the system due to use of belts and pulleys. Next chapter discusses the use of energy efficient belts in motor transmission systems. 


\section{Chapter 7}

\section{Replace Drive Belts On Large Motors with Energy Efficient Cog Belts}

Efficient belt drive systems along with appropriately sized energy efficient motors make a motor system really efficient. Only having energy efficient motors in the plant will not help if the belt drive systems used to transfer power are not efficient. $\mathrm{V}$ belts have been traditionally used for power transmission. But recent developments in the field of belt transmission have given rise to many efficient belt drives, which are very energy efficient when compared to the standard available belts. This chapter discusses the use of these cog belt drives in the wood manufacturing industry and also includes a sensitivity analysis on the crucial parameters of the energy savings equation which affect the energy savings.

\subsection{Introduction to cog belt drives}

In addition to internal inefficiencies in electric motors, which cause energy loss, the power available at the drive shaft of the motor cannot be transmitted to a machine through a belt without some additional energy losses. These losses come in the form of slippage, energy used to flex the belt as it goes around pulleys, and stretching and compression of the belt. A recent study has shown that V belts have a maximum efficiency of about $94 \%$. This means that $94 \%$ of the energy transferred to the drive shaft of the electric motor is transferred to the machinery performing the useful industrial task [41].

There are two readily available means to reduce the losses. One is to replace the belts with energy efficient cog belts. These belts slip less and can bend more easily that standard V belts. The other method is to use belts with teeth and also replace the pulleys with ones that have sprocket grooves (essentially installing a " timing chain"), which is referred to in industry as a high torque drive belt (HTD). In both cases, the belt can bend with less loss of energy and need not be stretched as tightly as the standard $\mathrm{V}$ belt, which in turn prolongs belt life. The cog belts also reduce slippage. Following are the factors, which affect the efficiency of a $\mathrm{V}$ belt or for that matter any power transmission belt [41]. 


\subsubsection{Friction}

The transfer of power in a belt drive relies critically on friction. The tensions in the two strands (the nominally straight parts of the belt not in contact with the pulleys) cause a normal pressure over the belt- pulley contact, and it is the corresponding distributed friction whose moment about the pulley centre equilibrates the shaft torque provided gross slip of the belt on the pulley surface does not occur due to friction breakaway. Ideally, for belts, the torque amplification ratio is equal to the radius ratio, so that the output power equals the input power and the efficiency is $100 \%$. However sliding friction results in a torque ratio which is less than ideal. A real belt drive is just the opposite - the torque ratio equals the ideal ratio, but creep results in the speed ratio being less than ideal. Creep - not to be confused with gross slip - is due to belt elements changing length as they travel between the maximum and the minimum tensions, and since the pulley is rigid then there must be relative motion between belt element and pulley. Since power equals the product of torque and (angular) speed, the consequence of the foregoing is that efficiency of belts is less than $100 \%$.

\subsubsection{Sheave Diameter}

While a sheave change may not be possible, in general, the larger the sheave, the greater the drive efficiency. The $\mathrm{V}$ belt is subjected to large compression stresses when confirming to sheave diameter. The cog belt has less material in the compression section of the belt, thereby minimizing rubber deformation and compression stresses. The result is higher operating efficiency for the cog belt.

\subsection{Advantages of cogged $\mathrm{V}$ belts over conventional $\mathrm{V}$ belts}

- They are more energy efficient as compared to conventional belts. (up to 6\% more efficient than conventional belts)

a Cogged belts bend more easily as compared to the conventional belts.

- As the cogged belts have slots perpendicular to the belt length, they exhibit reduced friction losses.

a Cogged belts run cooler as compared to conventional belts because of their lower energy absorption.

a Cogged belts last 20 to $30 \%$ longer than conventional V belts. 
- They reduce power transmission losses.

․ They reduce slippage.

\subsection{Current Practice and Observations in Wood Industry}

It is found in the audits so far, that most of the big size motors in Wood Industry in West Virginia use standard V belts. Almost every plant has an opportunity here to replace the existing $\mathrm{V}$ belts with energy efficient cog belt drives. Following is the example on the data and analysis for facility A. Currently, some of the belt motors are using standard V-belts to transmit power resulting in an unnecessary loss of energy. The list of all the big motors in facility A was obtained during the audit. The list can be seen in the Table 7.1 below.

\begin{tabular}{|c|c|}
\hline MILL MOTORS & hp \\
\hline Conveyor Motor & 7.5 \\
\hline Conveyor Motor & 10 \\
\hline Conveyor Motor & 15 \\
\hline Conveyor Motor & 15 \\
\hline Conveyor Motor & 7 \\
\hline Chipper Motor & 150 \\
\hline Compressor Motor & 40 \\
\hline Conveyor Motor & 3 \\
\hline Conveyor Motor & 55 \\
\hline Saw dust Motor & $10 \times 10$ \\
\hline Saw dust Motor & $15 \times 3$ \\
\hline Saw dust Motor & 75 \\
\hline Saw dust Motor & 15 \\
\hline Saw dust Motor & $15 \times 2$ \\
\hline Debarkers & 165 \\
\hline
\end{tabular}

Table 7.1: List of motors for facility $A$

\subsection{Recommended Action}

Replace standard wrapped V-belts with energy efficient cog belts on the respective drive systems. Only those motors with a horsepower rating of three or greater will be considered for belt replacement. Motors less than three horsepower provide inadequate payback justification 
and, hence, are not considered. The relevant data on the horsepower ratings for all the belt drive systems in the plants was collected and used for further analysis.

\subsection{Anticipated Savings}

Many studies in the literature have shown that a typically well-maintained industrial Vbelt is about $92 \%$ efficient. Field tests of cog belts for both large and small drives show gains in efficiency from $2.0 \%$ to $4.5 \%$. For our calculations, we will use the value of $4.0 \%$. We can calculate the yearly energy savings as shown in the following equation.

$$
\mathrm{ES}=\Sigma \mathrm{hp} / \eta \times \mathrm{LF} \times \mathrm{H} \times \mathrm{S}
$$

where:

$$
\begin{aligned}
& \text { ES = The anticipated energy savings (Btu/yr) } \\
& \text { Shp }=\text { The total horsepower for the large motors using standard V-belts in the } \\
& \text { plant. This is estimated to be } 981.5 \mathrm{hp} \text { based on the audit information acquired. } \\
& \eta \quad=\text { The average efficiencies of the motors } \\
& \mathrm{LF}=\text { The average load factor, assumed to be } 80 \% \text { based on industry averages. } \\
& \mathrm{H}=\text { The annual operating time calculated as } 90 \% \text { of the annual plant operating } \\
& \text { time. This is determined by }(0.9 \times 2340 \mathrm{hrs} / \mathrm{yr}=2106 \mathrm{hrs} / \mathrm{yr}) \text {. } \\
& \mathrm{S} \quad=\text { The estimated energy savings (taken here as } 4.0 \% \text { for cog belts) }
\end{aligned}
$$

Therefore for cog belts, energy savings are calculated as follows:

$$
\begin{aligned}
\mathrm{ES} & =(981.5 / 0.86) \times(2,545 \mathrm{Btu} / \mathrm{hp}) \times 0.8 \times 2106 \times 0.04 \\
& =195.74 \mathrm{MMBtu} / \mathrm{yr}
\end{aligned}
$$

The associated cost savings would be:

$$
\begin{aligned}
\text { Savings } & =195.74 \mathrm{MMBtu} / \mathrm{yr} \text { x } \$ 21.95 / \text { MMBtu } \\
& =\$ 4,296.58
\end{aligned}
$$




\subsection{Implementation \& Payback}

The installation of new cog belts could be carried out by maintenance personnel. The capital cost required would be about $\$ 25$ per drive. There are 52 belt drive systems, which should be changed. Therefore, the implementation cost would be:

$$
\begin{aligned}
\text { Implementation Cost } & =52 \times 25 \\
& =\$ 1,300
\end{aligned}
$$

Based on the above implementation cost of $\$ 1,300$ and energy cost savings of $\$ 4,296.58$, the simple payback period for this recommendation is four months.

\subsection{Sensitivity analysis for cog belt drives}

A sensitivity analysis of the savings achieved by replacing the conventional $\mathrm{V}$ belts with $\operatorname{cog} \mathrm{V}$ belt drives is done. The sensitivity is done with respect to two most important factors of the equation that affect the annual savings obtained. Other factors like the percent savings obtained are not considered for sensitivity analysis, as it is obvious that with increase in savings percentage the energy savings will increase. This sensitivity analysis is performed by varying only one important parameter in the equation and then the impact of that varied parameter is measure and analyzed. Like wise all the parameters are varied keeping all others constant and the sensitivity analysis is performed. The key parameters are varied within a practical range for the purpose of the analysis so as to measure the impact on the energy savings obtained. This analysis here is performed for the data collected from facility A, the analysis for other plants can be found in Appendix IV.

These factors are:

ㅁ Efficiency of motors

- Load factor of the motors or the drive system 


\begin{tabular}{|c|c|c|c|c|c|c|}
\hline hp & Eff. & LF & H & S & ES & Cost Savings \\
\hline \multicolumn{7}{|c|}{ Sensitivity with respect to efficiency of motors } \\
\hline 981.5 & 0.7 & 0.8 & 2,106 & $4.00 \%$ & 240.49 & 5,279 \\
\hline 981.5 & 0.74 & 0.8 & 2,106 & $4.00 \%$ & 227.49 & 4,993 \\
\hline 981.5 & 0.78 & 0.8 & 2,106 & $4.00 \%$ & 215.82 & 4,737 \\
\hline 981.5 & 0.82 & 0.8 & 2,106 & $4.00 \%$ & 205.29 & 4,506 \\
\hline 981.5 & 0.86 & 0.8 & 2,106 & $4.00 \%$ & 195.74 & 4,297 \\
\hline 981.5 & 0.9 & 0.8 & 2,106 & $4.00 \%$ & 187.04 & 4,106 \\
\hline 981.5 & 0.94 & 0.8 & 2,106 & $4.00 \%$ & 179.08 & 3,931 \\
\hline \multicolumn{7}{|c|}{ Sensitivity with respect to load factor } \\
\hline 981.5 & 0.86 & 0.3 & 2,106 & $4.00 \%$ & 73.40 & 1,611 \\
\hline 981.5 & 0.86 & 0.4 & 2,106 & $4.00 \%$ & 97.87 & 2,148 \\
\hline 981.5 & 0.86 & 0.5 & 2,106 & $4.00 \%$ & 122.34 & 2,685 \\
\hline 981.5 & 0.86 & 0.6 & 2,106 & $4.00 \%$ & 146.81 & 3,222 \\
\hline 981.5 & 0.86 & 0.7 & 2,106 & $4.00 \%$ & 171.28 & 3,760 \\
\hline 981.5 & 0.86 & 0.8 & 2,106 & $4.00 \%$ & 195.74 & 4,297 \\
\hline
\end{tabular}

Table 7.2: Sensitivity analysis for cog belt drives

\subsubsection{Sensitivity with respect to Efficiency of motors}

This analysis is done by changing the value of the efficiency of motors in the energy savings equation and keeping all other parameters of the equation constant. The efficiency of the motors is varied from $70 \%$ to $94 \%$. The efficiency value of a typical standard old motor is $70 \%$, while $94 \%$ is the efficiency of a typical new energy efficient motor. That's the reason above range is selected for the analysis. As seen in the Figure 7.1, the total savings obtained decrease with an increase in the efficiency value of the motor. There is a decrease in the total savings because, the efficiency of the motor appears in the denominator of the energy savings equation. This means that if the plant has electric motors in the high efficiency range say above $90 \%$, then this recommendation will result in less cost savings. But when the motors are standard and old, the efficiency is very low, then there is a potential for a large saving. As seen in the Table 7.1 , when the average efficiency of the motors is $70 \%$, the annual cost saving obtained is $\$$ 5,279 . Also at an efficiency of $94 \%$, the annual saving is $\$ 3,931$. 


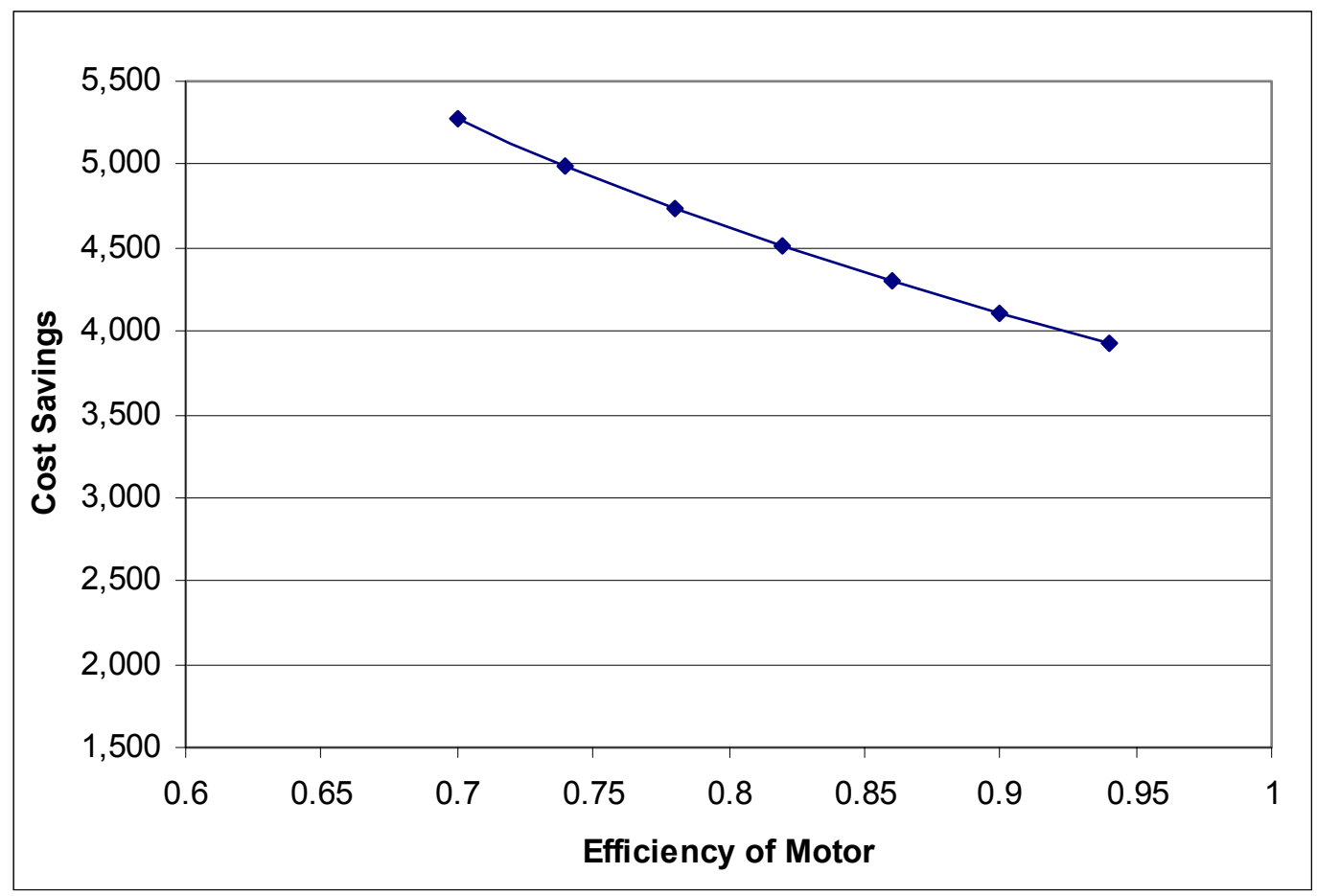

Figure 7.1: Sensitivity with respect to Efficiency of motor

\subsubsection{Sensitivity with respect to the load factor of the motors}

If the load factor of the motor changes, the efficiency of the motor changes along with it. If the motor load factor decreases, then the efficiency of the motor also decreases and if the motor load factor increases, this efficiency increases up to $75 \%$ to $80 \%$ load factor. But here the sensitivity analysis is performed considering a load factor change without any change in the efficiency of the motor. To get a better insight of the impact of the motor load factor on the energy saved, the efficiency value of the motor is assumed to be constant at 0.86 . This value is midway through the efficiency range of a standard efficiency motor. The maximum efficiency of a motor would be around $95 \%$ at full load or at $77 \%$ load, and the efficiency drops to around $75 \%$ if the motor load drops below $50 \%$. So $86 \%$ efficiency is assumed here as constant for the change in load.

As seen in the Table 7.1, the load factor of the motor driven systems is varied from 0.3 to 0.8 keeping all other parameters in the savings equation constant. The load factor range of 0.3 to 0.8 is selected at it is the typical range for most of the motor driven systems in an industrial set up. The load factor directly affects the total savings obtained. Load factor of $30 \%$, means 
that the amount of stresses on the belt transmission is less as compared to those at $80 \%$. So there is a steady increase in the cost savings achieved when the load factor is increased in that range. As can be seen in the 7.1, at a load of 0.3 , the net savings obtained are $\$ 1,611$, while for a load factor of 0.8 , the net savings obtained are $\$ 4,297$. This is also seen in the Figure 7.2, which shows a steady increase in the annual cost savings due to maintaining a higher load factor in the plant.

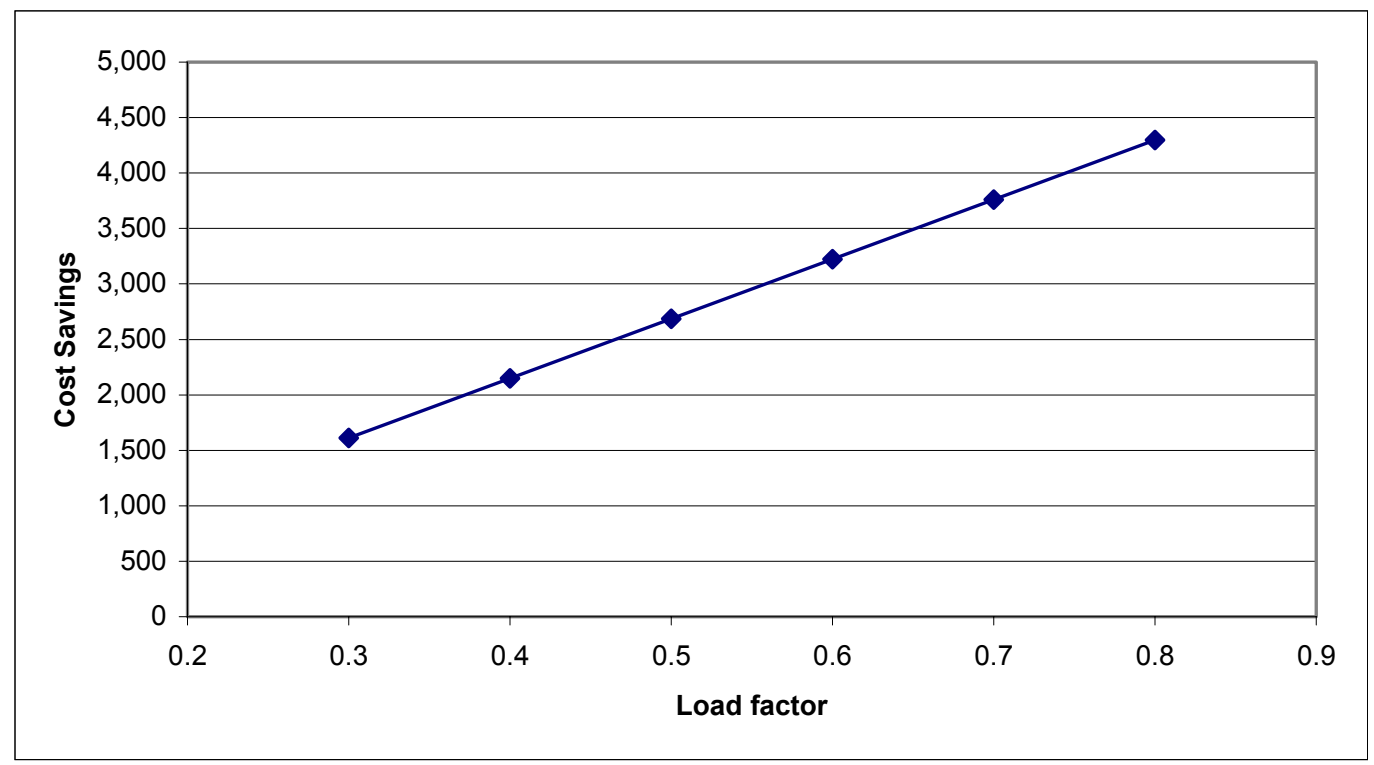

Figure 7.2: Sensitivity with respect to Load factor of motor

\subsection{Application considerations}

Replacing the existing standard $\mathrm{V}$ belts with energy efficient cog belts should be done very judiciously. Although cog belts are energy efficient and result in cost savings, they may not be compatible with the process requirements in some cases. Applications or processes, which require accurate timing, may not be suitable for a cog belt installation. Also applications, which constantly run at low load, may not be a favorable candidate for cog belts. Cog belts have been known to create problems at especially low loads. Also there are some processes that require some slip in the process and the cog belts may not be the right solution for that. So, before replacement of the standard V belts all these considerations should be taken into account. 


\subsection{Conclusions}

Use of energy efficient cog belts definitely result in energy savings. The standard V belts should be replaced with careful consideration to the different application considerations for each particular situation. As can be seen in the sensitivity analysis performed on the important parameters of the energy savings equation, it is seen that load factor and efficiency of the motor systems does play a very significant role in determining the energy savings and hence the payback period for the investment in cog belt drives. 


\section{Chapter 8}

\section{Summary and comparisons for the assessment findings}

The previous chapters discussed the various tools and the analysis conducted during the assessments conducted in the wood manufacturing industry. The summary of the data collected and the results are compared across all the plants visited. A comparison matrix of all the plants across some measured parameters is constructed and discussed in this chapter. A brief description of each plant is also prepared so as to get a better insight into the results. Specific energy consumption for different parameters is also calculated and plotted for further analysis.

\subsection{Description of each facility visited}

Seven wood manufacturing industries in West Virginia were audited. Each plant had its own special characteristic. Some general information about the operating hours, special processes, special energy consumption areas in the plant are discussed here.

\subsubsection{Facility A}

A manufacturing facility located in Preston County, West Virginia produces quality wood boards from logs. The plant uses only electrical energy and no oil or natural gas. The major component of this electrical load is contributed by electric motors. This facility has 75 employees and the average production is $35 \mathrm{mbf}$ (thousand board feet) of lumber per day. A brief description of the plants manufacturing process is described here. It is not intended to be a complete detailed description, but rather to provide general information on the processes, with a focus on energy requirements. Saw logs are trucked in to the plant by the logger contracted to haul them from the harvest site. Logs are stored in the area outside the plant and initial inspection and sorting is done. They are then fed to the debarker where the bark is abraded off. With the help of a material handling system they are sent to the Head saw where sideboards are cut off from the cant. The cant is then cut into desired dimensions. The boards proceed on a conveyor to the edger where smooth parallel edges are rendered on to the logs. The Trimmer then cuts the boards to square and precise lengths. The boards are then sent to grading and then final sorting and storage. The lumber is then packaged by grade and length and shipped via 
trucks. Waste is created at every stage in the process, which is in the form of sawdust and chips of wood. The waste generated is later on collected through conveyors and sold out. This facility works on a one shift and 5 days a week schedule for 52 weeks a year.

\subsubsection{Facility B}

B is located in Riverton, West Virginia produces quality wood boards from logs. The plant uses only electrical energy and no oil or natural gas. The major component of this electrical load is contributed by electric motors. This facility has 60 employees and the average production is $18.5 \mathrm{mbf}$ (thousand board feet) of lumber per day. The manufacturing process for this plant is very similar to that of previously discussed facility A, where in logs come in at the debarker and the boards are edged and trimmed to required dimensions and then sent for grading. This facility works 2 shifts and 5 days a week schedule for 52 weeks a year.

\subsubsection{Facility $C$}

Facility C is located in Mt. Storm, West Virginia produces quality wood boards from logs. The plant uses only electrical energy and no oil or natural gas. The major component of this electrical load is contributed by electric motors. This facility has 60 employees and the average production is $18 \mathrm{mbf}$ (thousand board feet) of lumber per day. The manufacturing process of this plant is same as facility C. This facility works 2 shifts and 5 days a week schedule for 52 weeks a year.

\subsubsection{Facility D}

The principal product of facility D in Webster Sprigs, WV is rough lumber. The raw material used is logs from different tree spices. The company has 91 employees. Annual sales for this company are approximately seven million dollars. A simplified description of the manufacturing processes performed at this facility is as follows which is slightly different from the earlier plants. Logs are received and stored in the yard. Logs are then debarked and moved to the band saw into slabs. The cut slabs are then edged, trimmed and graded. A portion of the graded lumber is shipped directly to the customer, while some lumber goes to the kiln for drying 
and is graded and prepared for shipment. Among other energy consuming equipment this facility has two drying kilns with a steam boiler.

\subsubsection{Facility E}

The principal product of facility E, Mount Hope, WV is lumber, wood, and wood pellet fuel. The raw materials are logs and saw dust. The company has 53 employees. Annual sales for the facility are approximately $\$ 9.5$ million. The plant operates for 2 shifts for 5 days a week, 52 weeks a year. The plant is broken down into two production areas. In the first area, the raw material is logs. These logs are debarked and then sawed into boards. In the second area, the raw material is the sawdust from the lumber mill, augmented by purchased sawdust. The second process produces pellet fuel by extruding sawdust into small pellets. The final products are then inspected, packaged, and shipped.

\subsubsection{Facility $\mathbf{F}$}

The principal product of facility F, Bartow, WV is rough sawn lumber and kiln dried lumber. The total employees at this plant are around 185 and there is one 10-hour production shift 5 days a week, 52 weeks a year. Average production of lumber is around $400 \mathrm{mbf}$ per week. Along with the conventional lumber manufacturing set up from debarker to grading this facility also has 16 dry kilns and 12 dehumidifiers. Some portion of the lumber is sent to dry kilns for drying. The dehumidifiers remove the humidity in the lumber at the same time dries it. There is a dehumidification refrigeration compressor on each dehumidifier. The facility also has 1 sawdust boiler and 2 oil boilers for dehumidification kilns. On an average $60 \%$ of green lumber obtained after grading is sent to dry kilns.

\subsubsection{Facility $G$}

Facility G is situated in Spencer, WV. The principal product of this company is pressure treated industrialized timber. There are around 75 employees at this plant and it runs on 2 shifts for 5 days a week, 52 weeks a year. The treatment plant runs in all the three shifts and is the major energy consumer of the facility. This plant is different from all the above plants discussed so far. The raw material is in the form of sawn square logs and it is further trimmed and graded at the plant. Further it is treated in a treatment plant on the site. 
Treatment of the trimmed logs is a 20 to 24 hour process. The company produces these treated logs for rail tiers. The plant also produces compound posts as per the requirement from the customers. There are two boilers in the treatment plant, one sawdust boiler and other is a gas boiler, which is a backup for the first boiler.

\subsection{Comparison matrix for the facilities visited}

A comparison matrix of the various parameters measures and analyzed during the assessment is made so as to get a better insight into the operations of each facility as regards to energy. The various parameters, which are compared, are general information about the plant, the utility bill analysis for each plant and then the demand sensitivity analysis details. Also some specific energy consumption indicators are calculated for each plant visited. The comparison matrix can be seen in the Table 8.1.

\subsubsection{General information}

The parameters compared under this heading are the location of the plant, the total number of employees in the plant, the average annual production of the plant in mbf $(1,000$ board feet), and the operating hours of the plant. The total number of employees is mentioned so as to get an idea of the labor productivity in the plant. The average annual production values are used for calculating the various specific energy consumption parameters down in the table.

As can be seen in the Table 8.1, the general information on the plants $A$ to $G$ is mentioned. The plants normally operate in one or two shift operations. Also can be seen in the table, the total number of employees is below 100 except for plant $F$ that is a big operation and has 185 employees. Also it is seen that the average annual production of lumber in mbf is very high for plants E, F and G. These plants have very high capacity and large product range.

\subsubsection{Utility bill analysis parameters}

The various parameters, which are compared under utility bill analysis, are utility rate schedule, which applies to each facility, and all electrical parameters like $\mathrm{kW}$ demand, $\mathrm{kWh}$ usage, total electricity charges of the plant, demand as a percent of the total electrical costs, 
the load factor of the plants, the power factor correction and the average MMBtu cost for the facility.

As can be seen in the Table 8.1, the rate schedules are for two utility service providers in the state. Allegheny Power (ALP) and American Electric Power (AEP). Each facility has its own rate schedule, which has its own way of calculating the demand cost, usage cost, power factor and the total electricity costs. Also it can be seen that the plant $\mathrm{F}$ has a huge annual peak demand recorded as compared to the other facilities. As mentioned earlier, the plant $\mathrm{F}$ has 16 dry kilns and 12 dehumidifiers in addition to the conventional lumber manufacturing set up. This is the reason why it reflects a high demand during the year.

Also it can be seen in the Table 8.1, the demand cost is not calculated for each plant. The demand cost calculation depends on the utility rate schedule. Some schedules calculate the demand and usage cost separately while others include all the costs under usage cost. As a result the demand as a percent of the total energy charges is not obtained for all the plants covered. It can be seen in the table that the plant A has the maximum demand as a percent of total electricity charges, which is around $60 \%$.

The load factor is calculated for each plant. The load factor of the plant depends on the number of operating shifts for the plant. So for a plant running for 1 shift the industrial plant average is $37 \%$, while for a 2 -shift operation it is around $72 \%$. So while analysis the load factor of the plant, the operation hours of the plant should be kept in mind so as to make a comparison with the industrial average.

The average $\mathrm{kW}$ demand, the minimum demand and the maximum demand recorded during the year are also mentioned for each plant. The difference between the maximum and the average demand and the difference between the maximum and minimum demand gives a fair idea of the possibility of leveling the load curve around the average. The power factor correction is not required for each plant. Overall it is observed that the plants maintain a very good power factor and there are no power factor penalties. As can be seen in the table, the power factor improvement is suggested for only plants A and E. The average cost of MMBtu is calculated for each plant. The average cost of MMBtu is calculated by dividing the total electricity charges of the utility for a year by the total $\mathrm{kWh}$ consumed during that year. It is a very good indicator of how the utility utilizes its energy and what is the cost of electricity usage in the plant. 


\begin{tabular}{|c|c|c|c|c|c|c|c|}
\hline FACILITIES & $\mathbf{A}$ & B & $\mathbf{C}$ & D & $\mathbf{E}$ & $\mathbf{F}$ & G \\
\hline \multicolumn{8}{|l|}{$\begin{array}{c}\text { GENERAL } \\
\text { INFORMATION }\end{array}$} \\
\hline Annual Production (mbf) & 9100 & 4680 & 4680 & 6000 & 27500 & 20800 & 15000 \\
\hline Total \# of employees & 75 & 50 & 60 & 91 & 53 & 185 & 65 \\
\hline \multicolumn{8}{|l|}{ UTILITY BILL ANALYSIS } \\
\hline Rate Schedule & ALP $15-\mathrm{D}$ & ALP C - 11 & ALP C - 12 & - & AEP - LCP & ALP 15 - D & ALP 11- C \\
\hline Annual kW Demand & 5042 & 5303 & 5096 & 9526 & 14677 & 28081 & 3139 \\
\hline Annual kWh Usage & 1054400 & 1787904 & 1892352 & 3962400 & 5918400 & 11469248 & 1090538 \\
\hline Demand Cost & 47563 & - & - & 84793 & 111648 & 234232 & - \\
\hline Load Factor & 0.28 & 0.47 & 0.52 & 0.58 & 0.54 & 0.56 & 0.22 \\
\hline Load Curves & Yes & Yes & Yes & Yes & Yes & Yes & Yes \\
\hline Min Demand & 313 & 379 & 408 & 658 & 1151 & 2131 & 550 \\
\hline Avg. Demand & 336 & 451 & 462 & 793 & 1223 & 2340 & 584 \\
\hline Max Demand & 362 & 536 & 529 & 986 & 1277 & 2488 & 638 \\
\hline Power factor Improvement & Yes & No & No & No & Yes & No & No \\
\hline Average MMBtu Cost & 21.95 & 16.45 & 16.23 & 14.13 & 11.25 & 13.83 & 23.18 \\
\hline
\end{tabular}

Table 8.1: Comparison matrix for the various plants 


\begin{tabular}{|c|c|c|c|c|c|c|c|}
\hline FACILITIES & $\mathbf{A}$ & $\mathbf{B}$ & $\mathbf{C}$ & $\mathbf{D}$ & $\mathbf{E}$ & $\mathbf{F}$ & $\mathbf{G}$ \\
\hline \multicolumn{8}{|l|}{ DEMAND SENSITIVITY ANALYSIS } \\
\hline Demand Sensitivity Analysis & Yes & Yes & Yes & Yes & Yes & Yes & No \\
\hline $\begin{array}{l}\text { Annual electric cost saved for } 5 \% \\
\text { decrease in } \mathbf{k W}\end{array}$ & \multirow{2}{*}{$\begin{array}{l}1578 \\
3165\end{array}$} & 1370 & 1421 & 9724 & 5577 & 26483 & - \\
\hline $\begin{array}{l}\text { Annual electric cost saved for } 10 \% \\
\text { decrease in } \mathrm{kW}\end{array}$ & & 2742 & 2839 & 19450 & 11154 & 53006 & - \\
\hline $\begin{array}{l}\text { Annual electricity saved per unit } \\
\text { of kW decrease }\end{array}$ & \multirow{2}{*}{$\begin{array}{c}317.14 \\
\text { No }\end{array}$} & \multirow{4}{*}{$\begin{array}{l}274 \\
\text { No } \\
\text { Yes } \\
\text { Yes }\end{array}$} & \multirow{4}{*}{$\begin{array}{l}285 \\
\text { No } \\
\text { Yes } \\
\text { No }\end{array}$} & \multirow{4}{*}{$\begin{array}{c}2209 \\
\text { No } \\
\text { Yes } \\
\text { Yes } \\
\end{array}$} & \multirow{4}{*}{$\begin{array}{l}1115 \\
\text { Yes } \\
\text { Yes } \\
\text { Yes } \\
\end{array}$} & \multirow{2}{*}{$\begin{array}{c}5295 \\
\text { Yes }\end{array}$} & \multirow{2}{*}{$\begin{array}{c}- \\
\text { Yes }\end{array}$} \\
\hline Motor Load Test Performed & & & & & & & \\
\hline Motor Master Analysis & Yes & & & & & Yes & Yes \\
\hline Cog belts replacement sensitivity analysis & Yes & & & & & Yes & Yes \\
\hline SPECIFIC ENERGY CONSUMPTION & & & & & & & \\
\hline Demand/ mbf of production (kW/mbf) & 0.6 & 1.1 & 1.1 & 1.6 & 0.5 & 1.4 & 0.2 \\
\hline Energy Usage/ mbf of production (kWh/mbf) & 116 & 382 & 404 & 660 & 215 & 551 & 73 \\
\hline Usage cost/ mbf of production (\$/mbf) & 3 & 21 & 22 & 18 & 4 & 15 & 6 \\
\hline Total Electricity cost/ mbf of production ( $\$ / \mathrm{mbf})$ & 9 & 21 & 22 & 32 & 8 & 26 & 6 \\
\hline
\end{tabular}

Table 8.1: Comparison matrix for the various plants (contd.) 


\subsubsection{Demand sensitivity analysis parameters}

A detailed demand sensitivity analysis is performed for each of the plants visited except facility $G$ where sufficient data on the plant demand is not available. Annual electricity saved per unit of $\mathrm{kW}$ decrease in demand is calculated for the plants A to F. Motor load test is also performed for the plants E, F and G. After the motor load test, the motor master analysis is performed for all the plants using Motor Master + software. Also the cog belt replacement analysis is performed for all the plants except the plant $\mathrm{C}$.

\subsubsection{Specific energy consumption parameters}

Only absolute energy consumption values for each plant don't give a good insight into the energy usage by the plant. For comparing energy consumption parameters across all the plants, ratios of energy with some common parameter of production are required. Thus the specific energy consumption values are calculated so as to get a proper basis for comparing the energy parameters across all the plants visited. Various parameters, which compare the specific energy consumption of the plant, are compared across all the plants. The various parameters are $\mathrm{kW}$ demand per mbf of production, energy usage $\mathrm{kWh}$ per mbf of production, usage cost in $\$$ per mbf of production and total electricity cost in $\$$ per mbf of production. Plots for each of these parameters across all the plants A to G are plotted and discussed in the following section.

\subsection{Plots for specific energy consumption}

Various parameters, which compare the energy patterns across all the plants, are discussed in the Table 8.1. Some of these parameters, which are good indicators of the energy usage, are plotted across all the plants to get a better view of the energy usage in these plants. These plots are for average MMBtu cost, energy usage per mbf of production, total electricity cost per mbf of production and usage cost per mbf of production.

\subsubsection{Plot of average MMBtu cost}

The average MMBtu cost is plotted for each plant. As mentioned earlier the average cost of MMBtu is the total electricity cost of the plant for the year divided by the total energy usage of the plant in MMBtu for that year. This parameter is good indicator of the total 
energy usage in the plant. The value of average MMBtu depends upon the number of operating hours of the plant. More the operating hours, more the kWh or MMBtu consumed for the plant and more the usage cost for that plant. The total cost comprises of demand and usage cost, so the average MMBtu might be high if the demand cost and hence the total cost of the company is very high for a period. As can be seen in the Figure 8.1, the average MMBtu cost is very high for plant A and G. The value is around an average of 14 \$/MMBtu for all other plants.

In case of $A$, it is the only one shift operation in all the plants. So the total cost of this plant constitute the large demand cost and the usage cost of 1 shift per day. The total MMBtu of energy consumed per year is low for this plant as compared to others. Also the total cost of electricity is very high for this kind of operation because of power factor penalty cost and also high demand cost. The plant $G$ has a treatment plant and has a different product as compared to the plants A to F. It treats the already square shaped logs in the plant for rail tiers. The treatment plant of this facility is the major energy consumer with other plants not consuming much energy. But there is big demand cost on this plant and the total energy bill therefore is high. Also the amount of MMBtu of energy consumed per year by this plant is very less as compared to other plants. So the average MMBtu cost of this plant is above $\$$ 20/MMBtu.

\subsubsection{Plot of energy usage per mbf of production}

This parameter is calculated by dividing the total annual energy consumed in kWh by the annual production of lumber in mbf. As can be seen in the Figure 8.2, this parameter largely varies across all the plants. For plant A, it is a one shift operation, but it produces high volume of lumber per shift as compared to plants B and $\mathrm{C}$ which produce less but consume more $\mathrm{kWh}$ as compared to $\mathrm{A}$. This shows that the plant $\mathrm{A}$ is highly efficient operation, in which produces more and consumes less energy as compared to plants B and C. Plant $\mathrm{D}$ is an operation, which has a kiln for drying along with the conventional lumber manufacturing set up. As a result it consumes a lot of $\mathrm{kWh}$ energy as compared to other plants. Also at the same time, plant D production of lumber per year is very less as compared to the amount of energy it consumers. The energy usage per mbf of production is very high. 
Plant $\mathrm{F}$ also has 16 kilns and 14 dehumidifiers in addition to the conventional lumber manufacturing process. As a result it consumes high amount of $\mathrm{kWh}$ per year. But at the same time the overall plant appears to be efficient as its output production per year is also very high. Therefore the value of energy usage is $551 \mathrm{kWh} / \mathrm{mbf}$ of production, which is still lower, then the plant $\mathrm{D}$ whose value is $660 \mathrm{kWh} / \mathrm{mbf}$. Plant $\mathrm{G}$ is as discussed earlier a totally different process and its value cannot be compared with the other plants.

\subsubsection{Plot of total electricity cost per mbf of production}

This parameter is obtained by dividing the total electricity cost of the facility by the annual mbf of lumber production at the plant. As can be seen in the Figure 8.3, this parameter varies almost same as the usage cost per mbf of production for all the plants. The reasons for such wide variation in the total electricity cost per mbf of production are same as the previous section. As the denominator in both the cases is same, there is not much difference in these plots.

\subsubsection{Plot of usage cost per mbf of production}

This parameter is obtained by dividing the usage cost of electricity in $\$$ by the total annual production of lumber in mbf for the facility. The usage cost of electricity is calculated differently for different rate schedules of the utility service provider. In some schedules, the rate structure is such that the utility cost include the demand cost and therefore the total cost and the utility cost are same for these facilities, while for others the demand cost can be separated from the usage cost. As can be seen in the Figure 8.4, this parameter varies across all the plants. As can be seen for the plants B, C and G this value of usage cost per mbf of production is equal to the total electricity cost per mbf of production due to their peculiar rate structure. This plot depends on the energy usage plot in the Figure 8.2. If the energy usage values of $\mathrm{kWh}$ in the Figure 8.2 are multiplied by the $\$ / \mathrm{kWh}$ cost or the usage cost for each facility then the plot of usage cost per mbf of production will be as obtained in Figure 8.4. As it can be seen the variation in the plots is same as that in the Figure 8.2. So the reasons for the different values for this parameter across all the facilities are same as the reasons mentioned in the section 8.3.2 earlier. 


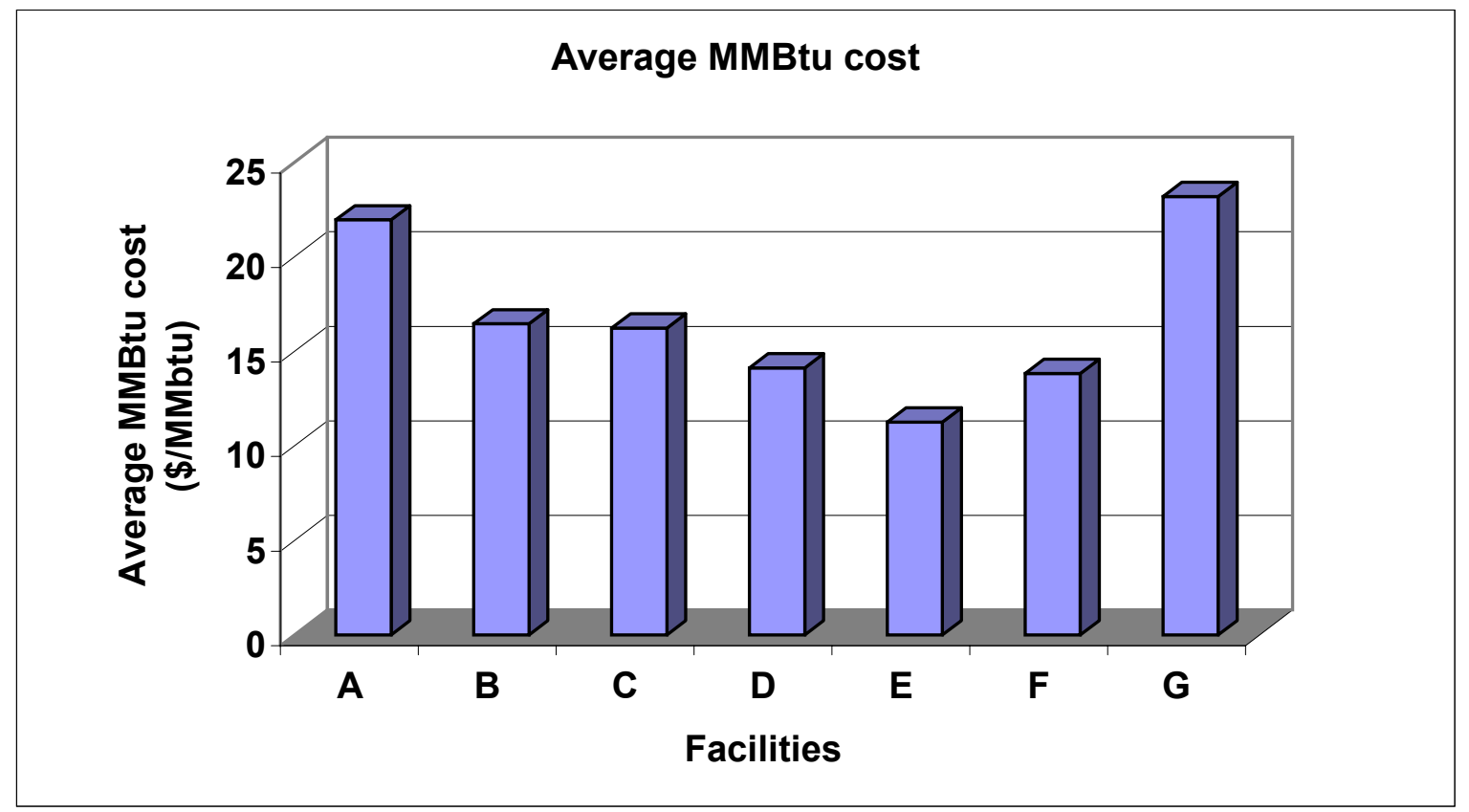

Figure 8.1: Plot of average MMBtu cost for the plants A to $\mathbf{H}$

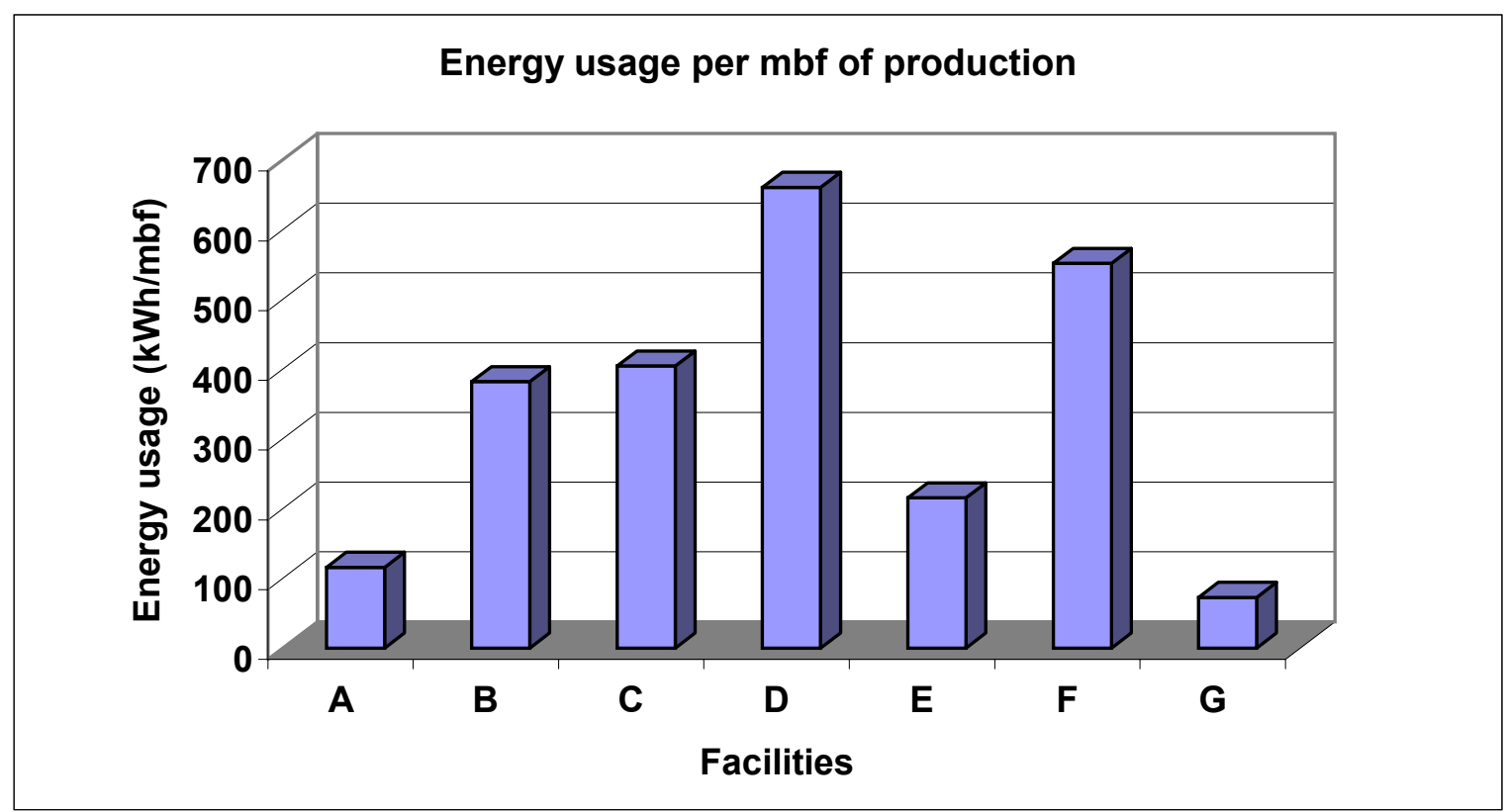

Figure 8.2: Plot of energy usage per mbf of production for the plants $A$ to $H$ 


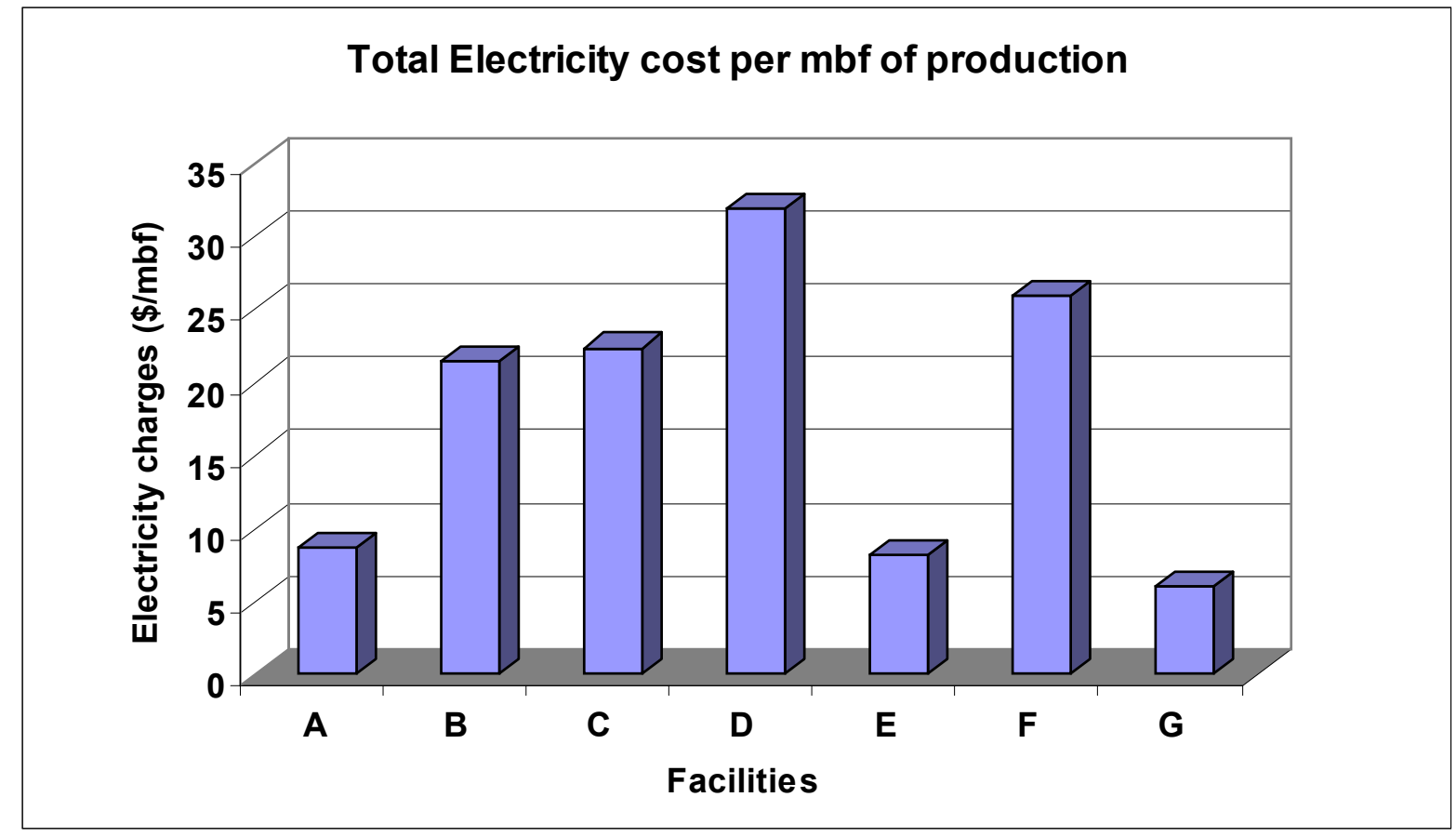

Figure 8.3: Plot of total electricity cost per mbf of production for the plants $A$ to $H$

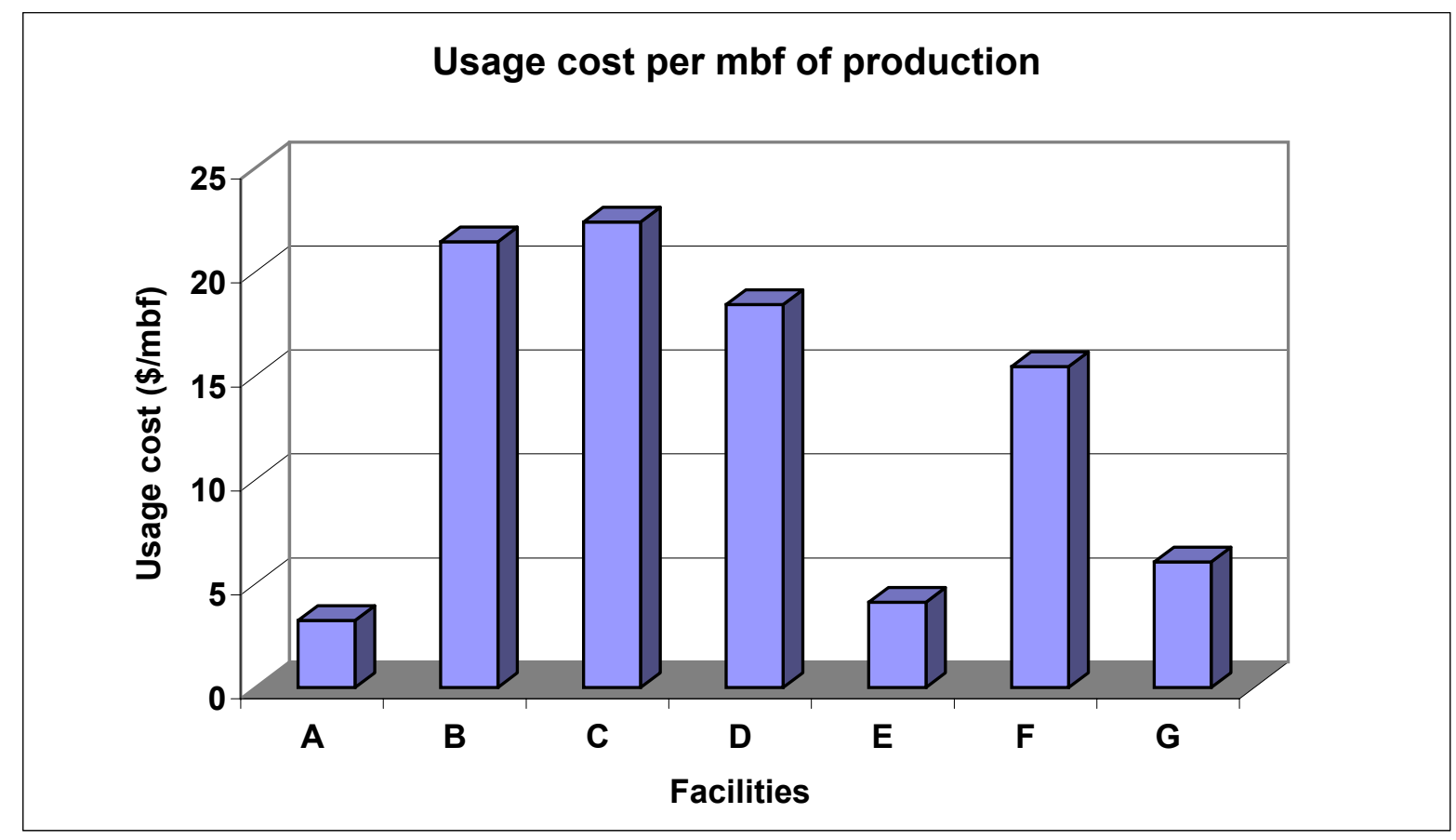

Figure 8.4: Plot of usage cost per mbf of production for the plants $A$ to $H$ 


\subsection{Future Work}

This research covered the analysis of electricity bills of the wood manufacturing plants. It also involved identifying the plant load curves, the plant load factor and the motor load test. The motor load test was useful in identifying the motors that can be suitable candidates for downsizing in future or on failures. A very detailed analysis of the various motor replacement decisions using Motor Master + software was also performed. Following future work is suggested in this research.

1. To conduct a more detailed and long-term load test on the various motors in the wood manufacturing plants. This analysis can be performed using instruments like power analyzers and other sophisticated load and efficiency measuring equipment.

2. From the long duration load test, identify the motors for downsizing and replace that motors with an appropriately sized motor.

3. Closely monitor the savings obtained from the replacement of the oversized motors and also monitor the demand savings obtained from the replacement. 


\section{Bibliography}

1. Dunning, Scott, and Ward, Todd, "Energy and waste saving measures for the paper and wood products industry", IEEE Conference Record of Annual Pulp and Paper Industry Technical Conference, Jun 21-26, 1998.

2. Singh, Harmohindar, Rojeski, Peter Jr., and Kapur, Arjun, "Energy conserving design concepts in wood dust collection systems", Proceedings of the Intersociety Energy Conversion Engineering Conference, v 4, Jul 31 - Aug 5, 1998, Published by IEEE, p 81-85, 1989.

3. McCoy, Gilbert A., Rooks, James A., and Tutterow, Vestal C., "Motor Master +: An energy-efficient motor selection and energy management tool for the pulp and paper industry”, IEEE Conference Record of Annual Pulp and Paper Industry Technical Conference, Jun 16-20, 1997.

4. Kueck, J.D., "Development of a method for estimating motor efficiency and analyzing condition", IEEE Conference Record of Annual Pulp and Paper Industry Technical Conference, Jun 21-26, 1998.

5. Gustafsson, Stig-Inge, "Load management measures in carpentry factory", International Journal of Energy Research, v 22, n 14, John Wiley \& Sons Ltd., p 1267-1274, Nov, 1998.

6. Buehlmann, Urs, Ragsdale, Cliff T., and Gfeller, B., "Spreadsheet based decision support system for wood panel manufacturing”, Decision Support Systems, 29, Elsevier Science Publishers B.V., P207-227, 3 Oct, 2000.

7. Garasimowicz, Gregory A., "Energy savings", Annual Meeting - Technical Section, Canadian Pulp and Paper Association, Preprints v Pt B, Jan 28-31, 1997.

8. Steele, Philip H., Wiedenbeck, Jan, and Shmulsky, Rubin, and Perera, Anura, “ Influence of lumber grade on machine productivity in the rough mill", Forest Products Journal, v 49, n 9, Forest Products Society, p 48-54, 1999.

9. Truong Pham, Duc, and Alcock, Robert J., "Automated grading and defect detection: a review", Forest Products Journal, v 48, n 4, Forest Products Society, p 34-42, Apr 1998. 
10. Teel, Dale, Wyland, Will, and Fossum, Ernest, "What are your real electric costs?", Energy Engineering, Journal of the Association of Energy Engineering, v 97, n 4, Fairmont Press Inc, p 61-70, 2000.

11. Lobodovsky, K.K., “Motor efficiency management”, Energy Engineering, Journal of the Association of Energy Engineering, v 91, n 2, Fairmont Press Inc, p 32-43, 1994.

12. Prestil, Angela L., and Wroblewski, Ronald G., "Saving energy with efficient motors and systems", Energy Engineering, Journal of the Association of Energy Engineering, v 93, n 6, Fairmont Press Inc, p 48-63, 1996.

13. Cole, Richard, and Thome, Terry, "Motors matched to load profiles lead to high efficiency service”, Pulp \& Paper, v 69, n 8, Miller Freeman Publ Inc, 6 pp 00334081, Aug 1995.

14. Murthy, S.S., Jha, C.S., Lakshmi, S.R., Rai, A.K., and Desai, D.A., "Energy conservation aspect of induction motors using improved design and power controllers", Proceedings of the Intersociety Energy Conversion Engineering Conference, v 2, Published by IEEE, p 677-682, Aug 6-11, 1998.

15. Bonnett, Austin H., "Quality and reliability of energy efficient motors", IEEE Industry Applications Magazine, v 3, n 1, Published by IEEE, p 22-31, Jan - Feb, 1997.

16. Horton, Scott B., “Are energy efficient motors cure-all for energy problems?", Consulting-Specifying Engineer, v 16, n 3, Cahner's Publishing Co., p 0892-5046, Sept, 1994.

17. Heydt, G.T., Hoffman, S.P., Risal, A., Sasaki, R.I., and Kemper, M.J., "Impact of energy saving technologies on electric distribution system power quality", IEEE International Symposium on Industrial Electronics, sponsored by: IEEE, p 176-181, May 25-27, 1994.

18. White, Peregrine, "Review of metering plans for DSM savings verification”, Energy Engineering: Journal of the Association of Energy, v 90, n 2, p 48-58, 1993.

19. Mircevski, Slobodan A., Kostic, Zvonimir A., and Andonov, Z. Lj., "Energy saving with pump's AC adjustable speed drives", Proceedings of the Mediterranean Electrotechnical Conference - MELECON, v 2, May 18-20, 1998. 
20. Simmons, Kevin E., and McCoy, Gilbert, "Motor Master +: An energy efficient motor selection and energy management tool", Strategic Planning for Energy and the Environment, V 16, n 1, Fairmont Press Inc, p 28-38, Summer 1996.

21. Auchstetter, Terry, "Tips of fitting the best motor", Power Transmission Design, v 38, n 5, Penton Publ Inc, p 39-41, May, 1996.

22. Li, Shujiang, Gao, Xianwen, and Chai, Tianyou, "Application of compound fuzzy control in the power saving of motor", Proceedings of the IEEE Conference on Decision and Control, v 2, Dec 11-13, 1996.

23. Cerci, Yunus, Cengel, Yunus A., and Turner, Robert H., "Reducing the cost of compressed air in industrial facilities", American Society of Mechanical Engineers, Advanced Energy Systems Division, AES, v 35, Nov 12-17, 1995.

24. Fontaine, Pascal, "Energy efficiency in air handling applications", Australian, Asian and Pacific Electrical World, v 60, n 7, Reed Bus Publications, p 42-43, Jul, 1995.

25. Blaabjerg, Frede, Pedersen, John K., Rise, Soren, and Hansen, Hans- Henrik, "Comparative study of energy saving benefits in soft starters for three-phase induction motors", Conference Record - IAS Annual Meeting (IEEE Industry Applications Society), IEEE , p 367-374, Oct 8-12, 1995.

26. De Ameida, Anibal, and Greenberg, Steve, "Technology assessment: energy efficient belt transmissions", Energy and Buildings, v 22, n 3, p 245-253, Aug, 1995.

27. United States Department of Energy, Motor Challenge Program, "Energy Efficient Electric Motor Selection Handbook", The Bonneville Power Administration, August, 1996.

28. United States Department of Energy, Motor Challenge Program, "Determining Electric Motor Load and Efficiency" (FACT SHEET), 2001.

29. United States Department of Energy, Motor Challenge Program, "Reducing Power Factor Cost" (FACT SHEET), 2001.

30. United States Department of Energy, "Solutions for Industry: Horse Power" (Bulletin), Industrial Electrotechnology Laboratory, and The Alternative Energy Corporation, 1993. 
31. United States Department of Energy, Motor Challenge Program, "Motor Master +2 : User Guide", Washington State University Cooperative Extension Energy Program, 1997.

32. Brown, Nelson, Courtyard, and Bethel, James, Samuel, "Lumber, $2^{\text {nd }}$ Edition”, John Wile \& Sons, Inc., 1958.

33. Williston, Ed M., "Lumber Manufacturing, The Design and Operation of Saw mills and Planer Mills", Miller Freeman Publications, Inc., 1988.

34. Edited by White, Vernon S., "Modern Sawmill Techniques: Proceedings of the first Sawmill Clinic", February, 1973.

35. United States Department of Energy, Energy Information Administration, “Manufacturing Energy Consumption Survey", www.eia.doe.gov, 1994 \& 1998.

36. United States Department of Energy, Office of Industrial technologies, Office of Energy Efficiency and Renewable Energy, "Forest Products - Industry of the Future", January, 2001.

37. West Virginia Bureau of Commerce, Division of Forestry, "The Forestry Industry of West Virginia ”, Division of Forestry, 2001.

38. Nagarajan, Sai V., "Design and Development of Expert Systems for Energy Conservation in Manufacturing Industries", West Virginia University, 1995.

39. Mate, Amol, and Barve, Harshavardhan, "Energy conservation and energy audit", a project report, department of Industrial engineering, Vishwakarma Institute of technology, Pune, 1999.

40. United States Department of Energy, Office of Industrial technologies, "Energy Management for motor driven systems", 2001.

41. United States Department of Energy, Motor Challenge Program, "Replace V-belts with cogged or synchronous belt drives" (FACT SHEET), 2001.

\section{Web References}

http://www.mafdel.com

* http://www.oit.doe.gov/bestpractices/explore_library/pdfs/motor3.pdf

* http://www.data-powertrans.com

- http://www.nationalhose.com 


\section{Appendix I}

\section{Utility Bill Analysis for facility C}

\section{Scenario at facility $\mathbf{C}$}

Facility C plant uses only electrical energy and no oil or gas energy is used in the plant. The major components of this electrical load being the electric motors, which constitute around 85 to $90 \%$ of the total connected load.

\section{Data Collection}

All the relevant data and electric bills were collected from facility $\mathrm{C}$ plant during the plant audit. Also some additional information on the electric bill was obtained from Allegheny Power Company. Facility $\mathrm{C}$ has Allegheny Power as its electricity provider. The Schedule C - Rate 11 is the contract schedule being followed for the energy bill calculations.

\section{Electric Cost Distribution}

This analysis of the electricity cost distribution normally involves the contribution of each of the components of the electricity bill, namely, the usage charge, the demand charge and the KVAr charge towards the total electric bill. But because of the bill calculation as per Rate 11, the demand and the KVAr charges couldn't be separated.. The load factor is also calculated from the electricity bills and shown in the Table 1.1. The load factor indicates the extent of utilization of available electrical capacity over time. The average $\mathrm{kWh}$ cost of electricity is calculated by taking the mean of all the energy usage cost available. The average cost of MMBtu is $\$ 16.23$ per MMBtu. As can be seen in the Figure 1.1, the total cost of electricity is plotted against the months. As seen in the figure the highest cost is encountered in the month of April and is probably production related. But the demand pattern appears to be constant throughout the year. The total electric cost averages $\$ 8,000$ per month. 


\begin{tabular}{|c|c|c|c|c|c|c|c|}
\hline Year & Month & $\begin{array}{c}\text { Energy } \\
\text { Usage } \\
\mathbf{( k W h )}\end{array}$ & $\begin{array}{c}\text { Billed } \\
\text { Demand } \\
\mathbf{( k W )}\end{array}$ & $\begin{array}{c}\text { Usage } \\
\text { Cost } \\
\mathbf{( \$ )}\end{array}$ & $\begin{array}{c}\text { Total } \\
\text { Cost } \\
\mathbf{( \$ )}\end{array}$ & $\begin{array}{c}\text { Load } \\
\text { Factor }\end{array}$ \\
\hline 1999 & Nov & 148,608 & 379.59 & $8,134.82$ & $8,134.82$ & 507.19 & 0.54 \\
\hline & Dec & 148,609 & 379.64 & $8,135.82$ & $8,135.82$ & 507.20 & 0.54 \\
\hline 2000 & Jan & 170,496 & 474.20 & $9,670.22$ & $9,670.22$ & 581.90 & 0.50 \\
\hline & Feb & 170,496 & 474.20 & $9,671.22$ & $9,671.22$ & 581.90 & 0.50 \\
\hline & Mar & 170,496 & 474.20 & $9,672.22$ & $9,672.22$ & 581.90 & 0.50 \\
\hline & Apr & 183,168 & 473.50 & $10,200.65$ & $10,200.65$ & 625.15 & 0.54 \\
\hline & May & 158,592 & 437.50 & $8,980.31$ & $8,980.31$ & 541.27 & 0.50 \\
\hline & Jun & 148,608 & 422.30 & $8,087.72$ & $8,087.72$ & 507.19 & 0.49 \\
\hline & Jul & 152,832 & 409.90 & $8,189.01$ & $8,189.01$ & 521.61 & 0.52 \\
\hline & Aug & 143,232 & 412.00 & $7,822.33$ & $7,822.33$ & 488.85 & 0.48 \\
\hline & Sep & 148,607 & 379.55 & $8,133.82$ & $8,133.82$ & 507.19 & 0.54 \\
\hline & Oct & 148,608 & 379.59 & $8,134.82$ & $8,134.82$ & 507.19 & 0.54 \\
\hline & Total & $\mathbf{1 , 8 9 2 , 3 5 2}$ & $\mathbf{5 , 0 9 6 . 2}$ & $\mathbf{1 0 4 , 8 3 2 . 9 6}$ & $\mathbf{1 0 4 , 8 3 2 . 9 6}$ & $\mathbf{6 , 4 5 8 . 5}$ & Avg $=\mathbf{0 . 5 2}$ \\
\hline
\end{tabular}

Table 1.1: Utility bill analysis for facility $C$

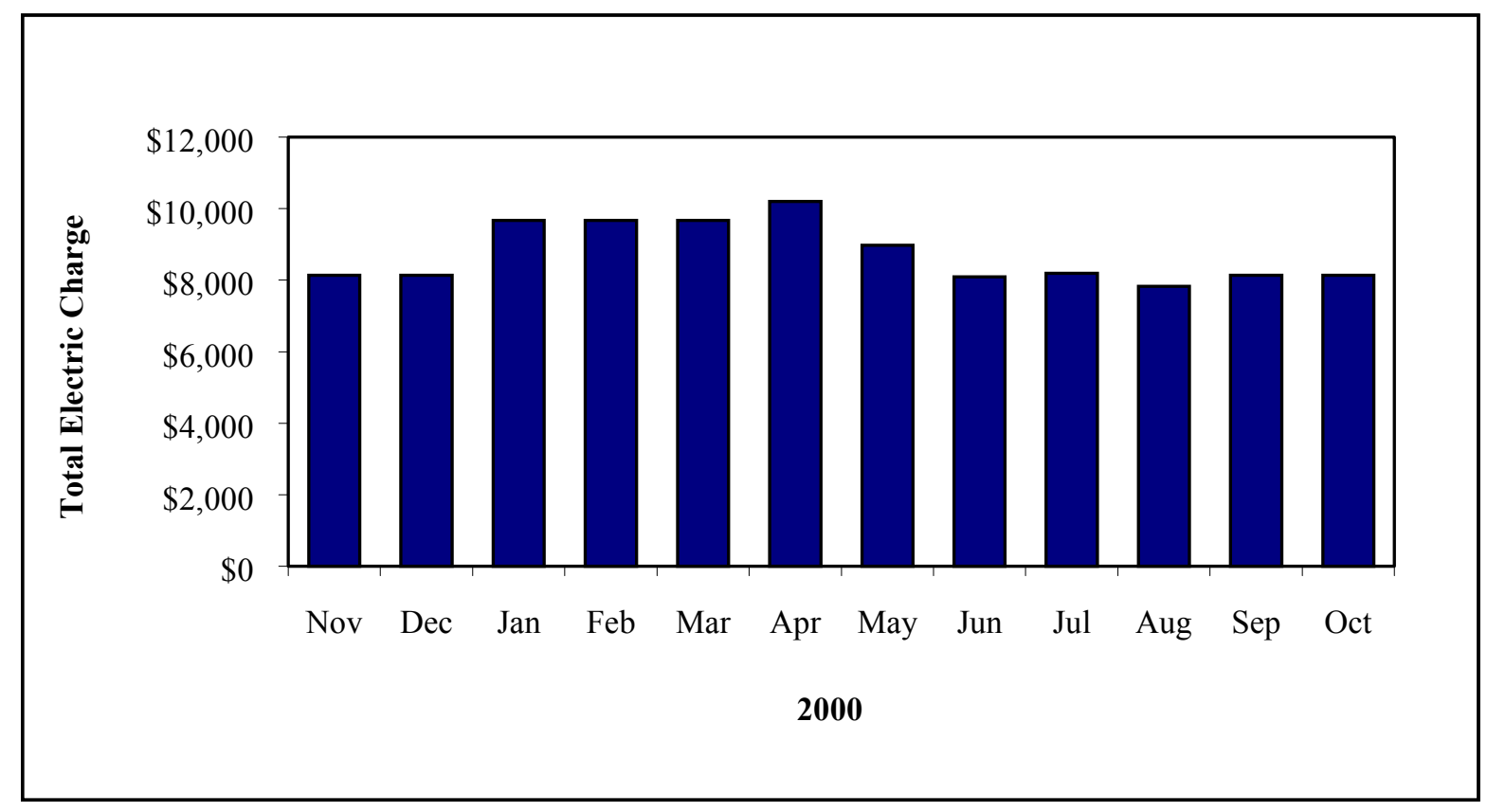

Figure 1.1: Electricity cost distribution for facility $\mathbf{C}$ 


\section{Utility Bill Analysis for facility B}

\section{Scenario at facility $B$}

Facility B plant uses only electrical energy and no oil or gas energy is used in the plant. The major component of this electrical loads being the electric motors, which constitute around 85 to $90 \%$ of the total connected load.

\section{Data Collection}

All the relevant data and electric bills were collected from Riverton plant during the plant audit. Also some additional information on the electricity bill was obtained from Allegheny Power. Facility B has Allegheny Power as its main electricity provider. The Schedule C - Rate 11 is the contract schedule being followed for the energy bill calculations.

\section{Electric Cost Distribution}

This analysis of the electricity cost distribution normally involves the contribution of each of the components of the electricity bill, namely, the Usage Charge, the Demand Charge and the KVAR charge towards the total electric bill. But because of the bill calculation as per Rate 11 , the demand and the KVAR charges couldn't be separated. The load factor is also calculated from the electricity bills and shown in the Table 1.2. Load factor is the ratio of the average kilowatt load over a billing period to the peak demand. The average $\mathrm{kWh}$ cost of electricity is calculated by taking the mean of all the energy usage cost available. The average cost of MMBtu is $\$ 16.45$ /MMBtu. As can be seen in the Figure 1.2 the total cost of electricity is plotted against the months. As seen in the figure the highest cost is encountered in the month of December. This peak cost might be encountered due to the extra space heating charges and also may be production related issues. Also it is seen that the approximately the total electric cost averages around $\$ 8,000$ per month. 


\begin{tabular}{|c|c|c|c|c|c|c|c|}
\hline Year & Month & $\begin{array}{c}\text { Energy } \\
\text { Usage } \\
\mathbf{( k W h )}\end{array}$ & $\begin{array}{c}\text { Billed } \\
\text { Demand } \\
\mathbf{( k W )}\end{array}$ & $\begin{array}{c}\text { Usage } \\
\mathbf{C o s t} \\
\mathbf{( \$ )}\end{array}$ & $\begin{array}{c}\text { Total } \\
\text { Cost } \\
\mathbf{( \$ )}\end{array}$ & MMBtu & $\begin{array}{c}\text { Load } \\
\text { Factor }\end{array}$ \\
\hline 2000 & Jan & 144,576 & 438 & 8,389 & 8,389 & 493 & 0.46 \\
\hline & Feb & 144,576 & 438 & 8,390 & 8,390 & 493 & 0.46 \\
\hline & Mar & 144,576 & 438 & 8,391 & 8,391 & 493 & 0.46 \\
\hline & Apr & 144,576 & 438 & 8,392 & 8,392 & 493 & 0.46 \\
\hline & May & 138,816 & 429 & 8,106 & 8,106 & 474 & 0.45 \\
\hline & Jun & 144,576 & 426 & 7,949 & 7,949 & 493 & 0.47 \\
\hline & Jul & 149,184 & 415 & 8,071 & 8,071 & 509 & 0.50 \\
\hline & Aug & 153,216 & 421 & 8,262 & 8,262 & 523 & 0.51 \\
\hline & Sep & 136,512 & 453 & 7,773 & 7,773 & 466 & 0.42 \\
\hline & Oct & 162,432 & 470 & 8,880 & 8,880 & 554 & 0.48 \\
\hline & Nov & 162,432 & 470 & 8,881 & 8,881 & 554 & 0.48 \\
\hline & Dec & 162,432 & 470 & 8,882 & 8,882 & 554 & 0.48 \\
\hline & Total & $\mathbf{1 , 7 8 7 , 9 0 4}$ & $\mathbf{5 , 3 0 3}$ & $\mathbf{1 0 0 , 3 6 4}$ & $\mathbf{1 0 0 , 3 6 4}$ & $\mathbf{6 , 1 0 2 . 0 6}$ & Avg $=\mathbf{0 . 4 7}$ \\
\hline
\end{tabular}

Table 1.2: Utility bill analysis for facility B

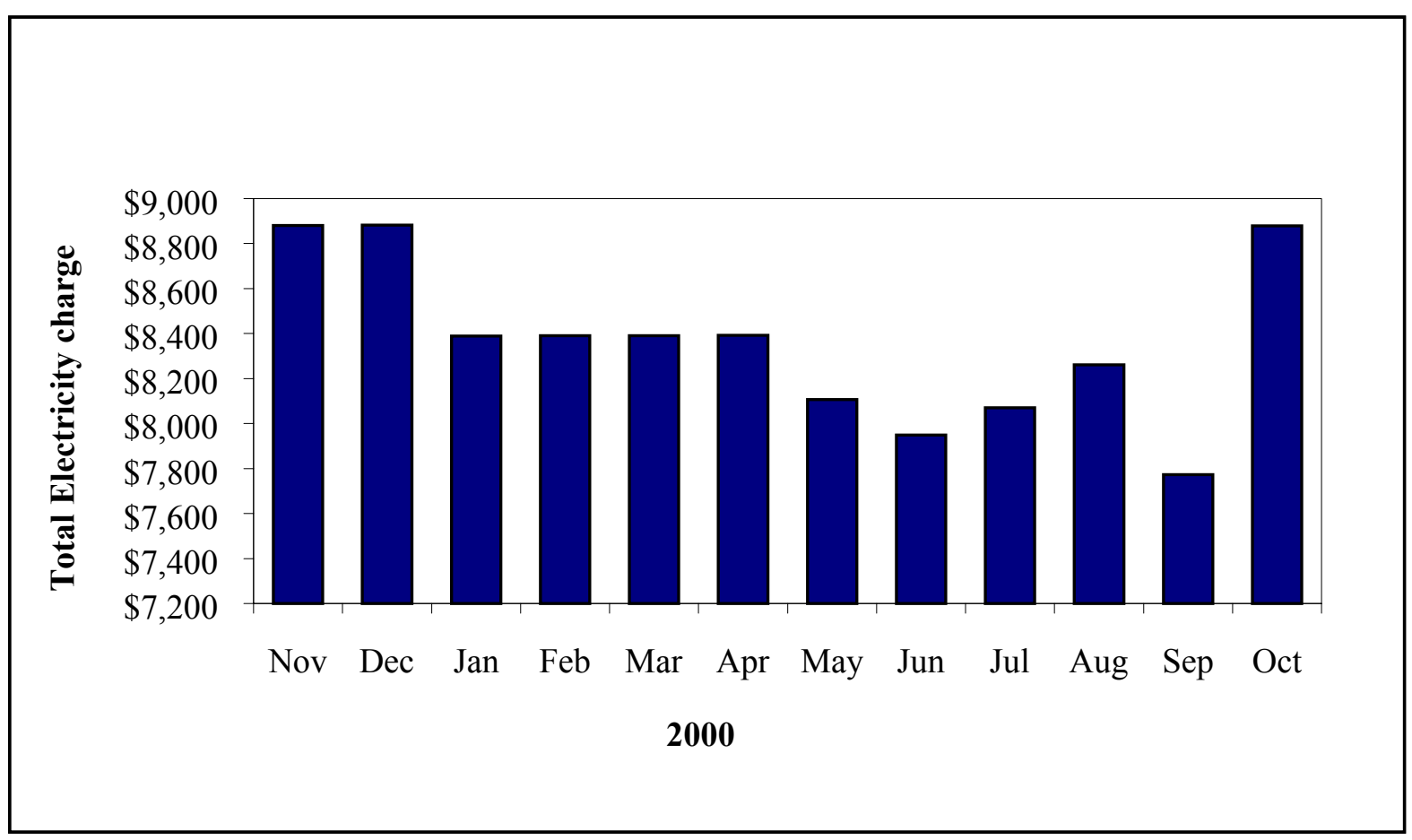

Figure 1.2: Electricity cost distribution for facility $B$ 


\section{Utility Bill Analysis for facility D}

\section{Scenario at facility $D$}

Facility D uses electrical energy and natural gas as energy in the plant. The major component of this energy charge is electricity. Electric motors being the major contributor, which constitute around 85 to $90 \%$ of the total connected load.

\section{Electric Cost Distribution}

This analysis of the electricity cost distribution normally involves the contribution of each of the components of the electricity bill, namely, the usage charge, the demand charge and the other charge towards the total electric bill. As seen in the Table 1.3, the values of energy usage in $\mathrm{kWh}$, billed demand in $\mathrm{kW}$, the usage cost in dollars and the total cost of electricity are obtained from the electric bills provided by the company. The load factor is also calculated from the electricity bills and shown in the table. The average $\mathrm{kWh}$ cost of electricity is calculated by taking the mean of all the energy usage cost available. The marginal cost of MMBtu is $\$ 7.89 /$ MMBtu. As can be seen in the Figure 1.3 the total cost of electricity is plotted against the months. Also it is seen that the approximately the total electric cost averages around $\$ 15,000$ per month. The demand as a percent of the total cost is calculated as follows:

\section{Demand as percentage of total cost $=$ Demand Cost $/$ Total Cost}

Using this formula the demand as a percent of total cost is calculated for each of the months. The average of this value is also calculated and is $44.41 \%$. 


\begin{tabular}{|c|c|c|c|c|c|c|c|c|c|}
\hline Months & $\begin{array}{l}\text { kWh } \\
\text { Used }\end{array}$ & $\begin{array}{c}\mathrm{kW} \\
\text { Demand }\end{array}$ & $\begin{array}{c}\text { kWh } \\
\text { charge } \\
(\$)\end{array}$ & $\begin{array}{c}\text { kW } \\
\text { Charge } \\
(\$)\end{array}$ & $\begin{array}{c}\text { Other } \\
\text { Charges } \\
(\$)\end{array}$ & $\begin{array}{c}\text { Total } \\
\text { Charge } \\
(\$)\end{array}$ & MMBtu & $\begin{array}{l}\text { Load } \\
\text { Factor }\end{array}$ & $\begin{array}{c}\text { Demand } \\
\text { as percent of } \\
\text { Total bill } \\
\end{array}$ \\
\hline Feb & 307,800 & 761.4 & 8523 & 6758 & 0 & 15281 & 1051 & 0.56 & 44 \\
\hline Mar & 307,200 & 715 & 8506 & 6389 & 0 & 14896 & 1048 & 0.60 & 43 \\
\hline Apr & 298,200 & 738.7 & 8257 & 6578 & 0 & 14835 & 1018 & 0.56 & 44 \\
\hline May & 280,800 & 686.9 & 7775 & 6166 & 0 & 13941 & 958 & 0.57 & 44 \\
\hline Jun & 253,200 & 658.8 & 7092 & 6002 & $(359.54)$ & 12734 & 864 & 0.53 & 47 \\
\hline Jul & 297,000 & 706.3 & 8319 & 6384 & $(421.74)$ & 14281 & 1014 & 0.58 & 45 \\
\hline Aug & 331,200 & 742 & 9277 & 6671 & $(500.30)$ & 15447 & 1130 & 0.62 & 43 \\
\hline Sep & 314,400 & 818.6 & 8806 & 7287 & $(446.45)$ & 15646 & 1073 & 0.53 & 47 \\
\hline Oct & 381,600 & 846.7 & 10689 & 7512 & $(541.87)$ & 17659 & 1302 & 0.63 & 43 \\
\hline Nov & 325,200 & 881.3 & 9109 & 7791 & $(461.78)$ & 16438 & 1110 & 0.51 & 47 \\
\hline Dec & 430,200 & 986 & 12050 & 8632 & $(610.88)$ & 20071 & 1468 & 0.61 & 43 \\
\hline Jan & 435,600 & 985 & 12201 & 8624 & $(618.55)$ & 20207 & 1487 & 0.61 & 43 \\
\hline Total & $3,962,400$ & $9,526.70$ & 110605 & 84793 & $(3,961.11)$ & 191,437 & Avg. & 0.58 & 44 \\
\hline
\end{tabular}

Table 1.3: Utility bill analysis for facility $D$

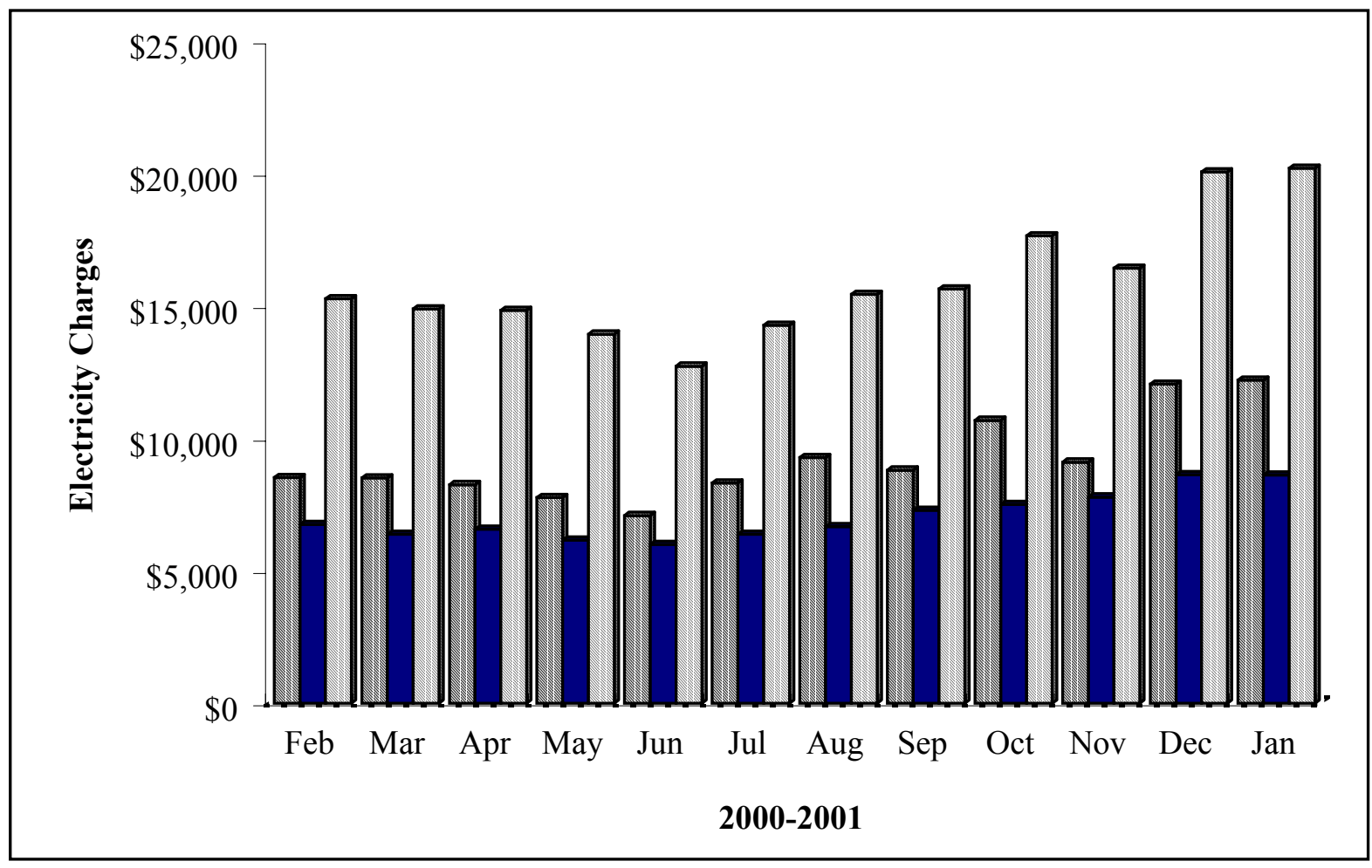

๑USAGE $\mathbf{D E M A N D}_{\mathrm{TOTAL}}$

Figure 1.3: Electricity cost distribution for facility D 


\section{Appendix II}

\section{Electrical Demand Analysis for facility C}

\section{Load profile of facility $\mathrm{C}$}

The peak demand for facility $\mathrm{C}$ is plotted for all the months available and a load profile of the connected load obtained. This is very important plot with respect to the amount of load variation, and the opportunities for reduction of demand charges at facility $\mathrm{C}$. The demand data in $\mathrm{kW}$ was obtained from Allegheny Power Company. The Figure 2.1 shows the plot of the plant demand in $\mathrm{kW}$ against the months of the year 1999-2000. As seen in the plot the curve appears to be cyclic indicating good potential for demand reduction. The average demand on the curve is $462 \mathrm{~kW}$, the upper limit is $529 \mathrm{~kW}$ and the lower limit is $408 \mathrm{~kW}$. There definitely lies some opportunity for improvement in the plant load factor and level the curves from the Figure 2.1. There is definitely some scope for reduction in the electrical demand of the plant.

\section{Sensitivity Analysis For Demand Reduction}

A sensitivity analysis for the reduction of $\mathrm{kW}$ demand is performed as seen in the Figure 2.2. As seen the percentage reduction in demand is plotted against the corresponding total electric charge. The percentage demand reduction is varied from the existing value to $20 \%$ reduction. Corresponding total costs are seen in the Table 2.1 below. The table shows the annual cost savings obtained for facility $\mathrm{C}$ for different levels of reduction in demand. Also the percentage change in the total electricity charge over the current annual charge is calculated. The slope of the line in the plot is calculated. This slope corresponds to the cost saving in total charge for one percent reduction in demand. It is seen that for every one percent reduction in $\mathrm{kW}$ demand for facility $\mathrm{C}$, the total electricity charges will come down by approximately $\$ 285 /$ year. Thus the control over the demand of the plant will play a crucial role in the energy efficiency program undertaken by the management. 


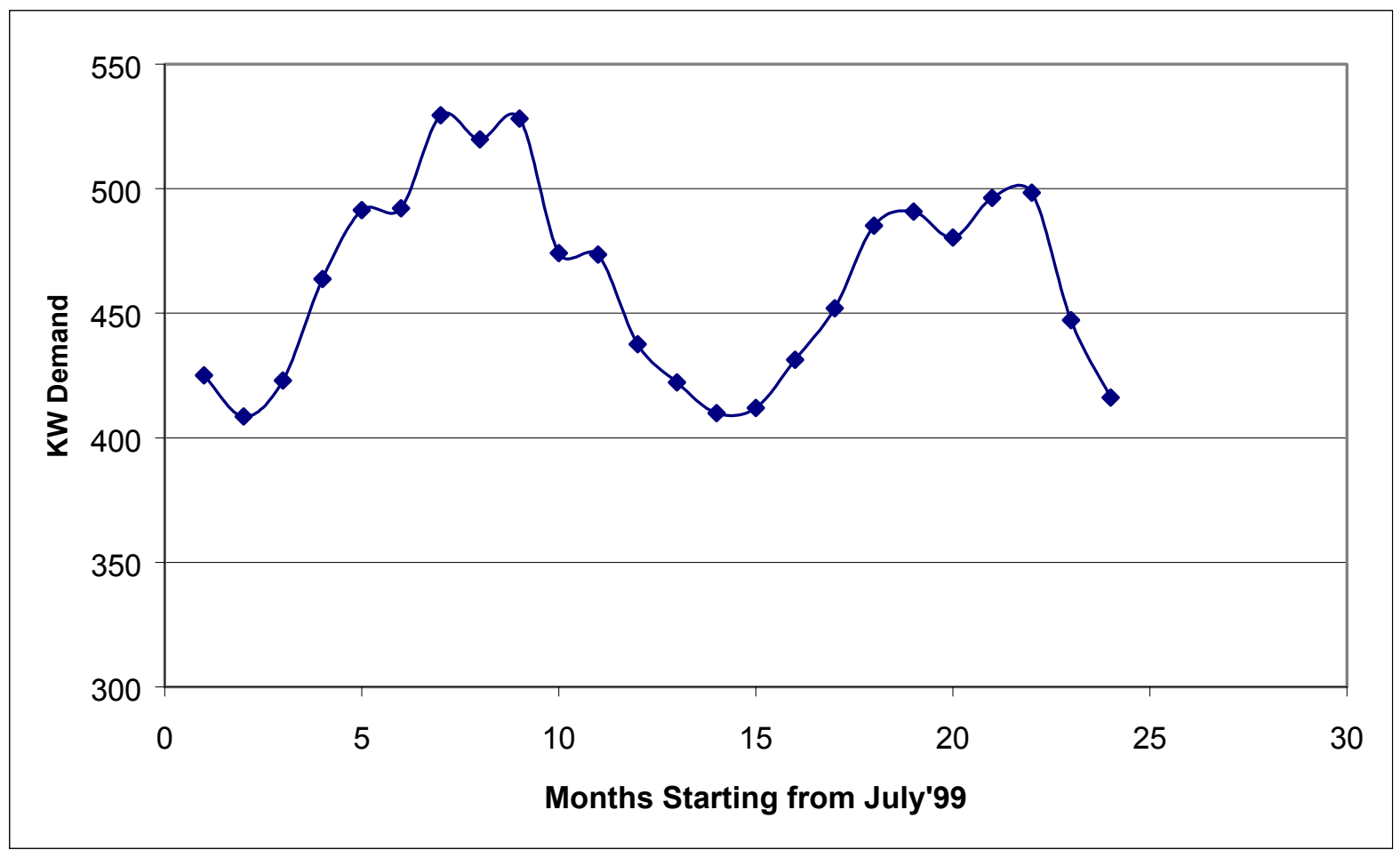

Figure 2.1: Load profile for facility $C$

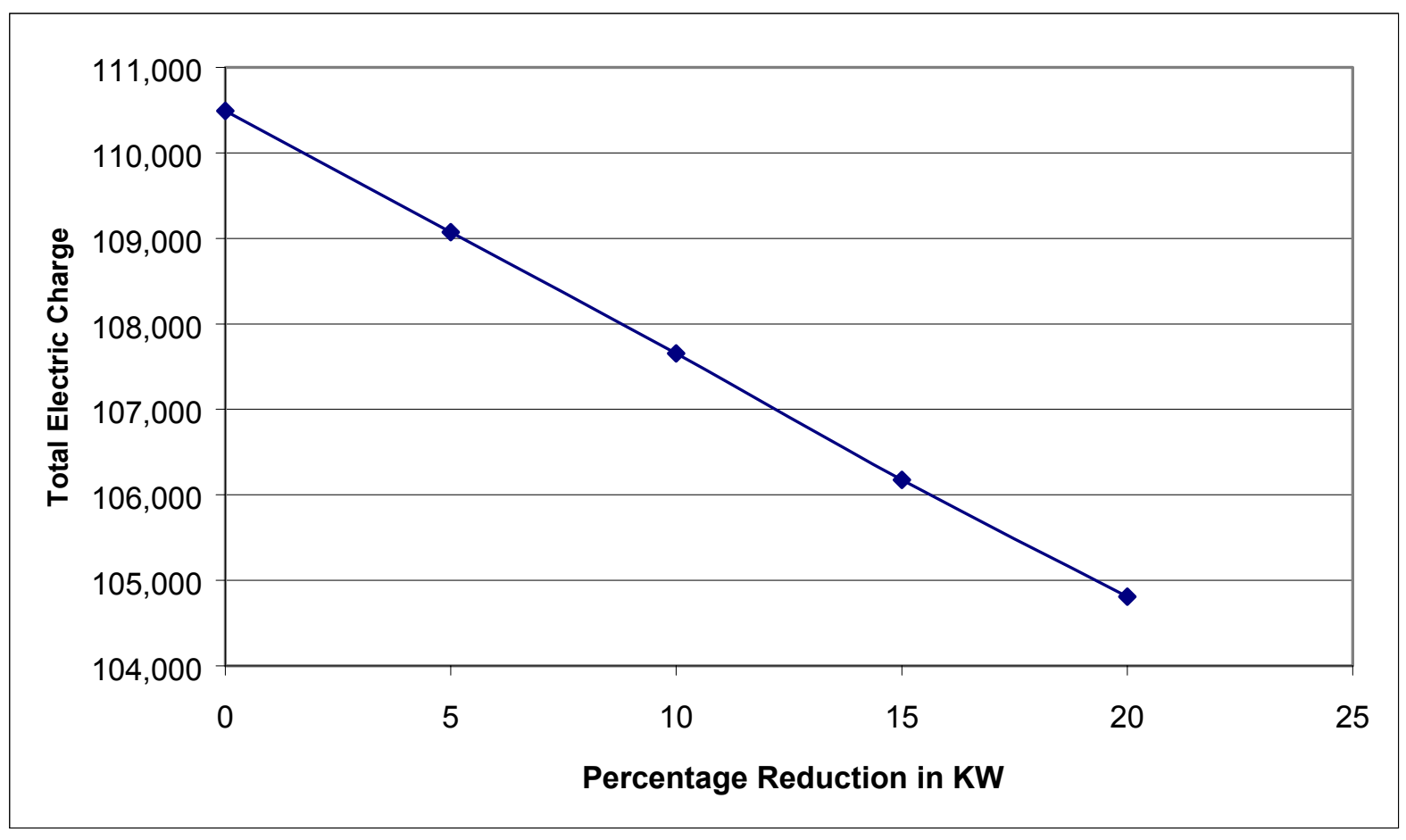

Figure 2.2: Plot for demand sensitivity analysis for facility $C$ 


\begin{tabular}{|c|c|c|c|c|c|c|c|c|c|}
\hline \multicolumn{2}{|c|}{ Present kW Demand } & \multicolumn{2}{|c|}{$5 \%$ Red in kW Demand } & \multicolumn{2}{|c|}{$10 \%$ Red in kW Demand } & \multicolumn{2}{|c|}{$15 \%$ Red in kW Demand } & \multicolumn{2}{|c|}{$20 \%$ Red in kW Demand } \\
\hline $\begin{array}{l}\text { Demand } \\
(\mathbf{k W})\end{array}$ & $\begin{array}{c}\text { Total Charge } \\
(\$)\end{array}$ & $\begin{array}{c}\text { Demand } \\
(\mathbf{k W})\end{array}$ & $\begin{array}{c}\text { Total Charge } \\
(\$)\end{array}$ & $\begin{array}{c}\text { Demand } \\
(\mathbf{k W})\end{array}$ & $\begin{array}{c}\text { Total Charge } \\
(\$)\end{array}$ & $\begin{array}{c}\text { Demand } \\
(\mathbf{k W})\end{array}$ & $\begin{array}{c}\text { Total Charge } \\
(\$)\end{array}$ & $\begin{array}{c}\text { Demand } \\
(\mathbf{k W})\end{array}$ & $\begin{array}{c}\text { Total Charge } \\
(\$)\end{array}$ \\
\hline 431 & 8,396 & 410 & 8,284 & 388 & 8,171 & 367 & 8,058 & 345 & 7,945 \\
\hline 410 & 8,458 & 389 & 8,351 & 369 & 8,243 & 348 & 8,136 & 328 & 8,029 \\
\hline 422 & 8,349 & 401 & 8,239 & 380 & 8,128 & 359 & 7,963 & 338 & 7,907 \\
\hline 438 & 8,980 & 416 & 8,866 & 394 & 8,751 & 372 & 8,637 & 350 & 8,522 \\
\hline 474 & 9,672 & 450 & 9,548 & 427 & 9,424 & 403 & 9,300 & 379 & 9,176 \\
\hline 474 & 9,672 & 450 & 9,548 & 427 & 9,424 & 403 & 9,300 & 379 & 9,176 \\
\hline 474 & 9,672 & 450 & 9,548 & 427 & 9,424 & 403 & 9,300 & 379 & 9,176 \\
\hline 474 & 9,672 & 450 & 9,548 & 427 & 9,424 & 403 & 9,300 & 379 & 9,176 \\
\hline 474 & 9,672 & 450 & 9,548 & 427 & 9,424 & 403 & 9,300 & 379 & 9,176 \\
\hline $\begin{array}{l}\text { \% Change in total } \\
\text { Charge over Present }\end{array}$ & $\mathbf{0}$ & & -1.29 & & -2.57 & & -3.91 & & -5.15 \\
\hline
\end{tabular}

Table 2.1: Demand sensitivity analysis for facility $\mathbf{C}$ 


\section{Electrical Demand Analysis for facility B}

\section{Load profile of facility $B$}

The peak demand for facility B is plotted for all the months available and a load profile of the connected load obtained. This is very important plot with respect to the amount of load variation, and the opportunities for reduction of demand charges at Riverton. The demand data in $\mathrm{kW}$ was obtained from Allegheny Power Company. The Figure 2.3 shows the plot of the plant demand in $\mathrm{kW}$ against the months of the year 1999-2000. As seen in the plot the curve appears to be cyclic indicating good potential for demand reduction. The average demand on the curve is $451 \mathrm{~kW}$, the upper limit is $536 \mathrm{~kW}$ and the lower limit is $379 \mathrm{~kW}$. Looking at these minimum and maximum figures, we can figure out that there lies an ample opportunity for leveling out the load profile and improve the load factor of the plant. There is definitely a possibility for electrical demand reduction.

\section{Sensitivity Analysis For Demand Reduction}

A sensitivity analysis for the reduction of $\mathrm{kW}$ demand is performed as seen in Figure 2.4. As seen the percentage reduction in demand is plotted against the corresponding total electric charge. The percentage demand reduction varies from the present to $20 \%$ reduction. Corresponding total costs are seen in the Table 2.2 below. Saving in total charge of electricity is calculated over the present charge. The table shows the annual cost savings obtained for facility $\mathrm{B}$ for different levels of reduction in demand. Also the percentage change in the total electricity charge over the current annual charge is calculated. The slope of the line in the plot is calculated. This slope corresponds to the cost saving in total charge for one percent reduction in demand. It is seen that for every $1 \%$ reduction in $\mathrm{kW}$ demand for facility B, the total electricity charges will come down by approximately $\$ 274$ per year. Thus the control over the demand of the plant will play a crucial role in the energy efficiency program undertaken by the management. 


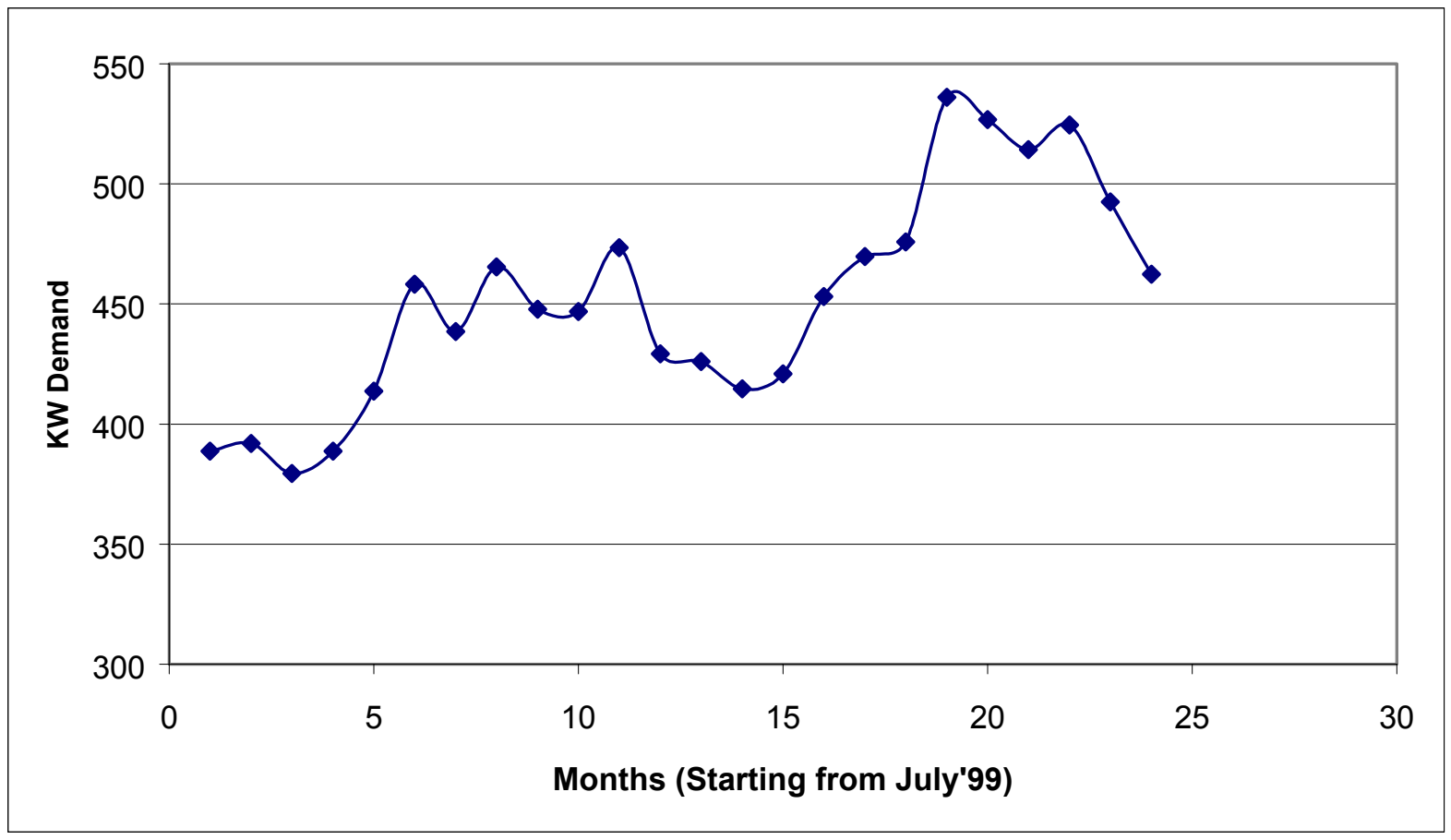

Figure 2.3: Load profile for facility $B$

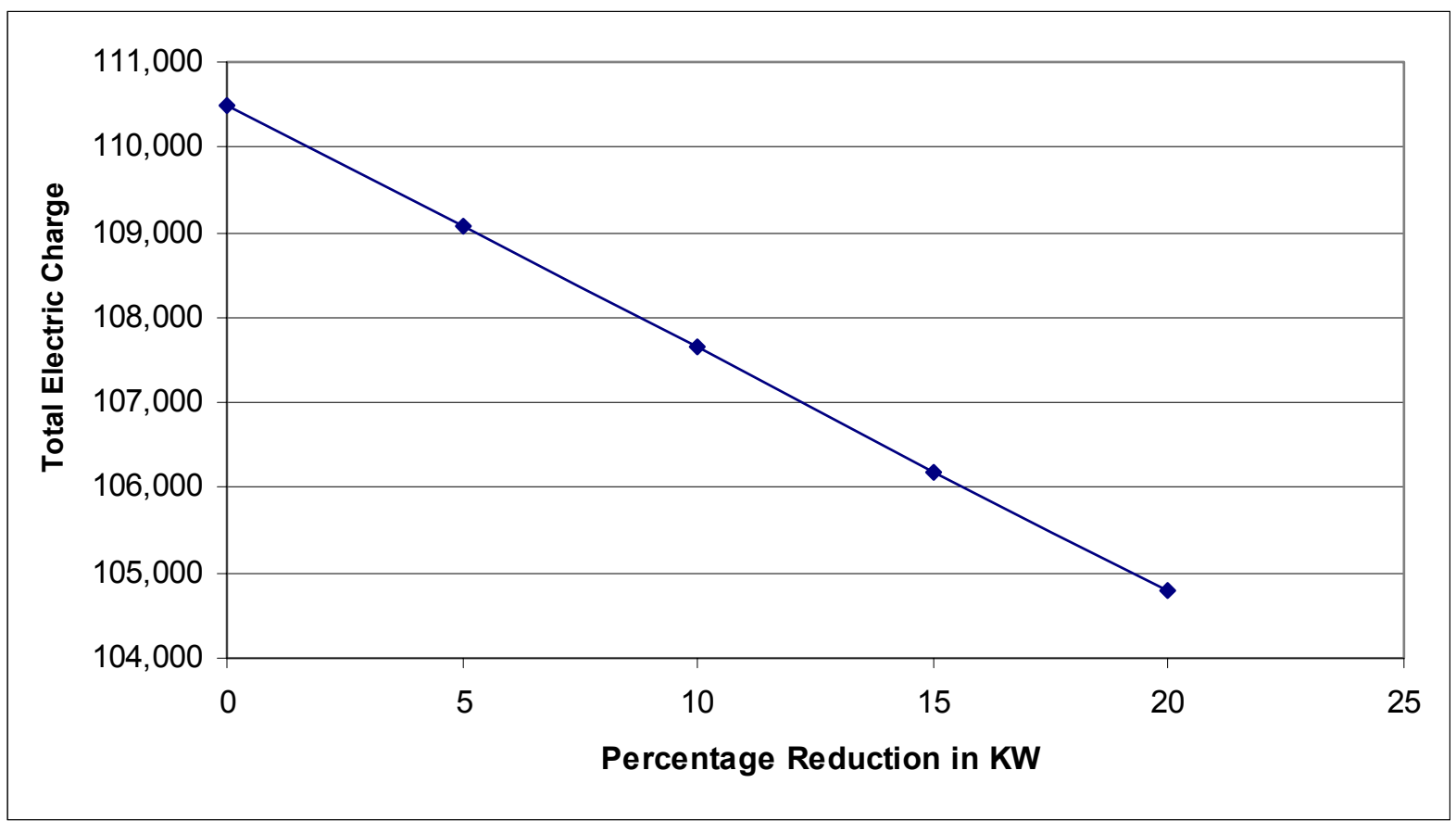

Figure 2.4: Plot for demand sensitivity analysis for facility $B$ 


\begin{tabular}{|c|c|c|c|c|c|c|c|c|c|}
\hline \multicolumn{2}{|c|}{ Present kW Demand } & \multicolumn{2}{|c|}{$5 \%$ Red in $\mathrm{kW}$ Demand } & \multicolumn{2}{|c|}{$10 \%$ Red in kW Demand } & \multicolumn{2}{|c|}{$15 \%$ Red in kW Demand } & \multicolumn{2}{|c|}{$20 \%$ Red in $\mathrm{kW}$ Demand } \\
\hline $\begin{array}{l}\text { Demand } \\
(\mathrm{kW})\end{array}$ & \begin{tabular}{|c|} 
Total Charge \\
$(\$)$
\end{tabular} & $\begin{array}{c}\text { Demand } \\
(\mathrm{kW})\end{array}$ & $\begin{array}{c}\text { Total Charge } \\
(\$)\end{array}$ & $\begin{array}{c}\text { Demand } \\
(\mathrm{kW})\end{array}$ & $\begin{array}{c}\text { Total Charge } \\
(\$)\end{array}$ & $\begin{array}{c}\text { Demand } \\
(\mathrm{kW})\end{array}$ & $\begin{array}{c}\text { Total Charge } \\
(\$)\end{array}$ & $\begin{array}{c}\text { Demand } \\
(\mathrm{kW})\end{array}$ & $\begin{array}{c}\text { Total Charge } \\
(\$)\end{array}$ \\
\hline 470 & \begin{tabular}{|c|}
9,165 \\
\end{tabular} & 446 & 9,043 & 423 & 8,920 & 399 & 8,797 & 376 & 8,674 \\
\hline 453 & 8,013 & 430 & 7,895 & 408 & 7,776 & 385 & 7,658 & 362 & 7,539 \\
\hline 421 & 8,531 & 400 & 8,421 & 379 & 8,311 & 358 & 8,201 & 337 & 8,091 \\
\hline 415 & 8,333 & 394 & 8,225 & 373 & 8,116 & 352 & 8,008 & 332 & 7,899 \\
\hline 426 & 8,203 & 405 & 8,092 & 383 & 7,980 & 362 & 7,869 & 341 & 7,757 \\
\hline 429 & 8,106 & 408 & 7,994 & 386 & 7,882 & 365 & 7,770 & 343 & 7,657 \\
\hline 438 & 8,392 & 416 & 8,277 & 394 & 8,163 & 372 & 8,048 & 350 & 7,934 \\
\hline 438 & 8,392 & 416 & 8,277 & 394 & 8,163 & 372 & 8,048 & 350 & 7,934 \\
\hline 438 & 8,392 & 416 & 8,277 & 394 & 8,163 & 372 & 8,048 & 350 & 7,934 \\
\hline 438 & 8,392 & 416 & 8,277 & 394 & 8,163 & 372 & 8,048 & 350 & 7,934 \\
\hline 438 & 8,392 & 416 & 8,277 & 394 & 8,163 & 372 & 8,048 & 350 & 7,934 \\
\hline \multirow[t]{2}{*}{438} & 8,392 & 416 & 8,277 & 394 & 8,163 & 372 & 8,048 & 350 & 7,934 \\
\hline & 100,704 & & 99,333 & & 97,962 & & 96,592 & & 95,221 \\
\hline $\begin{array}{c}\text { Savings obtained } \\
\text { over present demand } \\
(\$ / \text { Year })\end{array}$ & $\mathbf{0}$ & & 1,370 & & 2,742 & & 4,112 & & 5,483 \\
\hline $\begin{array}{l}\% \text { Change in total } \\
\text { charge over present }\end{array}$ & 0 & & -1.36 & & -2.72 & & -4.08 & & -5.44 \\
\hline
\end{tabular}

Table 2.2: Demand sensitivity analysis for facility $B$ 


\section{Electrical Demand Analysis for facility D}

\section{Load profile of facility $D$}

The peak kilowatt demand for facility $\mathrm{D}$ is plotted for all the months available and a load profile of the connected load obtained. This is very important plot with respect to the amount of load variation, and the opportunities for reduction of demand charges at plant. The Figure 2.5 shows the plot of the plant demand in $\mathrm{kW}$ against the months of the year 19992000. As seen in the plot the curve appears to be steady for some initial months and it peaks up in the later months. The peak demand occurring in winter may be due to electrical resistance space heating. The amount of variation seen in the plot is normal for any manufacturing facility. The average demand of on the curve is $793 \mathrm{~kW}$. Thus we can conclude there lies some opportunity for reduction in the plant demand at facility D.

\section{Sensitivity Analysis For Demand Reduction}

A sensitivity analysis for the reduction of $\mathrm{kW}$ demand is performed as seen in Figure 2.6. As seen the percentage reduction in demand is plotted against the corresponding total electric charge. The percentage demand reduction varies from the present to $20 \%$ reduction. Corresponding total costs are seen in the Table 2.3 below. The table shows the annual cost savings obtained for the plant for different levels of reduction in demand. Also the percentage change in the total electricity charge over the current annual charge is calculated. Saving in total charge of electricity is calculated over the present charge. The slope of the line in the plot is calculated. This slope corresponds to the cost saving in total charge for one percent reduction in demand. It is seen that for every one percent reduction in $\mathrm{kW}$ demand for facility D, the total electricity charges will come down by approximately \$2209/year. Thus the control over the demand of the plant will play a crucial role in the energy efficiency program undertaken by the management. 


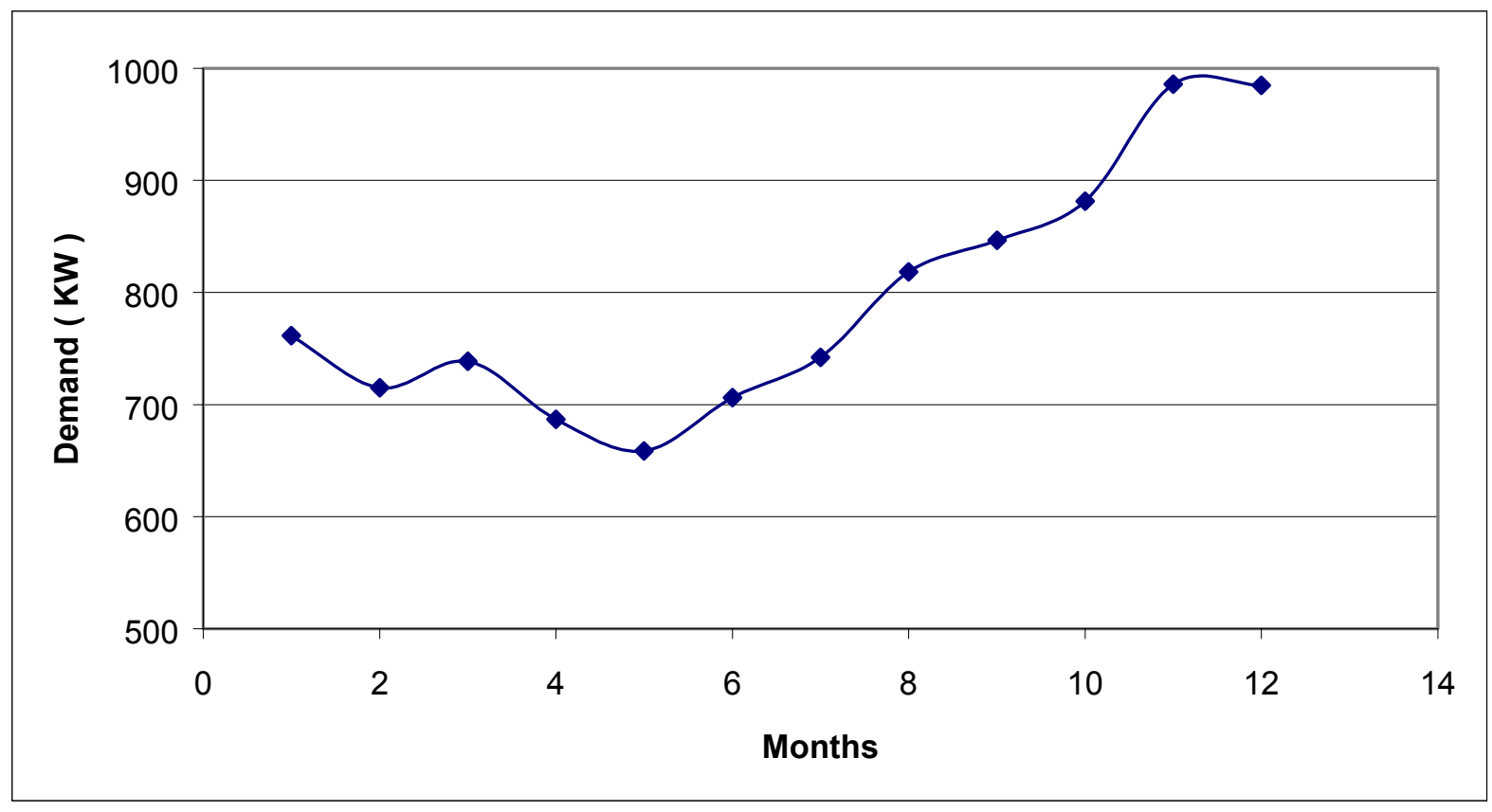

Figure 2.5: Load profile for facility D

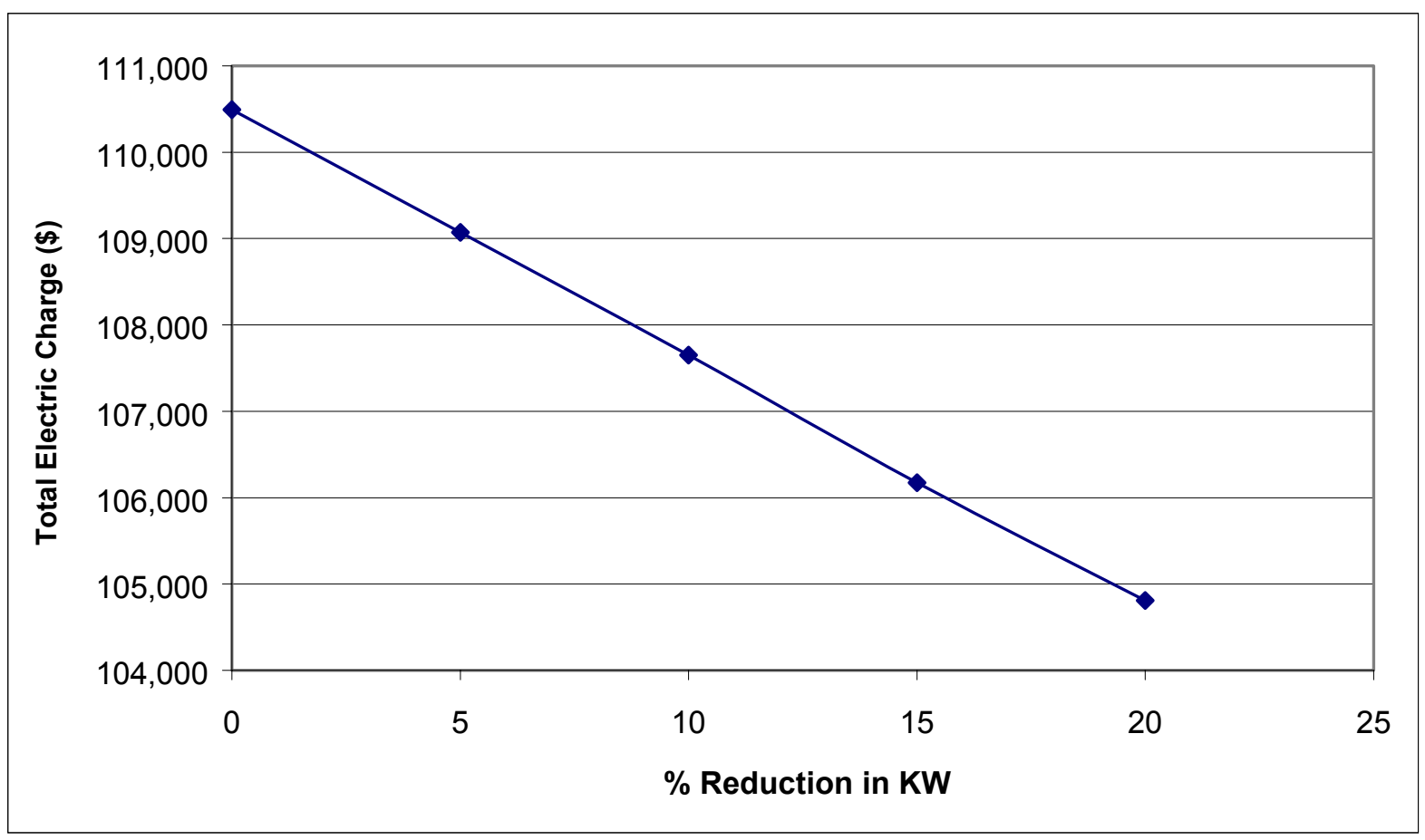

Figure 2.6: Plot for demand sensitivity analysis for facility D 


\begin{tabular}{|c|c|c|c|c|c|c|c|c|c|}
\hline \multicolumn{2}{|c|}{ Present kW Demand } & \multicolumn{2}{|c|}{$5 \%$ Red in kW Demand } & \multicolumn{2}{|c|}{$10 \%$ Red in kW Demand } & \multicolumn{2}{|c|}{$15 \%$ Red in kW Demand } & \multicolumn{2}{|c|}{$20 \%$ Red in $\mathrm{kW}$ Demand } \\
\hline $\begin{array}{c}\text { Demand } \\
(\mathbf{k W})\end{array}$ & $\begin{array}{c}\text { Total } \\
\text { Charge } \\
(\$)\end{array}$ & $\begin{array}{c}\text { Demand } \\
(\mathbf{k W})\end{array}$ & $\begin{array}{c}\text { Total Charge } \\
(\$)\end{array}$ & $\begin{array}{c}\text { Demand } \\
(\mathbf{k W})\end{array}$ & $\begin{array}{c}\text { Total Charge } \\
(\$)\end{array}$ & $\begin{array}{c}\text { Demand } \\
(\mathbf{k W})\end{array}$ & $\begin{array}{c}\text { Total Charge } \\
(\$)\end{array}$ & $\begin{array}{c}\text { Demand } \\
(\mathbf{k W})\end{array}$ & $\begin{array}{c}\text { Total Charge } \\
(\$)\end{array}$ \\
\hline 761 & 15,299 & 723 & 14,535 & 685 & 13,770 & 647 & 13,005 & 609 & 12,240 \\
\hline 715 & 14,870 & 679 & 14,126 & 644 & 13,383 & 608 & 12,639 & 572 & 11,896 \\
\hline 739 & 14,832 & 702 & 14,090 & 665 & 13,348 & 628 & 12,607 & 591 & 5,260 \\
\hline 687 & 13,889 & 653 & 13,194 & 618 & 12,500 & 584 & 11,806 & 550 & 11,111 \\
\hline 659 & 12,874 & 626 & 12,231 & 593 & 11,587 & 560 & 10,943 & 527 & 10,300 \\
\hline 706 & 14,510 & 671 & 13,785 & 636 & 13,059 & 600 & 12,334 & 565 & 11,608 \\
\hline 742 & 15,775 & 705 & 14,986 & 668 & 14,197 & 631 & 13,409 & 594 & 12,620 \\
\hline 819 & 15,991 & 778 & 15,192 & 737 & 14,392 & 696 & 13,593 & 655 & 12,793 \\
\hline 847 & 18,102 & 804 & 17,197 & 762 & 16,292 & 720 & 15,387 & 677 & 14,482 \\
\hline 881 & 16,848 & 837 & 16,006 & 793 & 15,164 & 749 & 14,321 & 705 & 13,479 \\
\hline 986 & 20,688 & 937 & 19,653 & 887 & 18,619 & 838 & 17,585 & 789 & 16,550 \\
\hline \multirow[t]{2}{*}{985} & 20,828 & 936 & 19,787 & 887 & 18,745 & 837 & 17,704 & 788 & 16,663 \\
\hline & 194,506 & & 184,782 & & 175,056 & & 165,331 & & 148,999 \\
\hline \begin{tabular}{|c|} 
Savings Obtained \\
over Present Demand \\
( $\$$ per Year $)$ \\
\end{tabular} & $\mathbf{0}$ & & 9,724 & & 19,450 & & 29,175 & & 45,507 \\
\hline \begin{tabular}{|c|}
$\%$ Change in total \\
Charge over Present \\
\end{tabular} & 0.00 & & -5.00 & & -10.00 & & -15.00 & & -23.40 \\
\hline
\end{tabular}

Table 2.3: Demand sensitivity analysis for facility $D$ 


\section{Appendix III}

\section{Motor load test data and calculations}

\section{Motor load test results at facility $\mathbf{G}$}

1) Motor load test on chipper shaker motor

\begin{tabular}{|l|l|l|l|}
\hline Company & Facility G & Location & Spencer, WV \\
\hline Date & $04 / 18 / 2002$ & Process & Chipper Shaker \\
\hline \multicolumn{3}{|c|}{ Motor Name Plate Data } \\
\hline Manufacturer & Lincoln Motors & Synchronous speed & $1800 \mathrm{rpm}$ \\
\hline Full load speed & $1760 \mathrm{rpm}$ & Voltage rating & $460 \mathrm{~V}$ \\
\hline Size & $40 \mathrm{hp}$ & Enclosure type & TEFC \\
\hline Operating speed & $1780 \mathrm{rpm}$ &
\end{tabular}

\section{Table 3.1: Motor load test data for a chipper shaker}

\section{Calculations for the field test}

$$
\begin{aligned}
\text { Slip } & =\text { RPM }_{\text {sync }}-\mathrm{RPM}_{\text {measured }} \\
\text { Slip } & =1800-1780 \\
& =20
\end{aligned}
$$

$$
\begin{aligned}
\text { Motor load } & =\frac{\text { Slip }}{\text { RPM }_{\text {sync }}-\text { RPM }_{\text {full load (nameplate) }}} \\
& =\frac{20}{1800-1760} \\
& =0.50
\end{aligned}
$$

Thus from the calculations it can be seen that the instantaneous load of the chipper shaker motor is 0.50 . 
2) Motor load test on treatment plant motor

\begin{tabular}{|l|l|l|l|}
\hline Company & Facility G & Location & Spencer, WV \\
\hline Date & $04 / 18 / 2002$ & Process & Treatment plant \\
\hline \multicolumn{4}{|c|}{ Motor Name Plate Data } \\
\hline Manufacturer & Marathon Electric & $\begin{array}{l}\text { Synchronous } \\
\text { speed }\end{array}$ & $1800 \mathrm{rpm}$ \\
\hline Full load speed & $1760 \mathrm{rpm}$ & $\begin{array}{l}\text { Voltage } \\
\text { rating }\end{array}$ & $460 \mathrm{~V}$ \\
\hline Size & $40 \mathrm{hp}$ & $\begin{array}{l}\text { Enclosure } \\
\text { type }\end{array}$ & TEFC \\
\hline Operating speed & $1762 \mathrm{rpm}$ & \multicolumn{2}{|l}{} \\
\hline
\end{tabular}

Table 3.2: Motor load test data for a treatment plant motor

\section{Calculations for the field test}

$$
\begin{aligned}
\text { Slip } & =\mathrm{RPM}_{\text {sync }}-\mathrm{RPM} \text { measured } \\
\text { Slip } & =1800-1762 \\
& =38
\end{aligned}
$$

$$
\begin{aligned}
\text { Motor load } & =\frac{\text { Slip }}{\mathrm{RPM}_{\text {sync }}-\mathrm{RPM}_{\text {full load (nameplate) }}} \\
& =\frac{38}{1800-1760} \\
& =0.95
\end{aligned}
$$

Thus from the calculations it can be seen that the instantaneous load of the treatment plant motor is 0.95 . 
3) Motor load test on trimmer motor

\begin{tabular}{|l|l|l|l|}
\hline Company & Facility G & Location & Spencer, WV \\
\hline Date & $04 / 18 / 2002$ & Process & Trimmer \\
\hline \multicolumn{4}{|c|}{ Motor Name Plate Data } \\
\hline Manufacturer & Lincoln Motors & Synchronous speed & $1800 \mathrm{rpm}$ \\
\hline Full load speed & $1745 \mathrm{rpm}$ & Voltage rating & $460 \mathrm{~V}$ \\
\hline Size & $10 \mathrm{hp}$ & Enclosure type & ODP \\
\hline Operating speed & $1774 \mathrm{rpm}$ & \\
\hline
\end{tabular}

Table 3.3: Motor load test data for a trimmer motor

\section{Calculations for the field test}

$$
\begin{aligned}
\text { Slip } & =\mathrm{RPM}_{\text {sync }}-\mathrm{RPM}_{\text {measured }} \\
\text { Slip } & =1800-1774 \\
& =26
\end{aligned}
$$

$$
\begin{aligned}
\text { Motor load } & =\frac{\text { Slip }}{\mathrm{RPM}_{\text {sync }}-\mathrm{RPM}_{\text {full load (nameplate) }}} \\
& =\frac{26}{1800-1745} \\
& =0.47
\end{aligned}
$$

Thus from the calculations it can be seen that the instantaneous load of the trimmer motor is 0.47 . 


\section{Motor load test results at facility $F$}

1) Motor load test on edger motor $I$.

\begin{tabular}{|l|l|l|l|}
\hline Company & Facility F & Location & Bartow, WV \\
\hline Date & $04 / 25 / 2002$ & Process & Edging \\
\hline \multicolumn{4}{|c|}{ Motor Name Plate Data } \\
\hline Manufacturer & Lincoln Motors & Synchronous speed & $1800 \mathrm{rpm}$ \\
\hline Full load speed & $1780 \mathrm{rpm}$ & Voltage rating & $460 \mathrm{~V}$ \\
\hline Size & $150 \mathrm{hp}$ & Enclosure type & ODP \\
\hline Operating speed & $1791 \mathrm{rpm}$ & \\
\hline
\end{tabular}

Table 3.4: Motor load test data for an edger motor I

\section{Calculations for the field test}

$$
\begin{aligned}
\text { Slip } & =\mathrm{RPM}_{\text {sync }}-\mathrm{RPM}_{\text {measured }} \\
\text { Slip } & =1800-1791 \\
& =9
\end{aligned}
$$

Motor load $=$

$$
\text { Slip }
$$$$
\mathrm{RPM}_{\text {sync }}-\mathrm{RPM} \text { full load (nameplate) }
$$$$
=
$$$$
9
$$$$
1800-1780
$$$$
=0.45
$$

Thus from the calculations it can be seen that the instantaneous load of the edger motor I is 0.45 . 


\section{2) Motor load test on edger motor II}

\begin{tabular}{|l|l|l|l|}
\hline Company & Facility F & Location & Bartow, WV \\
\hline Date & $04 / 25 / 2002$ & Process & Edging \\
\hline \multicolumn{4}{|c|}{ Motor Name Plate Data } \\
\hline Manufacturer & Lincoln Motors & Synchronous speed & $1800 \mathrm{rpm}$ \\
\hline Full load speed & $1780 \mathrm{rpm}$ & Voltage rating & $460 \mathrm{~V}$ \\
\hline Size & $150 \mathrm{hp}$ & Enclosure type & ODP \\
\hline Operating speed & $1790 \mathrm{rpm}$ & \\
\hline
\end{tabular}

Table 3.5: Motor load test data for an edger motor II

\section{Calculations for the field test}

$$
\begin{aligned}
\text { Slip } & =\mathrm{RPM}_{\text {sync }}-\mathrm{RPM} \text { measured } \\
\text { Slip } & =1800-1790 \\
& =10
\end{aligned}
$$

$$
\begin{aligned}
\text { Motor load } & =\frac{\text { Slip }}{\text { RPM }_{\text {sync }}-\mathrm{RPM}_{\text {full load (nameplate) }}} \\
& =\frac{10}{1800-1780} \\
& =0.5
\end{aligned}
$$

Thus from the calculations it can be seen that the instantaneous load of the edger motor II is 0.5 . 


\section{3) Motor load test on chipper motor I}

\begin{tabular}{|l|l|l|l|}
\hline Company & Facility F & Location & Bartow, WV \\
\hline Date & $04 / 25 / 2002$ & Process & Chipper \\
\hline \multicolumn{4}{|c|}{ Motor Name Plate Data } \\
\hline Manufacturer & Lincoln Motors & Synchronous speed & $1800 \mathrm{rpm}$ \\
\hline Full load speed & $1780 \mathrm{rpm}$ & Voltage rating & $460 \mathrm{~V}$ \\
\hline Size & $150 \mathrm{hp}$ & Enclosure type & TEFC \\
\hline Operating speed & $1790 \mathrm{rpm}$ & \\
\hline
\end{tabular}

Table 3.6: Motor load test data for a chipper motor I

\section{Calculations for the field test}

$$
\begin{aligned}
\text { Slip } & =\mathrm{RPM}_{\text {sync }}-\mathrm{RPM} \text { measured } \\
\text { Slip } & =1800-1790 \\
& =10
\end{aligned}
$$

$$
\begin{aligned}
\text { Motor load } & =\frac{\text { Slip }}{\text { RPM }_{\text {sync }}-\mathrm{RPM}_{\text {full load (nameplate) }}} \\
& =\frac{10}{1800-1780} \\
& =0.5
\end{aligned}
$$

Thus from the calculations it can be seen that the instantaneous load of the chipper motor I is 0.5 . 


\section{4) Motor load test on chipper motor II}

\begin{tabular}{|l|l|l|l|}
\hline Company & Facility F & Location & Bartow, WV \\
\hline Date & $04 / 25 / 2002$ & Process & Chipper \\
\hline \multicolumn{4}{|c|}{ Motor Name Plate Data } \\
\hline Manufacturer & Lincoln Motors & Synchronous speed & $1800 \mathrm{rpm}$ \\
\hline Full load speed & $1760 \mathrm{rpm}$ & Voltage rating & $460 \mathrm{~V}$ \\
\hline Size & $150 \mathrm{hp}$ & Enclosure type & TEFC \\
\hline Operating speed & $1788 \mathrm{rpm}$ & \\
\hline
\end{tabular}

Table 3.7: Motor load test data for a chipper motor II

\section{Calculations for the field test}

$$
\begin{aligned}
\text { Slip } & =\mathrm{RPM}_{\text {sync }}-\mathrm{RPM} \text { measured } \\
\text { Slip } & =1800-1788 \\
& =12
\end{aligned}
$$

$$
\begin{aligned}
\text { Motor load } & =\frac{\text { Slip }}{\mathrm{RPM}_{\text {sync }}-\mathrm{RPM}_{\text {full load (nameplate) }}} \\
& =\frac{12}{1800-1760} \\
& =0.30
\end{aligned}
$$

Thus from the calculations it can be seen that the instantaneous load of the chipper motor II is 0.30 . 


\section{5) Motor load test on trimmer motor}

\begin{tabular}{|l|l|l|l|}
\hline Company & Facility F & Location & Bartow, WV \\
\hline Date & $04 / 25 / 2002$ & Process & Trimmer \\
\hline \multicolumn{4}{|c|}{ Motor Name Plate Data } \\
\hline Manufacturer & Lincoln Motors & Synchronous speed & $1800 \mathrm{rpm}$ \\
\hline Full load speed & $1730 \mathrm{rpm}$ & Voltage rating & $460 \mathrm{~V}$ \\
\hline Size & $200 \mathrm{hp}$ & Enclosure type & TEFC \\
\hline Operating speed & $1762 \mathrm{rpm}$ & \\
\hline
\end{tabular}

Table 3.8: Motor load test data for an trimmer motor

\section{Calculations for the field test}

$$
\begin{aligned}
\text { Slip } & =\mathrm{RPM}_{\text {sync }}-\mathrm{RPM} \text { measured } \\
\text { Slip } & =1800-1762 \\
& =38
\end{aligned}
$$

$$
\begin{aligned}
\text { Motor load } & =\frac{\text { Slip }}{\text { RPM }_{\text {sync }}-\mathrm{RPM}_{\text {full load (nameplate) }}} \\
& =\frac{38}{1800-1730} \\
& =0.54
\end{aligned}
$$

Thus from the calculations it can be seen that the instantaneous load of the trimmer motor is 0.54 . 
6) Motor load test on dehumidifier motor

\begin{tabular}{|l|l|l|l|}
\hline Company & Facility F & Location & Bartow, WV \\
\hline Date & $04 / 25 / 2002$ & Process & Dehumidifier \\
\hline \multicolumn{4}{|c|}{ Motor Name Plate Data } \\
\hline Manufacturer & Lincoln Motors & Synchronous speed & $1800 \mathrm{rpm}$ \\
\hline Full load speed & $1775 \mathrm{rpm}$ & Voltage rating & $460 \mathrm{~V}$ \\
\hline Size & $75 \mathrm{hp}$ & Enclosure type & ODP \\
\hline Operating speed & $1779 \mathrm{rpm}$ & \\
\hline
\end{tabular}

Table 3.9: Motor load test data for an trimmer motor

\section{Calculations for the field test}

$$
\begin{aligned}
\text { Slip } & =\mathrm{RPM}_{\text {sync }}-\mathrm{RPM}_{\text {measured }} \\
\text { Slip } & =1800-1779 \\
& =21
\end{aligned}
$$

$$
\begin{aligned}
\text { Motor load } & =\frac{\text { Slip }}{\text { RPM }_{\text {sync }}-\mathrm{RPM}_{\text {full load (nameplate) }}} \\
& =\frac{21}{1800-1775} \\
& =0.84
\end{aligned}
$$

Thus from the calculations it can be seen that the instantaneous load of the dehumidifier motor is 0.84 . There were 6 dehumidifier motors in the dry kiln in this plant and all were having a load factor of around 0.84 . 


\section{Appendix IV}

\section{Sensitivity analysis for $\operatorname{cog}$ belt drives for facility $\mathbf{C}$}

\section{Sensitivity with respect to Efficiency of motors}

This analysis is done by changing the value of the efficiency of motors in the energy savings equation and keeping all other parameters of the equation constant. The efficiency of the motors is varied from $70 \%$ to $94 \%$. The value of $70 \%$ efficiency is a very typical for a standard old motor, while $94 \%$ is the efficiency of a typical new energy efficient motor. That's the reason above range is selected for the analysis. As seen in the Figure 4.1, the total savings obtained decrease with an increase in the efficiency value of the motor. There is a decrease in the total savings because, the efficiency of the motor appears in the denominator of the energy savings equation. This means that if the plant has electric motors in the high efficiency range say above $90 \%$, then this recommendation will result in less cost savings. But when the motors are standard and old, the efficiency is very low, then there is a potential for a large saving. As seen in the Table 4.1, when the average efficiency of the motors is $70 \%$, the annual cost saving obtained is $\$ 10,450.2$. Also at an efficiency of $94 \%$, the annual saving is $\$ 7,782.38$.

\section{Sensitivity with respect to the load factor of the motors}

As seen in the Table 4.1, the load factor of the motor driven systems is varied from 0.3 to 0.8 keeping all other parameters in the savings equation constant. The load factor range of 0.3 to 0.8 is selected at it is the typical range for most of the motor driven systems in an industrial set up. The load factor directly affects the total savings obtained. Load factor of $30 \%$, means that the amount of stresses on the belt transmission is less as compared to those at $80 \%$. So there is a steady increase in the cost saving achieved when the load factor is increased in that range. At a load of 0.3 , the net savings obtained are \$3,189.97 while for a load factor of 0.8 , the net savings obtained are $\$ 8,506.32$. Figure 4.2 also confirms the same results showing that the energy savings directly increase with increase in load factor of the motor drive systems. 


\begin{tabular}{|c|c|c|c|c|c|c|}
\hline hp & Eff. & LF & H & S & ES & Cost Savings \\
\hline \multicolumn{6}{|c|}{ Sensitivity with respect to Efficiency of motors } \\
\hline 1,285 & 0.7 & 0.8 & 4,212 & $4.00 \%$ & 630 & 10,352 \\
\hline 1,285 & 0.74 & 0.8 & 4,212 & $4.00 \%$ & 596 & 9,793 \\
\hline 1,285 & 0.78 & 0.8 & 4,212 & $4.00 \%$ & 565 & 9,290 \\
\hline 1,285 & 0.82 & 0.8 & 4,212 & $4.00 \%$ & 538 & 8,837 \\
\hline 1,285 & 0.86 & 0.8 & 4,212 & $4.00 \%$ & 513 & 8,426 \\
\hline 1,285 & 0.9 & 0.8 & 4,212 & $4.00 \%$ & 490 & 8,052 \\
\hline 1,285 & 0.94 & 0.8 & 4,212 & $4.00 \%$ & 469 & 7,709 \\
\hline \multicolumn{7}{|c|}{ Sensitivity with respect to Load factor } \\
\hline 1,285 & 0.86 & 0.3 & 4,212 & $4.00 \%$ & 192 & 3,160 \\
\hline 1,285 & 0.86 & 0.4 & 4,212 & $4.00 \%$ & 256 & 4,213 \\
\hline 1,285 & 0.86 & 0.5 & 4,212 & $4.00 \%$ & 320 & 5,266 \\
\hline 1,285 & 0.86 & 0.6 & 4,212 & $4.00 \%$ & 384 & 6,320 \\
\hline 1,285 & 0.86 & 0.7 & 4,212 & $4.00 \%$ & 448 & 7,373 \\
\hline 1,285 & 0.86 & 0.8 & 4,212 & $4.00 \%$ & 513 & 8,426 \\
\hline
\end{tabular}

Table 4.1: Sensitivity analysis calculation for $\operatorname{cog}$ belt drives

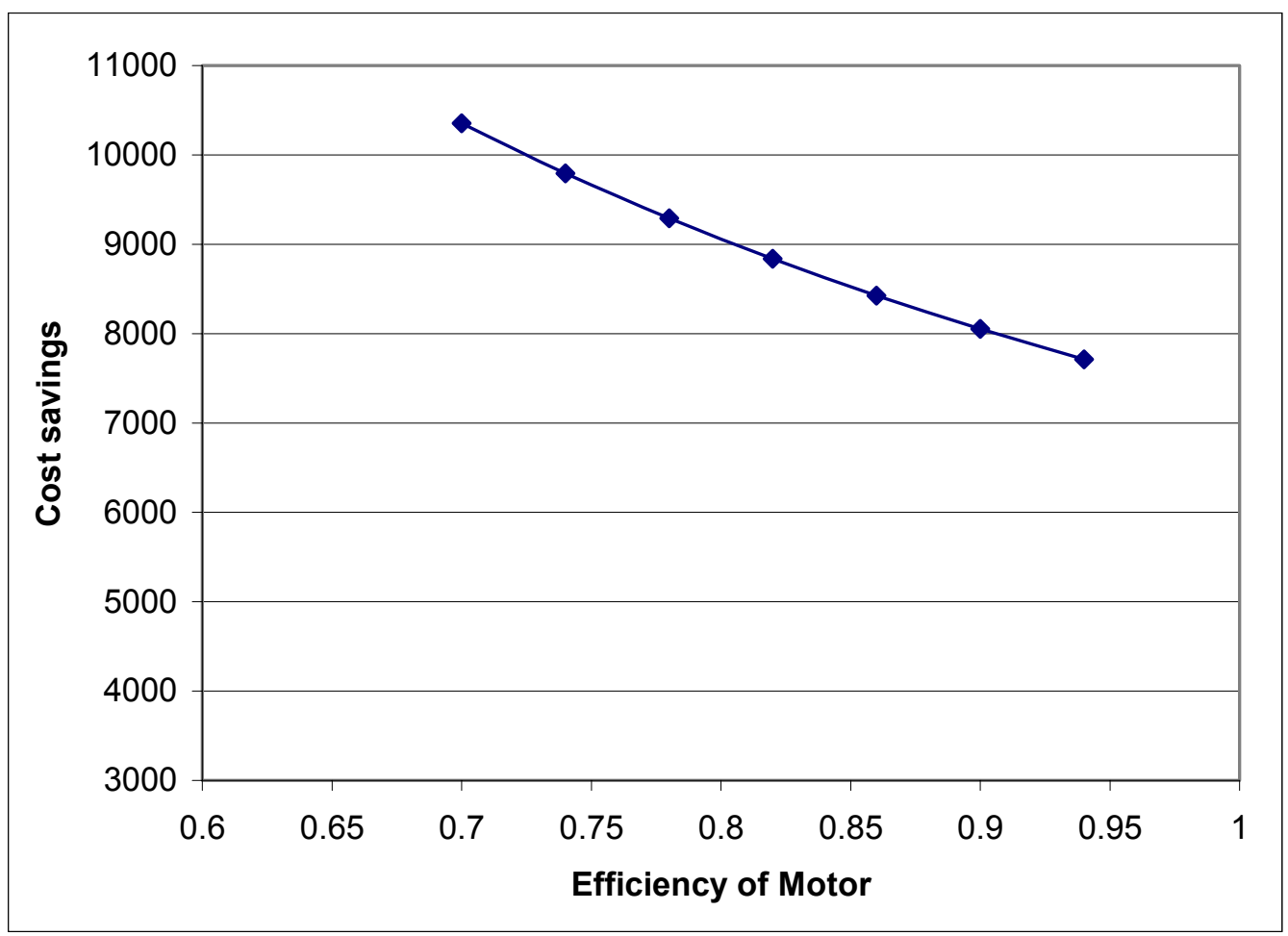

Figure 4.1: Sensitivity analysis with respect to efficiency of motor 


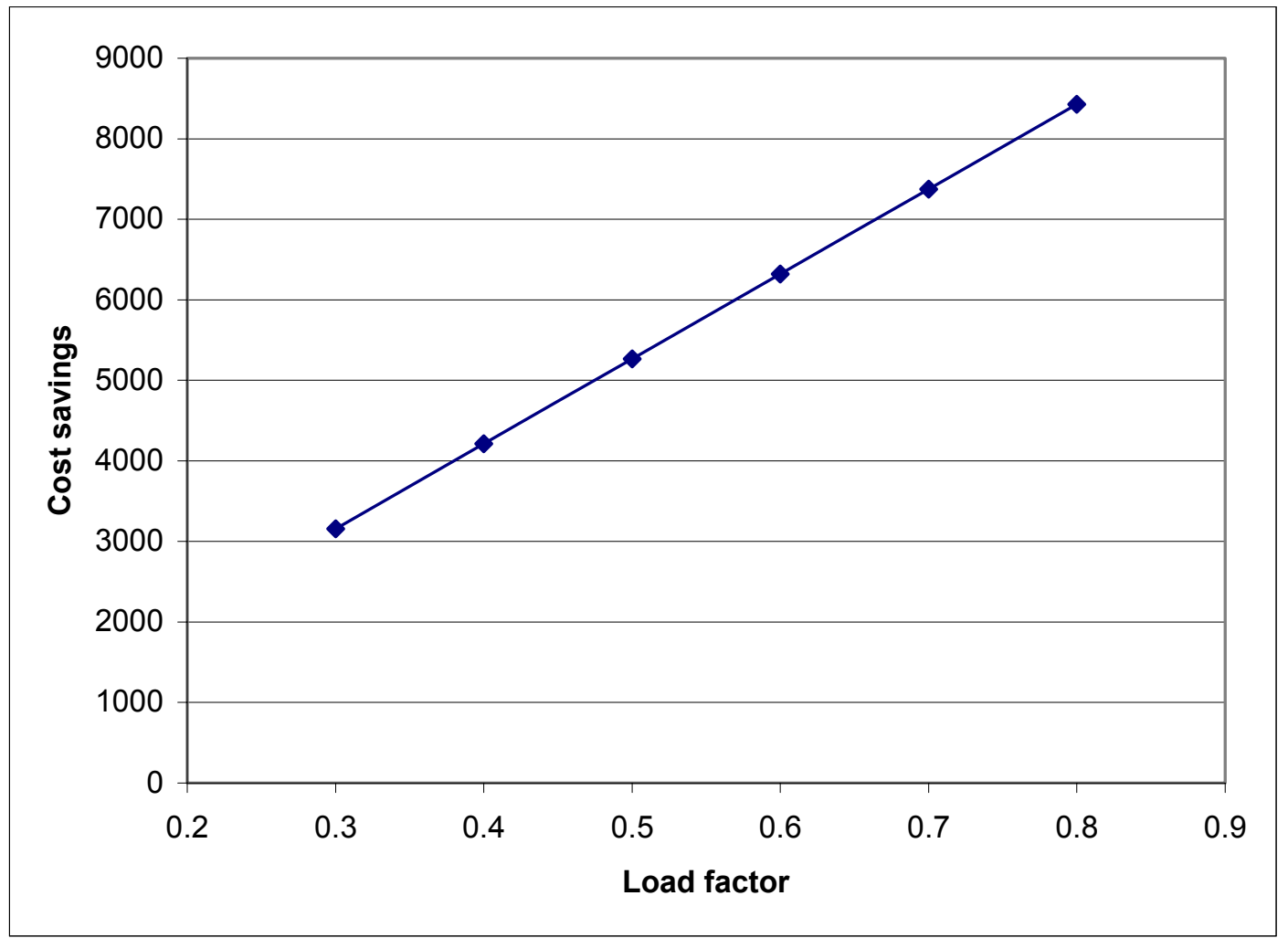

Figure 4.2: Sensitivity analysis with respect to load factor 


\section{Sensitivity analysis for $\operatorname{cog}$ belt drives for facility B}

\section{Sensitivity with respect to Efficiency of motors}

This analysis is done by changing the value of the efficiency of motors in the energy savings equation and keeping all other parameters of the equation constant. The efficiency of the motors is varied from $70 \%$ to $94 \%$. The value of $70 \%$ efficiency is a very typical for a standard old motor, while $94 \%$ is the efficiency of a typical new energy efficient motor. That's the reason above range is selected for the analysis. As seen in the Figure 4.3, the total savings obtained decrease with an increase in the efficiency value of the motor. There is a decrease in the total savings because, the efficiency of the motor appears in the denominator of the energy savings equation. This means that if the plant has electric motors in the high efficiency range say above $90 \%$, then this recommendation will result in less cost savings. But when the motors are standard and old, the efficiency is very low, then there is a potential for a large saving. As seen in the Table 4.2, when the average efficiency of the motors is $70 \%$, the annual dollar saving obtained is $\$ 10,352.2$. Also at an efficiency of $94 \%$, the annual saving is $\$ 7,709.09$.

\section{Sensitivity with respect to the load factor of the motors}

As seen in the Table 4.2, the load factor of the motor driven systems is varied from 0.3 to 0.8 keeping all other parameters in the savings equation constant. The load factor range of 0.3 to 0.8 is selected at it is the typical range for most of the motor driven systems in an industrial set up. The load factor directly affects the total savings obtained. Load factor of $30 \%$, means that the amount of stresses on the belt transmission is less as compared to those at $80 \%$. So there is a steady increase in the cost savings achieved when the load factor is increased in that range. As can be seen in the table, at a load of 0.3 , the net savings obtained are $\$$ $3,159.83$ while for a load factor of 0.8 , the net savings obtained are $\$ 8,426.22$. Figure 4.4 also confirms the same results showing that the energy savings directly increase with increase in load factor of the motor drive systems. 


\begin{tabular}{|c|c|c|c|c|c|c|}
\hline hp & Eff. & LF & H & S & ES & Cost Savings \\
\hline \multicolumn{6}{|c|}{ Sensitivity with respect to Efficiency of motors } \\
\hline 1,285 & 0.7 & 0.8 & 4,212 & $4.00 \%$ & 630 & 10,352 \\
\hline 1,285 & 0.74 & 0.8 & 4,212 & $4.00 \%$ & 596 & 9,793 \\
\hline 1,285 & 0.78 & 0.8 & 4,212 & $4.00 \%$ & 565 & 9,290 \\
\hline 1,285 & 0.82 & 0.8 & 4,212 & $4.00 \%$ & 538 & 8,837 \\
\hline 1,285 & 0.86 & 0.8 & 4,212 & $4.00 \%$ & 513 & 8,426 \\
\hline 1,285 & 0.9 & 0.8 & 4,212 & $4.00 \%$ & 490 & 8,052 \\
\hline 1,285 & 0.94 & 0.8 & 4,212 & $4.00 \%$ & 469 & 7,709 \\
\hline \multicolumn{7}{|c|}{ Sensitivity with respect to Load factor } \\
\hline 1,285 & 0.86 & 0.3 & 4,212 & $4.00 \%$ & 192 & 3,160 \\
\hline 1,285 & 0.86 & 0.4 & 4,212 & $4.00 \%$ & 256 & 4,213 \\
\hline 1,285 & 0.86 & 0.5 & 4,212 & $4.00 \%$ & 320 & 5,266 \\
\hline 1,285 & 0.86 & 0.6 & 4,212 & $4.00 \%$ & 384 & 6,320 \\
\hline 1,285 & 0.86 & 0.7 & 4,212 & $4.00 \%$ & 448 & 7,373 \\
\hline 1,285 & 0.86 & 0.8 & 4,212 & $4.00 \%$ & 513 & 8,426 \\
\hline
\end{tabular}

Table 4.2: Sensitivity analysis calculation for $\operatorname{cog}$ belt drives

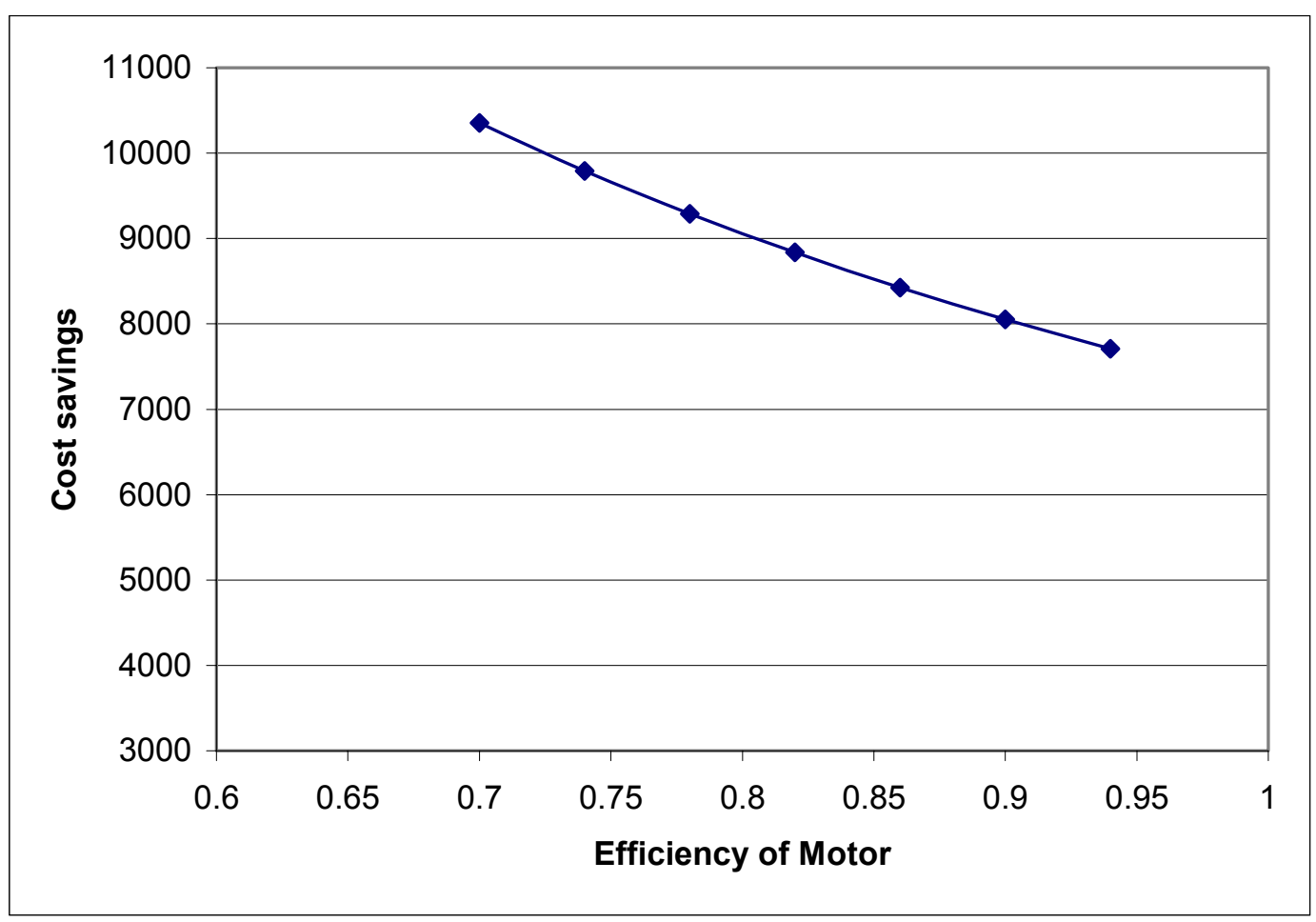

Figure 4.3: Sensitivity analysis with respect to efficiency of motor 


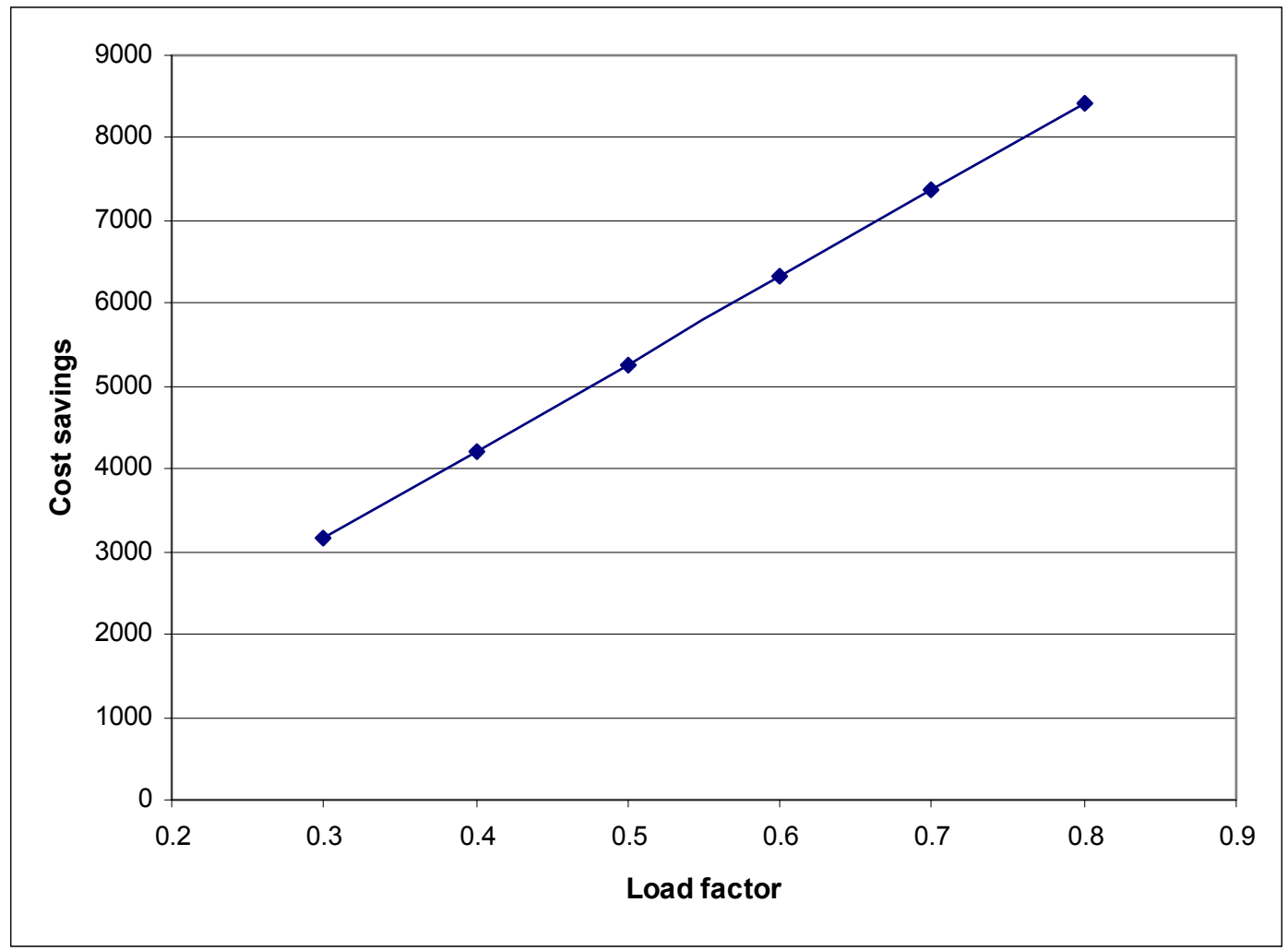

Figure 4.4: Sensitivity analysis with respect to load factor 